\title{
Performance Modeling of Right-of-Way Stormwater LID Practices-Exfiltration System
}

\author{
by \\ Krishna Khadka \\ B.Eng., Tribhuvan University, Nepal, 2009 \\ An MRP \\ presented to Ryerson University \\ in partial fulfillment \\ of the requirements for the degree of
}

\begin{abstract}
Master of Engineering
\end{abstract}
in the Program of

Civil Engineering

Toronto, Ontario, Canada, 2020

CKrishna Khadka, 2020 


\section{Author's Declaration}

I hereby declare that I am the sole author of this MRP. This is a true copy of the MRP, including any required final revisions.

I authorize Ryerson University to lend this MRP to other institutions or individuals for the purpose of scholarly research.

I further authorize Ryerson University to reproduce this MRP by photocopying or by other means, in total or in part, at the request of other institutions or individuals for the purpose of scholarly research.

I understand that my MRP may be made electronically available to the public. 


\begin{abstract}
Performance Modeling of Right-of-Way Stormwater LID Practices-Exfiltration System

Krishna Khadka

Master of Engineering

Civil Engineering

Ryerson University

2020
\end{abstract}

Rapid population growth and ever-growing urbanizations are posing a significant challenge to stormwater management in urban communities. An exfiltration system (ES), one of the innovative low impact development (LID) techniques, principally similar to the Etobicoke Exfiltration System (EES), was constructed in Mosaik Glenway Homes, residential subdivision, Newmarket, as a stormwater management facility. This typical ES is the simple addition to the conventional storm sewer system, and consists of a filter fabric encased granular stone trench with embedded perforated PVC pipe beneath the storm sewer at a very gentle slope $(0.5 \%)$.

In order to assess the hydrologic performance of the exfiltration system (ES), the monitored ES inflow and overflow time series data were analyzed. Both continuous and event-based monitoring data analysis depicts that the ES has a significant impact on the water balance, reducing the surface runoff by $84 \%$ and achieving a substantial reduction of peak flow, thereby maintaining the contemporary stormwater management goals (post-development infiltration volume to predevelopment level). This typical ES can store up to $123 \mathrm{~m} 3$ of runoff volume and exfiltrates to the surrounding soils. The average ES exfiltration rate ranged from 0.76 to $1.05 \mathrm{~mm} / \mathrm{hr}$ over four observed complete drainage periods (full capacity to empty), indicates that the system is draining at a much slower rate than that was assumed when designing the exfiltration system $(7.7 \mathrm{~mm} / \mathrm{hr})$. As a consequence, it causes the system to require a much longer period to achieve complete drainage (drawdown) than the estimated 78 hours. 
PCSWMM model was developed to analyze the annual water balance cycle and determine suitable alternative measures to control the ES overflow. Eight meaningful events were selected to calibrate and validate the model, most sensitive parameters such as hydraulic conductivity and imperviousness of subwatershed were calibrated to fit simulated ES inflow with observed inflow whereas orifice discharge coefficient and hydraulic conductivity of storage trench were calibrated for ES-overflow. Rainfall events larger than $24 \mathrm{~mm}$ exceeded the storage capacity of the granular trench and caused overflow from the exfiltration system (ES2). Model results indicate that ES2 overflow could be easily avoided by diverting some amount of ES2 inflow to the underutilized upstream exfiltration system (ES1) by constructing diversion storm sewer to drain flow accumulated at manhole 5 (MH5) to manhole 4 (MH4). 


\section{Acknowledgments}

I would like to express my sincere gratitude to my supervisor, Dr. Darko Joksimovic, whose expertise was invaluable in formulating the research and methodology in particular. I would like to thank Prof. Dr. James Li for his valuable comments and reviews to make this project work technically sound and insightful research. I am very grateful to their constant support and guidance to accomplish this MEng project report. 


\section{Table of Contents}

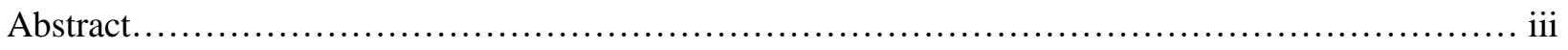

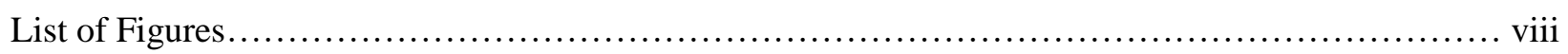

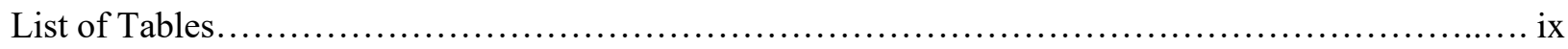

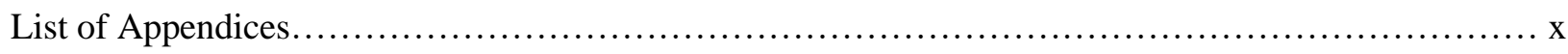

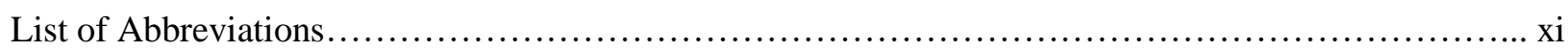

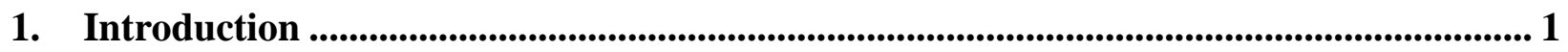

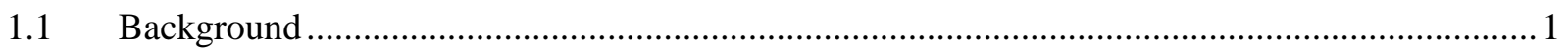

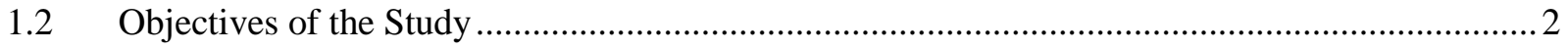

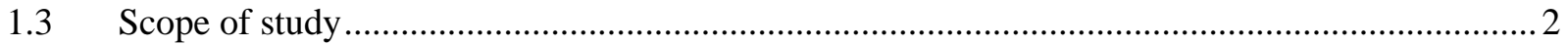

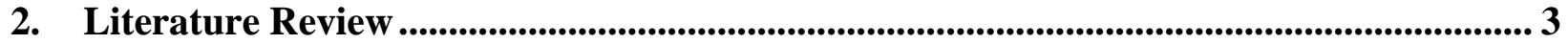

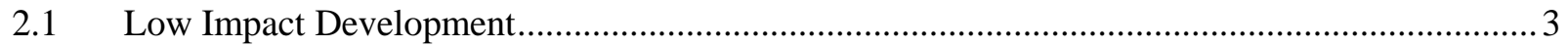

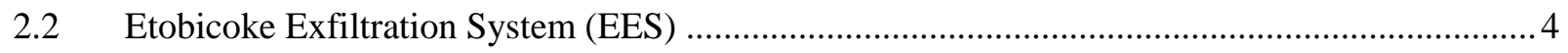

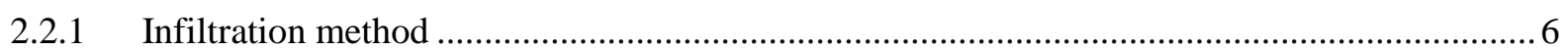

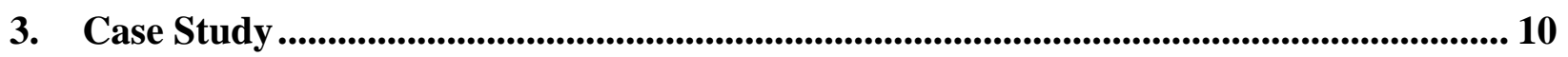

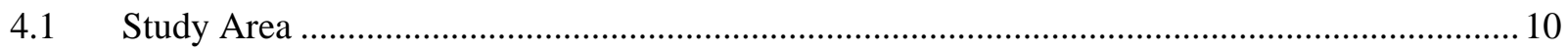

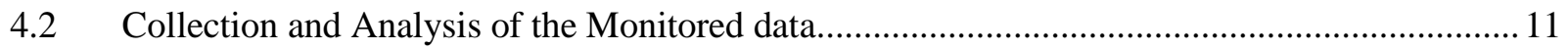

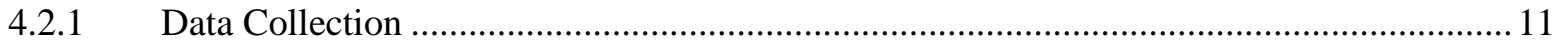

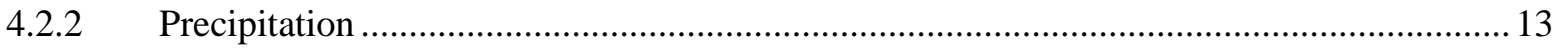

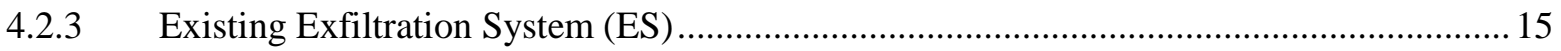

4.2.4 Performance Analysis of Existing ES ...................................................................... 21

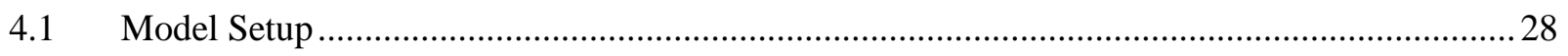

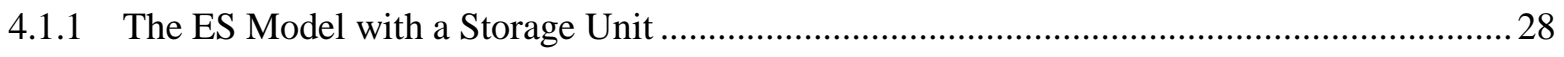

4.1.2 Orifice flow to the Exfiltration storage …........................................................................ 34

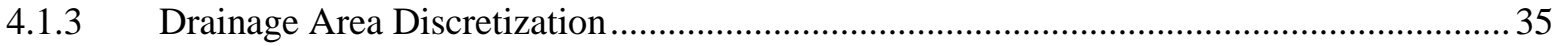

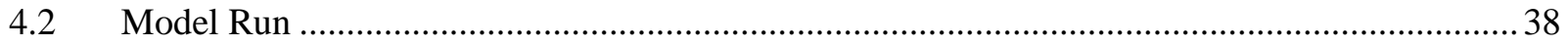

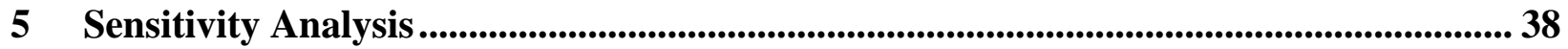

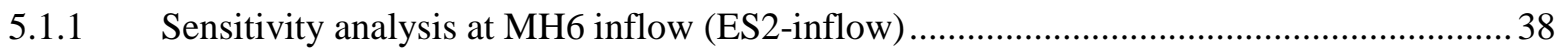

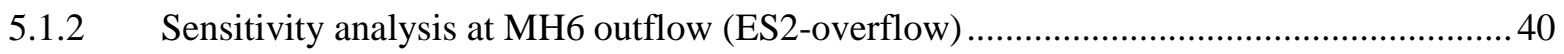

6 Calibration and Validation of Model................................................................................ 41 
6.1.1 Calibration of the model at MH6 inflow (ES2-inflow) ................................................ 42

6.1.2 Calibration of Model at MH6 outflow (ES2-Overflow) .................................................. 46

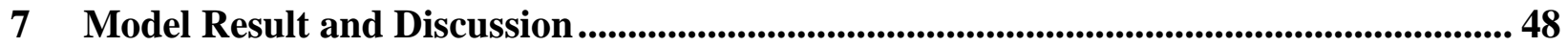

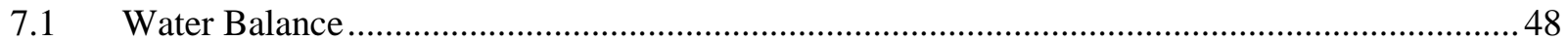

8 Future Retrofit to avoid ES2 overflow .................................................................................... 49

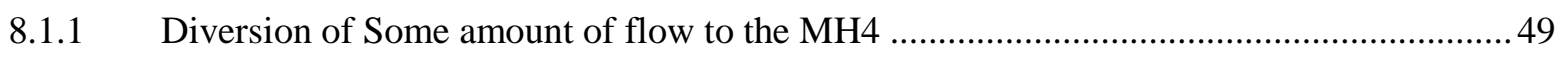

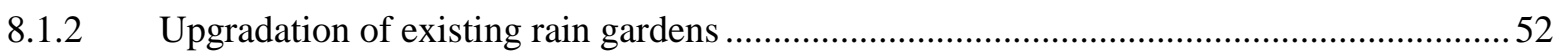

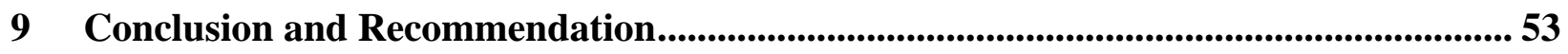

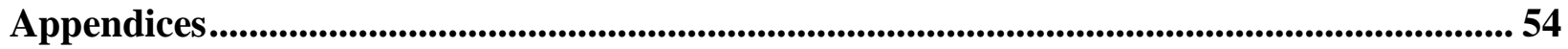

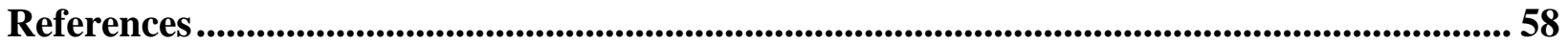




\section{List of Figures}

Figure 1: Example of some LID Techniques (CHI Water, 2012) 4

Figure 2. Concept of Etobicoke Exfiltration System (Li and Tran, 2015) 5

Figure 3: Typical cross-section of Etobicoke Exfiltration System (Li and Tran, 2015) 6

Figure 4: Two-zone representation of the Green-Ampt infiltration model $\quad 7$

Figure 5: Illustration of infiltration capacity as a function of cumulative infiltration 8

Figure 6: Methodology Flow chart $\quad 9$

Figure 7: Study Area, Masaik Glenway Homes Inc. Subdivision in Google Earth 11

Figure 8: Location of different monitoring equipment 13

Figure 9: Monitored rainfall data of the study area 14

Figure 10: Selected events highlighted by grey color and red enclosure 15

Figure 11: Exfiltration system ES1 and ES2 and a conventional storm sewer in between 16

Figure 12: Cross-section of Exfiltration System 17

Figure 13: Longitudinal section of ES 18

Figure 14: Performance Analysis of ES2 based on monitored data 19

Figure 15: The monitored overflow events at outlet of MH6 (ES2 overflow) 20

Figure 16: The monitored water level at MH6 21

Figure 17: Four selected monitoring duration to evaluate ES performance 23

Figure 18: Average exfiltration rate (drainage period $242 \mathrm{hrs}$ starting from $24^{\text {th }}$ July, 2018) 24

Figure 19: Average exfiltration rate $\quad 24$

Figure 20: Average exfiltration rate (drainage period $127 \mathrm{hrs}$ starting from $8^{\text {th }}$ Aug 2018) 25

Figure 21: Peak flow reductions of ES for selected events $\quad 27$

Figure 22: Overall ES performance in terms of runoff volume reductions 28

Figure 23: Schematic diagram of exfiltration via storage unit model 29

Figure 24. Storage Tabular Curve for ES2 (MH6- MH7) 31

Figure 25. Storage volume Curve for ES2 31

Figure 26: Different sections of ES representation to calculate trench surface area 32

Figure 27: Subwatershed discretization 36

Figure 28: L-profile of Storm sewer along with exfiltration system from MH6 to MH7 37

Figure 29: Ranking of the sensitive parameter for maximum total inflow at MH6 inflow 39

Figure 30: change in the objective function due to each parameter over the uncertainty range $\quad 40$

Figure 31: Ranking of the sensitive parameter for total flow at ES-2 overflow 41

Figure 32: Calibration of model at MH6 inflow 43

Figure 33: Calibration and validation of all events at ES2 inflow 43

Figure 34: Calibration of event 1 at ES2 inflow 44

Figure 35: Calibration and validation of all events for peak inflow at ES2 inflow 45

Figure 36: Comparison of simulated and observed flow at MH6 inflow 46

Figure 37: Calibration of the model for total outflow at MH6 outlet 47

Figure 38: Calibration of the model for an overflowing event at MH6 outlet 47

Figure 39: Water balance analysis of ES for the annual hydrologic cycle 49

Figure 40: Some portion of MH6 drainage area diverting towards MH4 50

Figure 41: Overflow from MH4 outlet sewer pipe after flow diversion $\quad 50$

Figure 42: Overflow from MH6 outlet sewer pipe after flow diversion $\quad 51$

Figure 43: Offline Rain gardens like structures in Mosaik Homes Glenway subdivisions 52 


\section{List of Tables}

Table 1: Stormwater monitoring data 12

Table 2: Monthly Potential Evapotranspiration $\quad 13$

Table 3: Selected events for the analysis of ES performance 15

Table 4: The overflow events at control manhole (MH6) 20

Table 5: Average exfiltration rate and runoff reduction for different monitoring periods 25

Table 6: Peak flow Performance Analysis of ES2 based on monitored data 27

Table 7: Green and Ampt Method Parameters $\quad 30$

Table 8: Tabular curve calculation at different sections 34

Table 9: Calibration and Validation of events for total inflow volume 45

Table 10: Inflow and overflow to MH4 after flow diversion $\quad 51$ 


\section{List of Appendices}

Figure A1: Comparison of observed and modeled overflow at MH6 with level and rainfall 54

Figure A2: Calibration of event 2 at ES2 inflow $\quad 54$

Figure A3: Calibration of event 3 at ES2 inflow $\quad 55$

Figure A4: Calibration of event 4 at ES2 inflow $\quad 55$

Figure A5: Calibration of event 5 at ES2 inflow 56

Figure A6: Calibration and validation of event 6 at ES2 inflow 56

Figure A7: Calibration and Validation of event 7 at ES2 inflow $\quad 57$

Figure A8: Calibration and validation of event 8 at ES2 inflow 57 


\section{List of Abbreviations}

AES = Atmospheric Environment Service

BMP = Best Management Practice

$\mathbf{C B}=$ Catch basin

$\mathbf{C N}=$ Curve Number

$\mathbf{C V C}=$ Credit Valley Conservation

DEM = Digital Elevation Model DH Duffin Heights

ES = Exfiltration System

EES = Etobicoke Exfiltration System

GIS = Geographical Information System

LID $=$ Low Impact Development

LSRCA = Lake Simcoe Region Conservation Authority

MH = Manhole

NSE $=$ Nash Sutcliffe Efficiency

NVCA = Nottawasaga Valley Conservation Authority

PCSWMM = Personal computer Stormwater management model

PET $=$ Potential Evapotranspiration

PFE $=$ Peak Flow Error

PFR $=$ Peak Flow Rate

$\mathbf{S C E}=$ Schaeffer's Consulting Engineers

SCS $=$ Soil Conservation Service

SRTC = Sensitivity-based Radio Tuning Calibration

SW $=$ Stormwater

SWM = Stormwater Management

SWMF = Stormwater Management Facility

SWMM = Stormwater Management Model

SWMPD = Stormwater Management Planning and

TRCA = Toronto and Region Conservation Authority

TTT $=$ Treatment Train Tool

US EPA = United States Environmental Protection Agency 


\section{Introduction}

\subsection{Background}

Rapid urbanization, in the form of expansion of roads, sidewalks, parking lots and buildings, poses significant challenges to stormwater management that has become an increasingly challenging issue for urban communities. In many cases, due to increased imperviousness, rainwater can no longer follow its natural path, resulting in increased runoff volume, peak flow and its associated problems such as flooding, altered stream flow, erosion, algae growth, poor water quality, alteration of groundwater characteristics, and ultimately threats to aquatic habitat (TRCA, 2012). To address these issues, the Province of Ontario has undergone a series of transformations of stormwater management (SWM) approach evolving from its traditional flood control approach to integrated treatment train approach (SWMPD Manual, 2003).

One of the innovative LID technologies, Exfiltration System (ES), locally recognized as Etobicoke Exfiltration System (EES), was developed and constructed in 1993 in Etobicoke, Toronto (Li and Tran, 2015). The ES is basically designed to provide on-site retention as well as additional infiltration storage for water quality and quantity control. Large storm events, especially followed by similar events, may cause to exceed the storage capacity of the exfiltration system, resulting in the overflow from ES. The positive aspect of ES is that it is constructed beneath the storm sewer, i.e., below the frost line, so it does not freeze and works typically even in the snowmelts throughout winter and early spring.

A typical exfiltration system, constructed in Mosaik Homes Glenway, residential subdivision was the first project of its kind in the town of Newmarket. In the Mosaik subdivision, different LID 
techniques have been installed as a treatment train approach, and performance has been monitored by various agencies to assess the suitability of each LID in a site-specific case (STEP, 2018). The ES project was basically designed for the on-site retention of a $25 \mathrm{~mm}$ rainfall event for 24 hours to comply with Lake Simcoe Region Conservation Authority (LSCRA), stormwater management (SWM) technical guidelines (LSCRA, 2016). Most importantly, the exfiltration system is supposed to reduce significant amounts of runoff volume through exfiltration, contributing to the removal of phosphorus and suspended sediment considerably.

\subsection{Objectives of the Study}

The first objective of this study was to evaluate the hydrologic water balance performance of the existing exfiltration systems (ES) installed at Mosaik Homes Glenway subdivision by analyzing the monitored time series data. The second objective of this research was to develop, calibrate and validate a PCSWMM model to conduct further analysis. The third objective was to use the calibrated model to determine the suitable techniques in order to eliminate the overflow from the existing exfiltration system.

\subsection{Scope of study}

This research study is confined to a comprehensive assessment of the performance of ES constructed in Mosaik Homes Glenway Subdivision, Newmarket, based on observed and model result with stormwater management objectives, peak flow control, runoff volume control. The research is focused on volumetric control of runoff, without considering water quality aspects by using the ES performance monitoring data collected by TRCA and information provided in the Schaeffer's Consulting Engineer Report, 2014. 


\section{Literature Review}

\subsection{Low Impact Development}

As an innovative SW management facility, Low Impact Developments (LID) techniques are rapidly evolving in North American cities to control and mitigate the adverse effects of urbanization. This simple approach implements engineered small scale hydrologic controls to replicate the predevelopment hydrologic regime through infiltration, filtration, evaporation, storage, and onsite detention of runoff close to its source. LID employs principles such as preserving and recreating natural landscape features, minimizing effective imperviousness to create functional and appealing site drainage that treats stormwater as a resource rather than a waste product. Indeed, LID refers to a set of practices that reduce runoff and pollutant concentrations by managing runoff close to the site. LID practices promote the natural phenomena of infiltration, evapotranspiration, filtration, temporary storage, detention to reduce surface runoff, lower peak flow, and reduce pollutants' concentration (USEPA, 2018).

In compliance with the requirements of local municipalities, different local conservation authorities, and Ministry of Environment, Conservation and Parks (MOECP); many residential subdivisions are currently implementing different LID techniques. Some of the most commonly used LID techniques include vegetative swales, rain gardens, rain barrels, street planter, porous pavement, and infiltration trenches, as shown in Figure 1. 


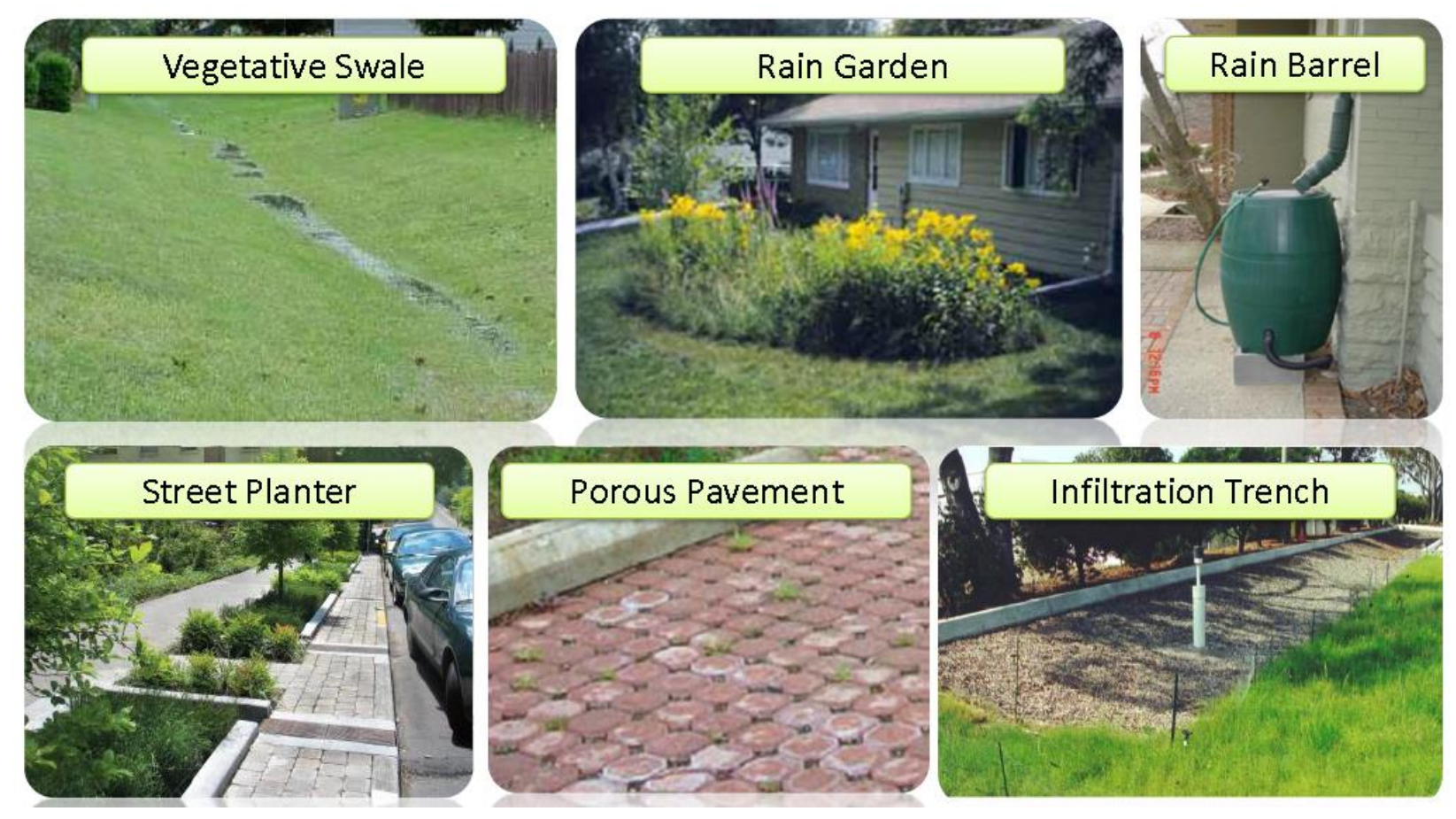

Figure 1: Example of some LID Techniques (CHI Water, 2012)

The ultimate objective of LID is to maintain the pre-development hydrologic regime;

specifically, flow and pollutant loadings, in order to protect the downstream aquatic life and natural habitat. Therefore, by implementing LID principles and practices, water can be managed in a way that reduces the impact of built areas and promotes the natural movement of water within an ecosystem or watershed. Applied on a broad scale, LID can maintain or restore a watershed's hydrologic and ecological functions (USEPA, 2018).

\subsection{Etobicoke Exfiltration System (EES)}

Etobicoke Exfiltration System (EES) is one of the innovative LID techniques, conceptualized, and implemented more than two decades ago. The system was first constructed in the early 1990s and it continues to work effectively today with minimal maintenance effort. It is a relatively simple addition to the conventional stormwater design, and useful technique to reduce runoff and pollutants loading by promoting exfiltration via the stone trench that is installed with the 
construction of storm sewers. The upstream manhole receives the stormwater from the catch basin (CB), and two perforated pipes are installed beneath the storm sewer to convey the water collected in manhole to the stone trench for exfiltration to native soil. The conceptual diagram and the crosssection of the EES are presented in Figures 2 and 3, respectively.

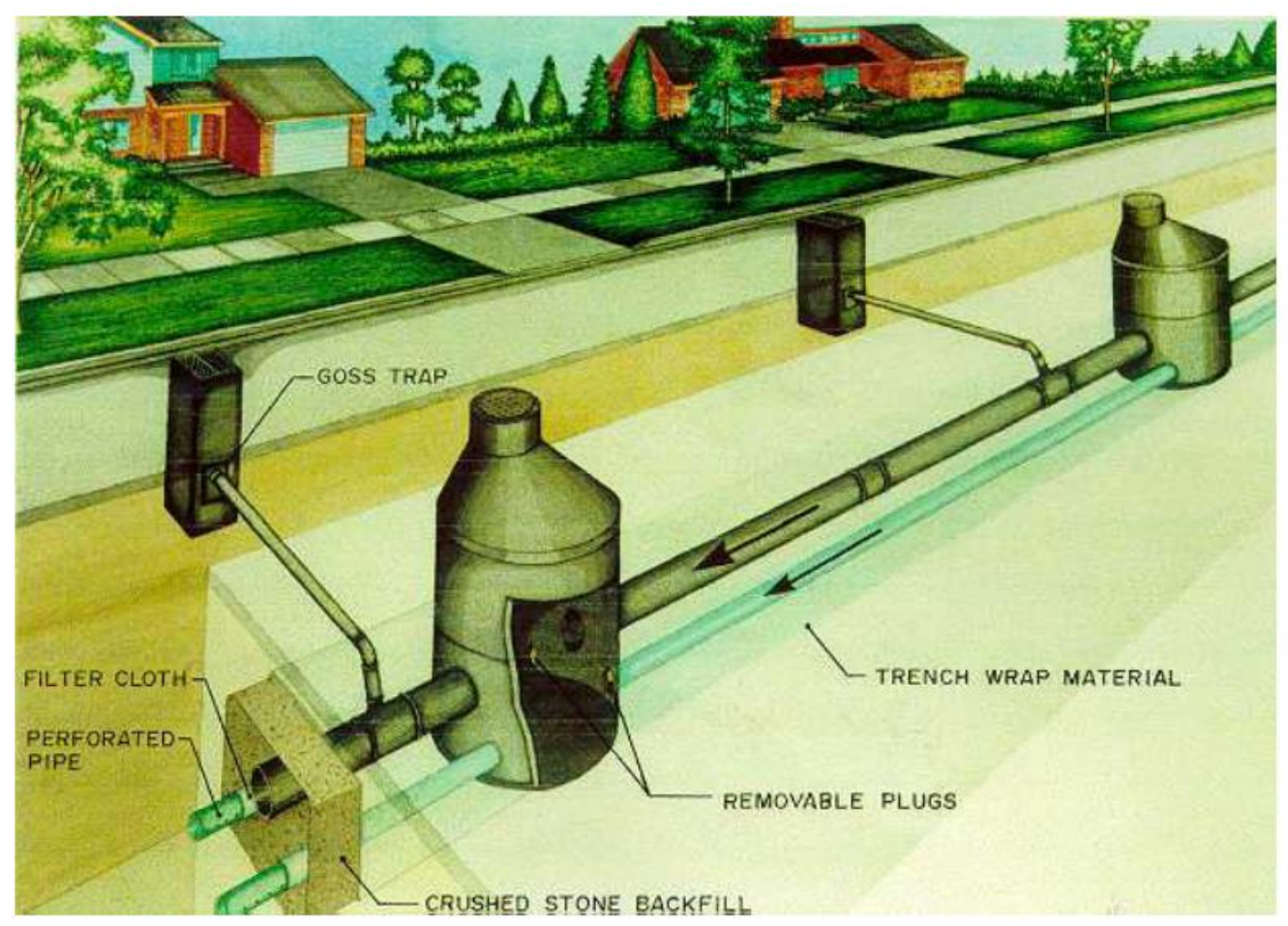

Figure 2. Concept of Etobicoke Exfiltration System (Li and Tran, 2015)

As depicted in Figure 3, two $200 \mathrm{~mm}$ diameter perforated PVC pipes wrapped by filter fabric are installed beneath the storm sewer by connecting upstream and downstream manhole. The exfiltration system is mechanically plugged at downstream manhole to make it a storage system instead of a conveyance system. Granular stones are placed within a stone trench covering the area between the bottom of the trench and inlet elevation of the main storm sewer. The void space among granular stone inside the stone trench provides a storage volume for exfiltration. Both the PVC pipes and storm sewer are embedded inside the granular stone trench and the whole stone 
trench is encased by filter fabric. Thus, the filter fabrics prevent both the perforated pipes and stone trench from clogging, sediment intrusion and granular material loss (Li and Tran, 2015).

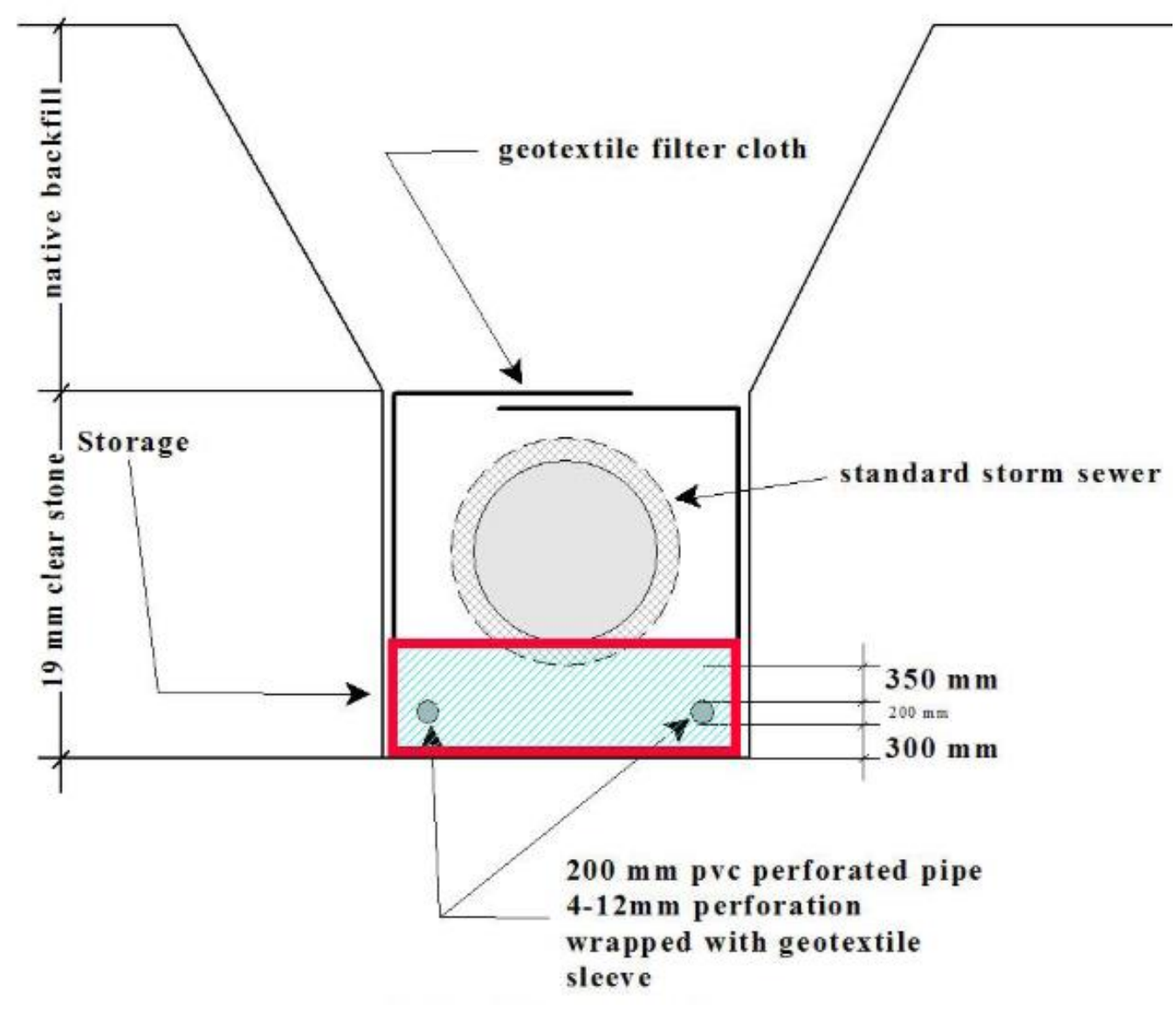

Figure 3: Typical cross-section of Etobicoke Exfiltration System (Li and Tran, 2015)

\subsubsection{Infiltration method}

Based on the SWMM Manual (CHI, 2017), the storage unit loss (exfiltration) is calculated using the Green-Ampt method. Since the surrounding soil of the ES is not saturated at the beginning of the rainfall event, the hydraulic conductivity is a function of the suction head and the soil moisture content. Consequently, the exfiltration rate into the surrounding soil of the trench and the potential cumulated infiltration volume were calculated based on the Green-Ampt method. 
The Green and Ampt infiltration process is based on the concept that infiltrated water moves vertically downward in a saturated layer, beginning from the surface, as presented in Figure 4. In the wetted zone, the moisture content $\theta$ is at saturation $\theta_{\mathrm{s}}$, while the moisture content in the nonwetted zone is at some known initial level $\theta_{i}$. Darcy's Law gives the water velocity within the wetted zone as a function of the saturated hydraulic conductivity $K$ s, the capillary suction head along the wetting front $\psi_{\mathrm{s}}$, the depth of ponded water at the surface ' $d$ ', and the depth of the saturated layer below the surface $L_{\mathrm{s}}$ :

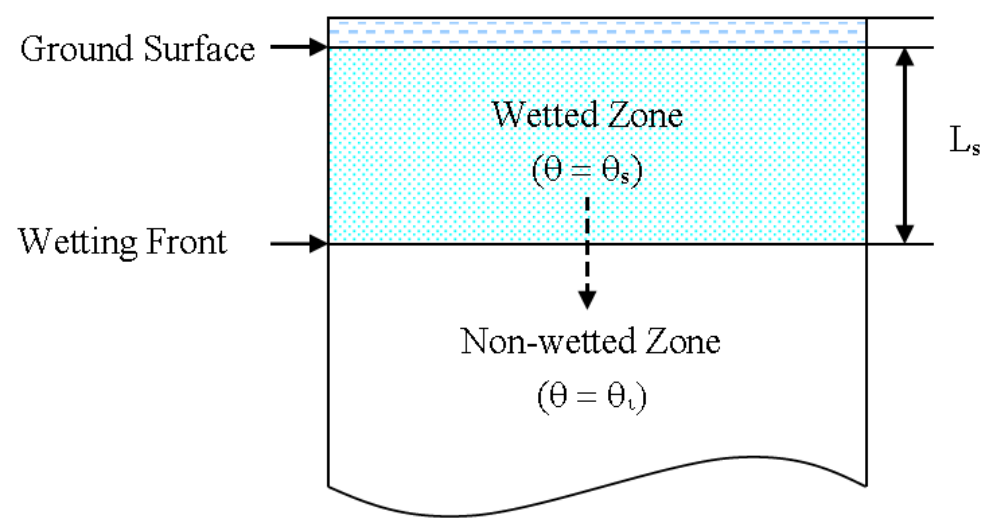

Figure 4: Two-zone representation of the Green-Ampt infiltration model

Equation 1, Green and Ampt Infiltration Rate, (USEPA SWMM Manual, 2016)

$f=K_{s}\left[\frac{d+L_{s}+\psi_{s}}{L_{s}}\right]$

Where,

$f=$ infiltration rate, $\mathrm{mm} / \mathrm{hr}$

$d=$ depth of saturated layer, $\mathrm{mm}$

$L s=$ depth of saturated layer below surface

$K s=$ Saturated hydraulic conductivity, $\mathrm{mm} / \mathrm{hr}$

$\Psi S=$ Capillary suction head, $\mathrm{mm}$ 
The depth of the saturated layer $\mathrm{L}_{\mathrm{s}}$ can be expressed in terms of the cumulative infiltration, $\mathrm{F}$, and the initial moisture deficit to be filled below the wetting front, $\theta_{d}=\theta_{s}-\theta_{i}$ as $L_{s}=F / \theta_{d}$. Substituting this into Equation 1 and assuming that $\mathrm{d}$ is small compared to the other depths, the infiltration rate (f) and the cumulative infiltration (F) becomes as presented in Equations (2) and (3) respectively.

Equation 2, Green and Ampt Infiltration Rate, (USEPA SWMM Manual, 2016)

$$
f=K\left(\frac{\psi \Delta \theta}{F(t)}+1\right)
$$

Equation 3, Cumulative Infiltration at time t, F(t) (USEPA SWMM Manual, 2016)

$$
F(t)=K t+\psi \Delta \theta \ln \left(1+\frac{F(t)}{\psi \Delta \theta}\right)
$$

Where,

$\mathrm{F}=$ cumulative infiltration volume, $\mathrm{mm}$

$\mathrm{K}=$ hydraulic conductivity, $\mathrm{mm} /$

$\Psi=$ suction head, $\mathrm{mm}$

$\theta=$ soil moisture content

The illustration of infiltration rate as a function of cumulative infiltration volume for the Green and Ampt method is presented in Figure 5.

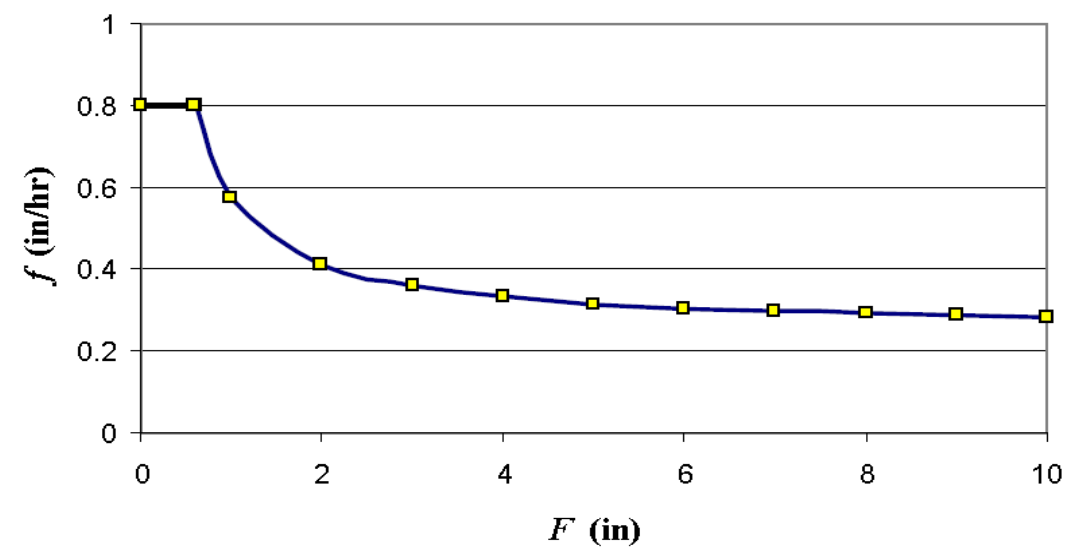

Figure 5: Illustration of infiltration capacity as a function of cumulative infiltration 
This research methodology comprises data collection, hydrologic performance analysis of existing ES, model setup, calibration and validation of the model, and finally an insightful analysis of the model's result with conclusions and recommendations. The entire research methodology consists of four steps, as presented in Figure-6.

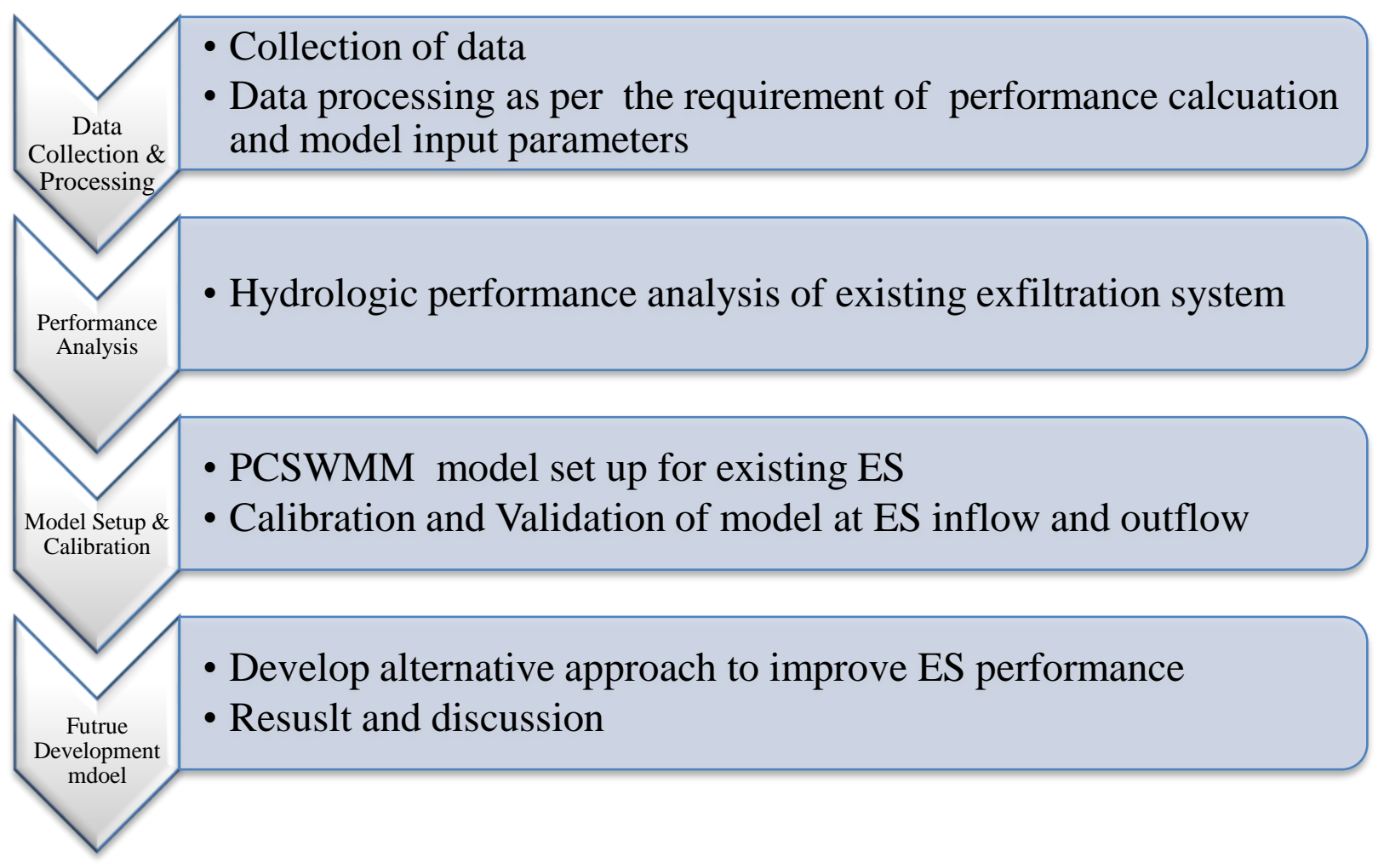

Figure 6: Methodology Flow chart

The first step was to collect the necessary drainage area data for the analysis, such as rainfall data, storm sewer flow data, drainage network, profile and cross-sections of sewer, road profile and catch basin leader, hydrological, and geotechnical data. The collected data were processed as per the requirement of analysis and model input parameters.

In the second step, monitored data were used to evaluate the performance of existing ES. The hydrologic performance was assessed based on peak flow and runoff volume control. 
In the third step, a PCSWMM model was developed, calibrated, and validated with observed flow data of the existing ES conditions. To set up the model, the drainage area was discretized into finer subwatersheds, and subwatershed properties were assigned as mentioned in the Schaeffer's Consulting Engineers' report. The model was run at five minutes time interval to determine the ES performance and most sensitive parameters and that needed to be calibrated for the further use of the model. The subsequent step involved the use of the calibrated model for future development, in this step, some alternatives were taken into account to control the overflow from the ES.

The final step involved the water balance analysis of the model result for full annual hydrological cycle with respect to runoff reduction via ES. All the ES modeling in this study was performed using the PCSWMM 5.01.012. The detailed methodology of the model development and data used for the model setup are discussed in the preceding sections.

\section{Case Study}

This research case study is entirely focused on the performance analysis of the previously constructed storm sewer system in conjunction with ES in Mosaik Glenway Homes, residential subdivisions, Newmarket. Finally, the observed ES inflow-outflow data and model water balance results were analyzed based on the monitored data collected by TRCA and the information provided in Schaeffer's Consulting Engineers' report in 2014.

\subsection{Study Area}

Mosaik Homes and Glenway Subdivision was selected as the study area, which is located at the southeast corner of Bathurst Street and Davis drive, in the Town of Newmarket. It is bounded by Sweetwater Crescent to the East and Yarafield Crescent in the West. The study area is focused on the ES along McGregor Farm Trail storm sewer and its contributing drainage areas for MH4, 
MH5, and MH6. This study area covers 2.6ha of land and consists of single-family houses, whereas the total area of the whole Mosaik subdivision is approximately 11 ha. In Figure 7 , the entire boundary of Mosaik subdivisions is represented by green polygon, whereas the study area is represented by the red polygon.

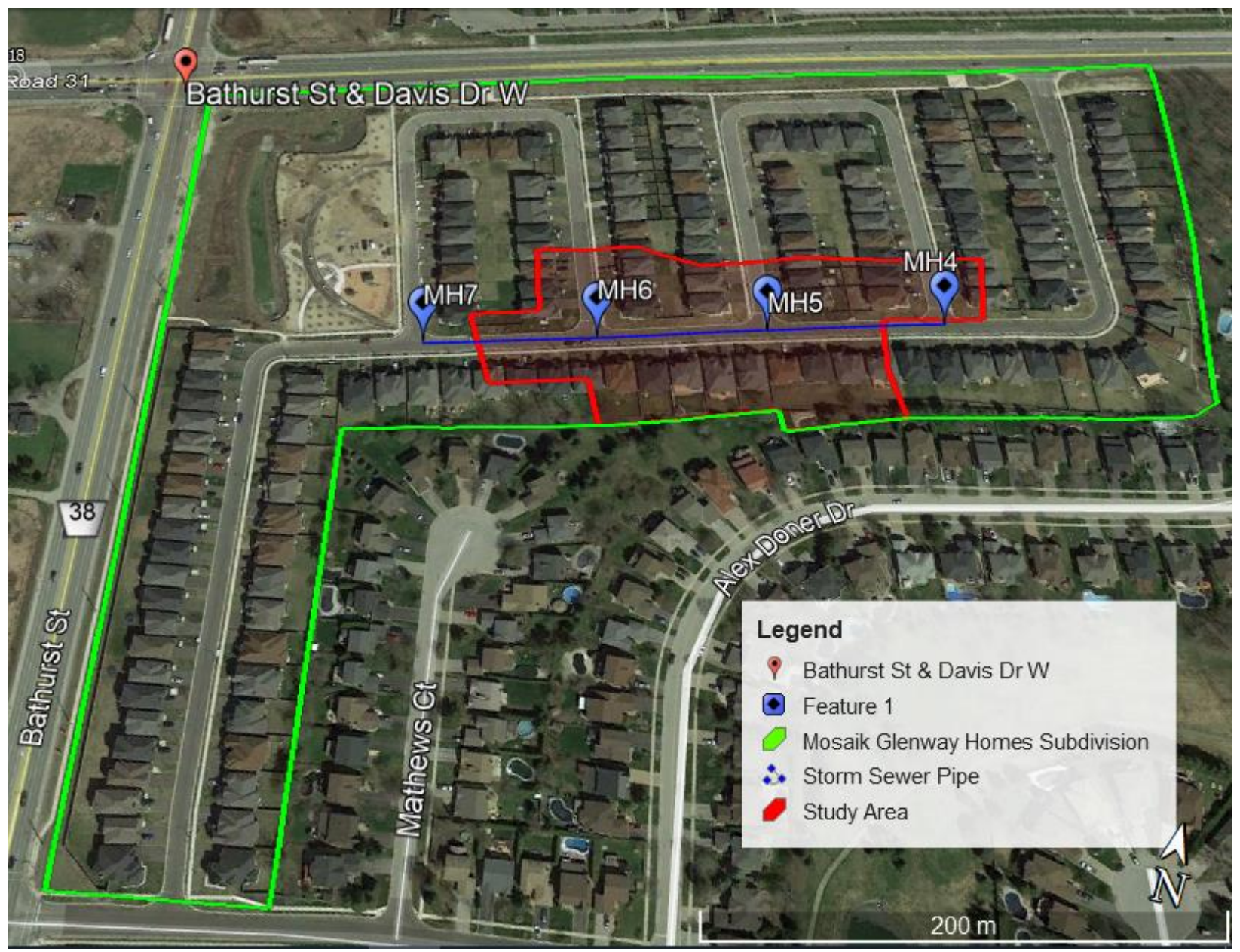

Figure 7: Study Area, Masaik Glenway Homes Inc. Subdivision in Google Earth

\subsection{Collection and Analysis of the Monitored data}

\subsubsection{Data Collection}

As discussed in previous sections, all the required data to analyze ES performance and set up models were acquired from TRCA monitored data and stormwater management report prepared by Schaeffer's Consulting Engineer (SCE) in 2014. The elevation and dimensions of hydraulic 
structures such as storm sewer pipe, catch basin leader, exfiltration trench, road drainage slope, etc. were obtained from detailed drawings prepared by Schaeffer's Consulting Engineer. The data pertaining to the hydraulic, hydrologic, topographical, geotechnical, etc. properties of the study area were all derived from the SWM report, drawings and data annexed on Schaeffer's Consulting Engineers Report, 2014. Based on the TRCA data collection report, the following data set was monitored in 5 minutes time interval as presented in Table 1.

Table 1: Stormwater monitoring data

\begin{tabular}{|l|l|l|l|l|}
\hline S.n. & Types of Data & Monitoring Equipment & Monitored Duration & Installed Location \\
\hline 1 & Precipitation & Tipping bucket rain gauge & $1 / 1 / 2018$ to $12 / 27 / 2018$ & Mosaik Subdivision \\
\hline 2 & Inflow & AV flow probe & $5 / 18 / 2018$ to $1 / 24 / 2019$ & MH6 inlet \\
\hline 3 & Overflow & AV flow probe & $5 / 18 / 2018$ to $1 / 24 / 2019$ & MH6 outlet \\
\hline 4 & Water Level & Pressure transducer & $7 / 22 / 2018$ to $12 / 17 / 2019$ & MH6 \\
\hline
\end{tabular}

As depicted in Figure 8, a tipping bucket rain gauge was installed at the corner of Mosaik subdivisions premises, and area-velocity flow meters were installed at the inlet and outlet pipe of manhole 6 (MH6). In addition to flow meters, the water level sensor was installed at manhole 6 (MH6) to collect the data for hydrologic performance analysis of ES. The contributing drainage area of MH6 is 1.32ha; there is no flow contribution from the area downstream of MH6. 


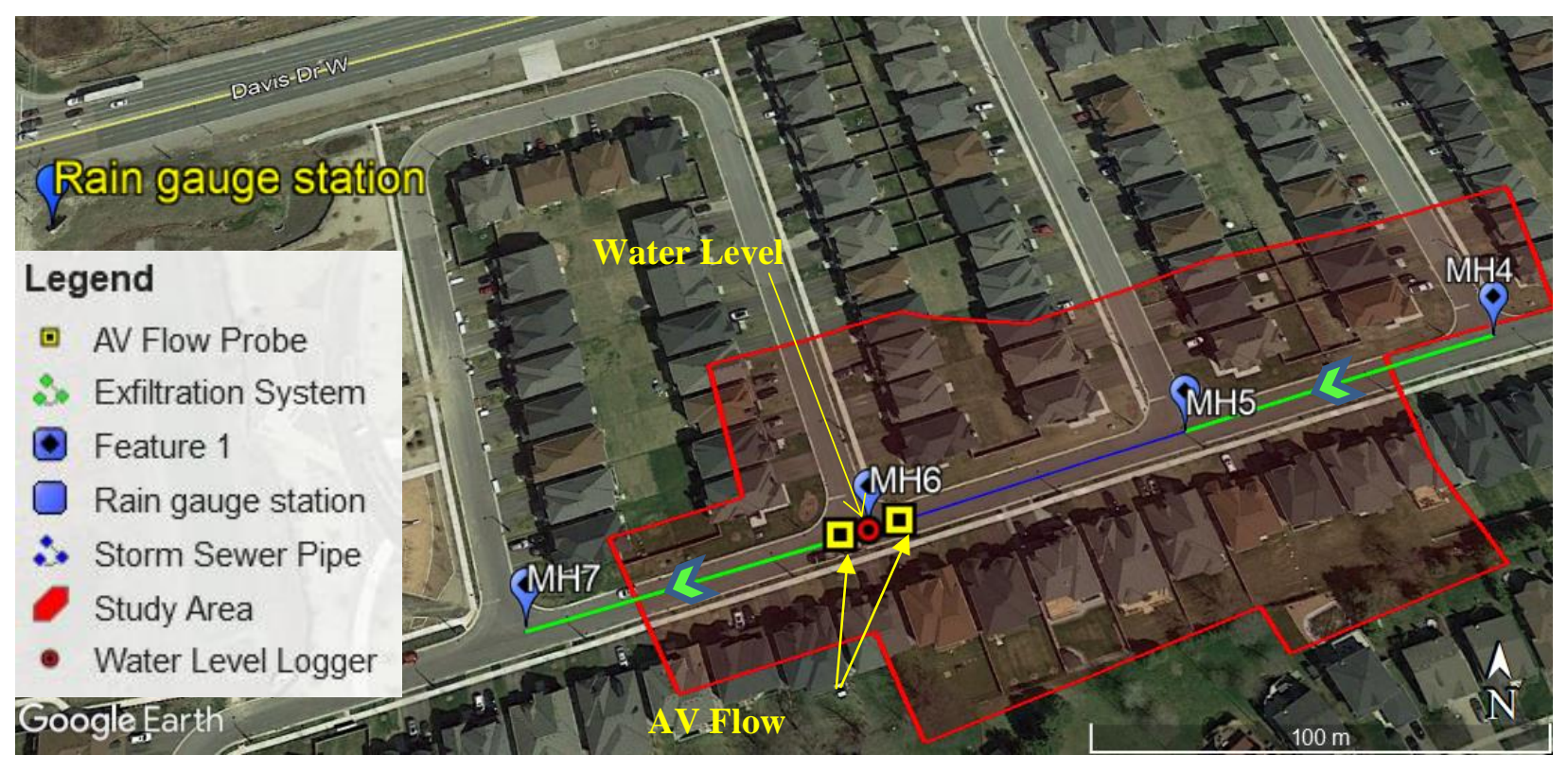

Figure 8: Location of different monitoring equipment

\subsubsection{Evapotranspiration}

Average monthly evapotranspiration data was acquired for water balance analysis as well as PCSWMM model input. For this research study, monthly averages of daily Potential Evapotranspiration (PET) values were acquired from the LID study report prepared by the Sustainable Technologies and Evaluation Program (STEP, 2019) for the Mosaik Homes Glenway Subdivision (same study area) as presented in Table 2.

Table 2: Monthly Potential Evapotranspiration (STEP, 2019)

\begin{tabular}{|l|l|l|l|l|l|l|l|l|l|l|l|l|}
\hline Months & Jan & Feb & Mar & Apr & May & Jun & Jul & Aug & Sep & Oct & Nov & Dec \\
\hline $\begin{array}{l}\text { Monthly } \\
\text { Evaporation } \\
\text { (mm/day) }\end{array}$ & 0.03 & 0.04 & 0.29 & 1.13 & 2.45 & 3.77 & 4.35 & 3.84 & 2.67 & 1.35 & 0.47 & 0.1 \\
\hline
\end{tabular}

\subsubsection{Precipitation}

As discussed in section 4.2.1, the precipitations data were collected from the tipping bucket rain gauge station installed at the corner of the Mosaik subdivision premises. The continuous precipitation time series data from $1^{\text {st }}$ Jan to $17^{\text {th }}$ Dec 2018 were collected from the TRCA 
monitoring report. Based on the provided data, the annual variation of rainfall in 5 minutes time interval is shown in Figure 9, and properties of precipitation were obtained as follows:

Maximum 5-minute rainfall intensity $\mathrm{f}=100.8 \mathrm{~mm} / \mathrm{hr}$

Total annual rainfall $=814.4 \mathrm{~mm}$

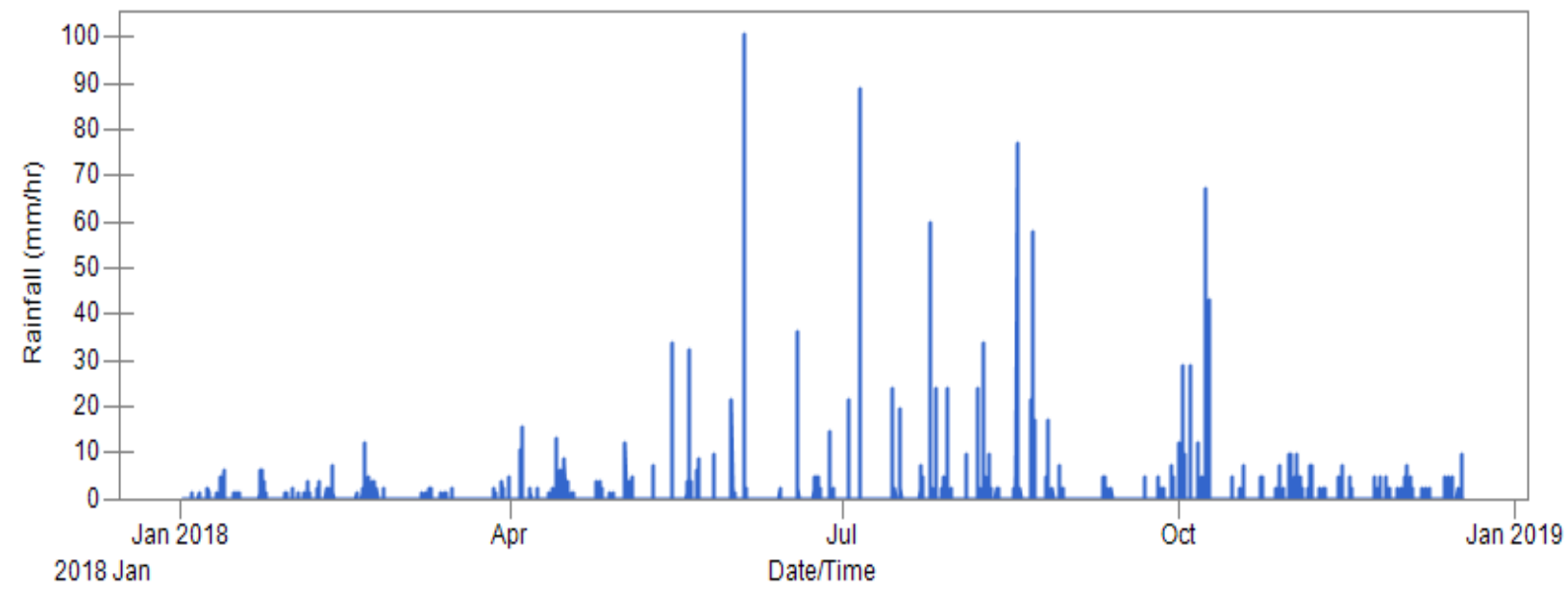

Figure 9: Monitored rainfall data of the study area

\subsubsection{Event Analysis}

Although there were many monitored events, only eight meaningful events were selected for ES performance analysis and to calibrate and validate the PCSWMM model. Since the observed flow and level data were available only from June 2018 to Dec 2018. So, characteristics of eight peak events that were selected are listed in Table 3 and they are highlighted in grey color with red enclosure, as shown in Figure 10. 
Table 3: Selected events for the analysis of ES performance

\begin{tabular}{|r|l|c|c|c|c|}
\hline Event & \multicolumn{1}{|c|}{ Date } & $\begin{array}{c}\text { Duration } \\
\text { (hr) }\end{array}$ & $\begin{array}{c}\text { Maximum } \\
\text { Rainfall }(\mathbf{m m} / \mathbf{h r})\end{array}$ & $\begin{array}{c}\text { Average Rainfall } \\
(\mathbf{m m} / \mathbf{h r})\end{array}$ & $\begin{array}{c}\text { Total Rainfall } \\
\text { Depth }(\mathbf{m m})\end{array}$ \\
\hline 1 & Jul 24,2018 5:50 PM & 3.58 & 60 & 6.81 & 24.4 \\
\hline 2 & Jul 26,2018 2:15 PM & 2.83 & 24 & 1.48 & 4.2 \\
\hline 3 & Jul 29,2018 4:25 PM & 1.17 & 24 & 2.23 & 2.6 \\
\hline 4 & Aug 07,2018 12:00 PM & 1.17 & 24 & 3.6 & 4.2 \\
\hline 5 & Aug 08,2018 8:50 PM & 2.17 & 33.6 & 5.91 & 12.8 \\
\hline 6 & Aug 17,2018 12:15 PM & 11.42 & 76.8 & 2.94 & 33.6 \\
\hline 7 & Aug 21,2018 8:00 PM & 22.33 & 57.6 & 2.29 & 51.2 \\
\hline 8 & Oct 08,2018 7:35 PM & 2 & 67.2 & 4.5 & 9 \\
\hline
\end{tabular}

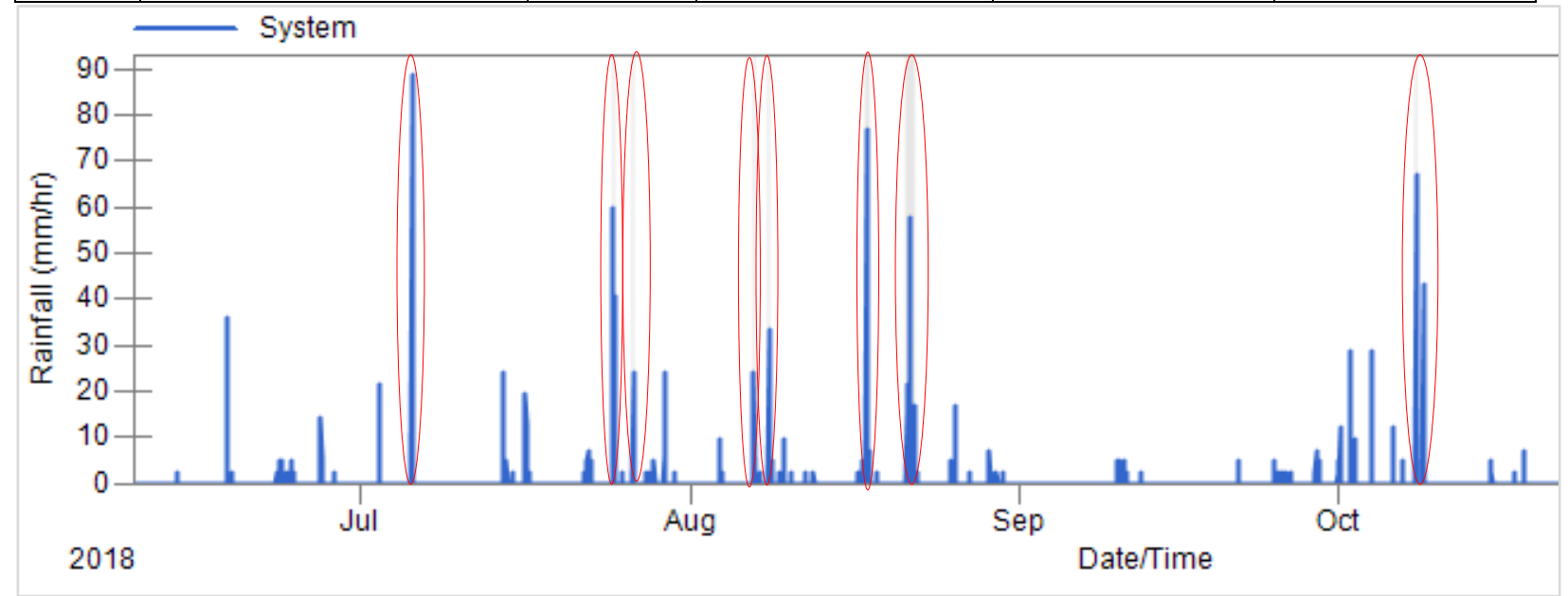

Figure 10: Selected events highlighted by grey color and red enclosure

\subsubsection{Existing Exfiltration System (ES)}

There are two separate sections of exfiltration systems that were constructed in the study area, as shown in Figure 11. The first exfiltration systems (ES1) 81.5m long was installed beneath the storm sewer pipe connecting manhole 4 (MH4) to manhole 5 (MH5) and second exfiltration system (ES2) 80m long was installed beneath the storm sewer pipe below the manhole 6 (MH6) to manhole 7 (MH7). Manholes MH4 and MH7 represents the upstream and downstream manholes in the study area. 


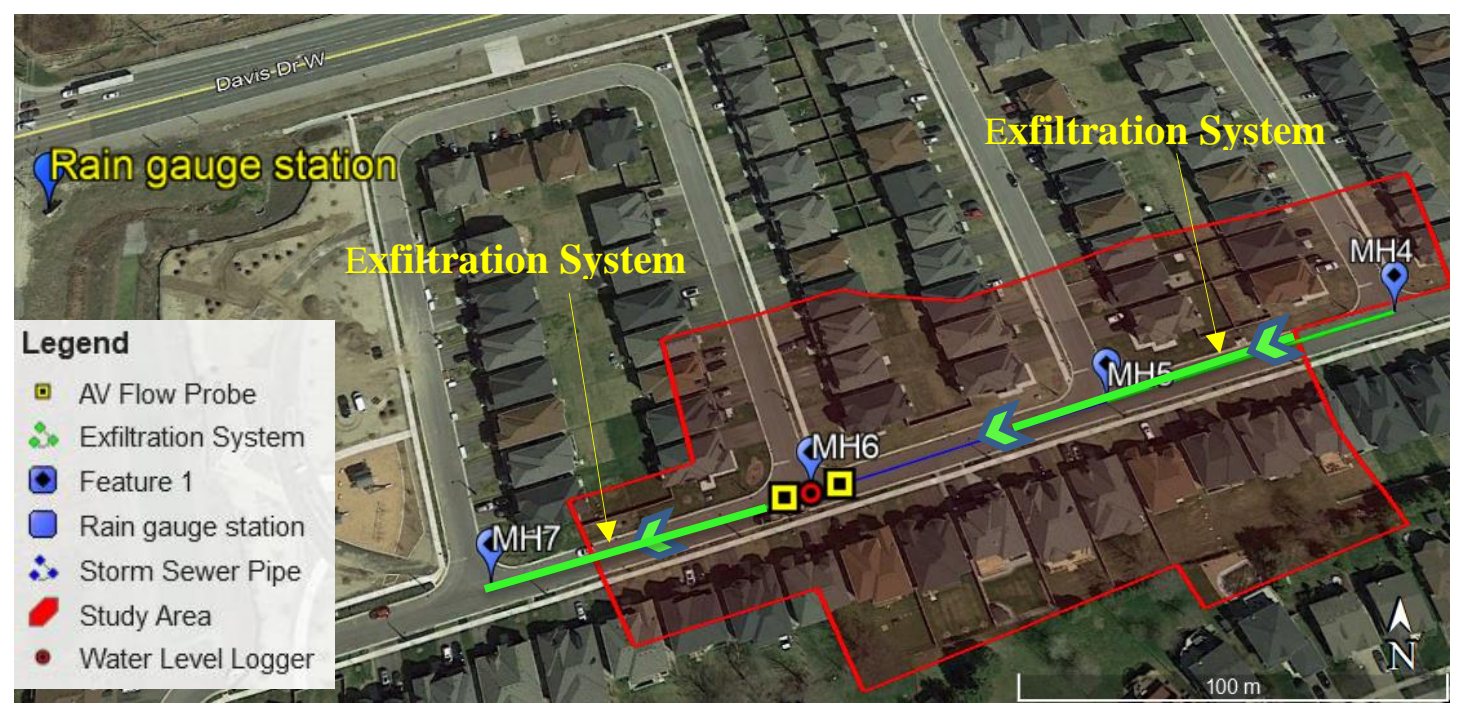

Figure 11: Exfiltration system ES1 and ES2 and a conventional storm sewer in between

Each ES section consists of $300 \mathrm{~mm}$ diameter perforated pipe embedded in $1.5 \mathrm{~m}$ deep and $2.5 \mathrm{~m}$ wide stone trench at $0.5 \%$ longitudinal slope. Stone trench along with perforated pipe was installed beneath the storm sewer with mechanical plugging at the downstream end. Mechanical plug promotes the stored water to store into the granular trench and exfiltrate into the surrounding soil as shown in Figure 13. Moreover, the cut-off wall at MH7 will prevent water from the trench to move downstream. The whole section of the granular trench was wrapped by filter fabric to prevent the intrusion of outside soil and sediments and loss of granular materials. The typical cross-section of ES constructed in the subject area is shown in Figure 12. 


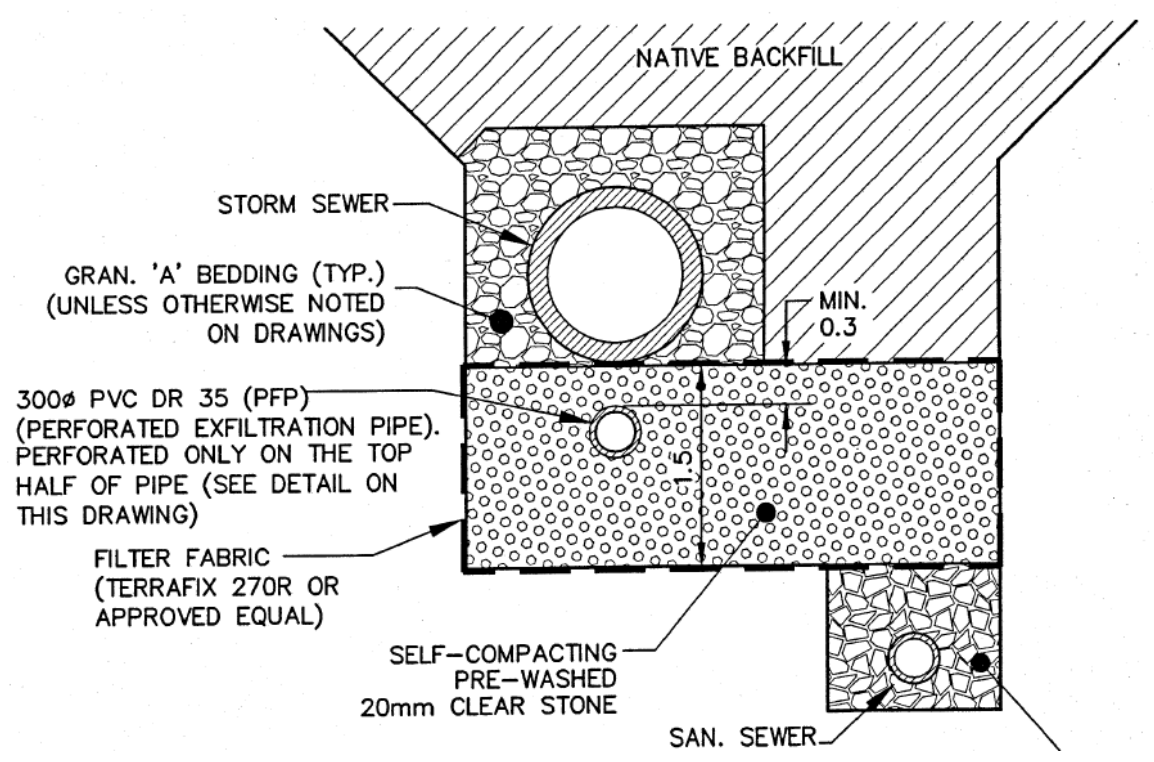

Figure 12: Cross-section of Exfiltration System (Schaeffer's Consulting Engineers Report, 2014)

The surface runoff from the subcatchment enters into the catch basins that are connected to the upstream manhole of an ES. The volume of a storage unit was reduced by 60 percent assuming a $40 \%$ porosity of the $13 \mathrm{~mm}-16 \mathrm{~mm}$ granular stones. The void space storage volume was defined by the storage curve i.e. tabular curve of surface area versus height of trench, which is discussed in detail in following sections 4.1.1. The seepage properties of the storage unit were assumed as same as the abutting subcatchment area. The storage capacity ES is calculated as below:

Storage Capacity of ES $=0.4 * 80 * 2.5 * 1.5+0.6 * \pi * 0.32 / 4 * 80=123.4 \mathrm{~m}^{3}$ 


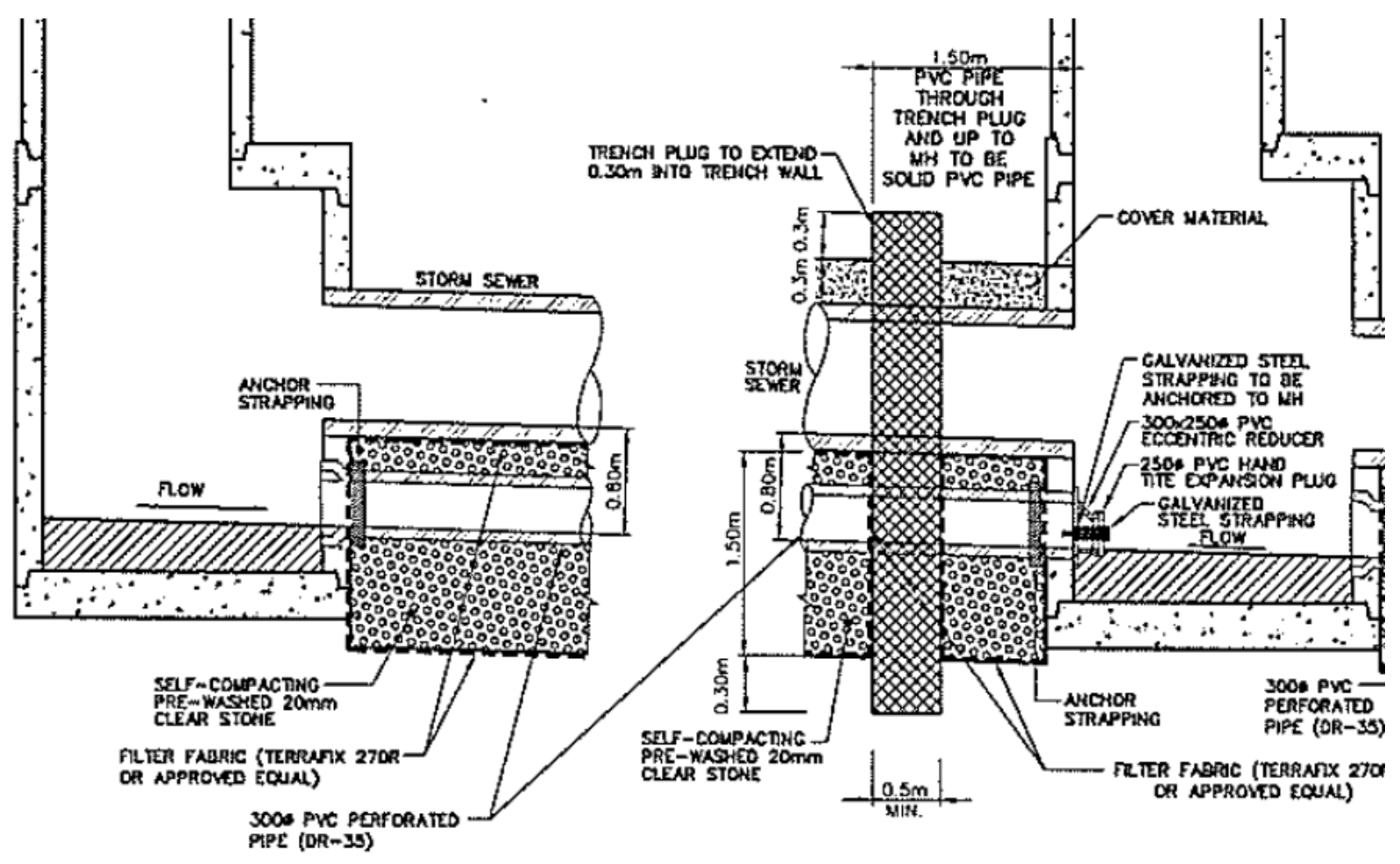

Figure 13: Longitudinal section of ES

\subsubsection{Inflow to ES}

The area velocity flow probes were installed at the inlet and outlet sewer pipe of control manhole, MH6. The inflow and overflow data were collected at 5 minutes interval using an automatic data logger. The monitored flow data for control manhole were available from July to Dec 2018, as shown in Figure 15. The total runoff volume of $317,700 \mathrm{~m}^{3}$ was observed at the inlet of control manhole from $7^{\text {th }}$ July to $17^{\text {th }}$ Dec 2018 . The inflow rate in L/s and rainfall intensity in $\mathrm{mm} / \mathrm{hr}$ is presented in Figure 14. 


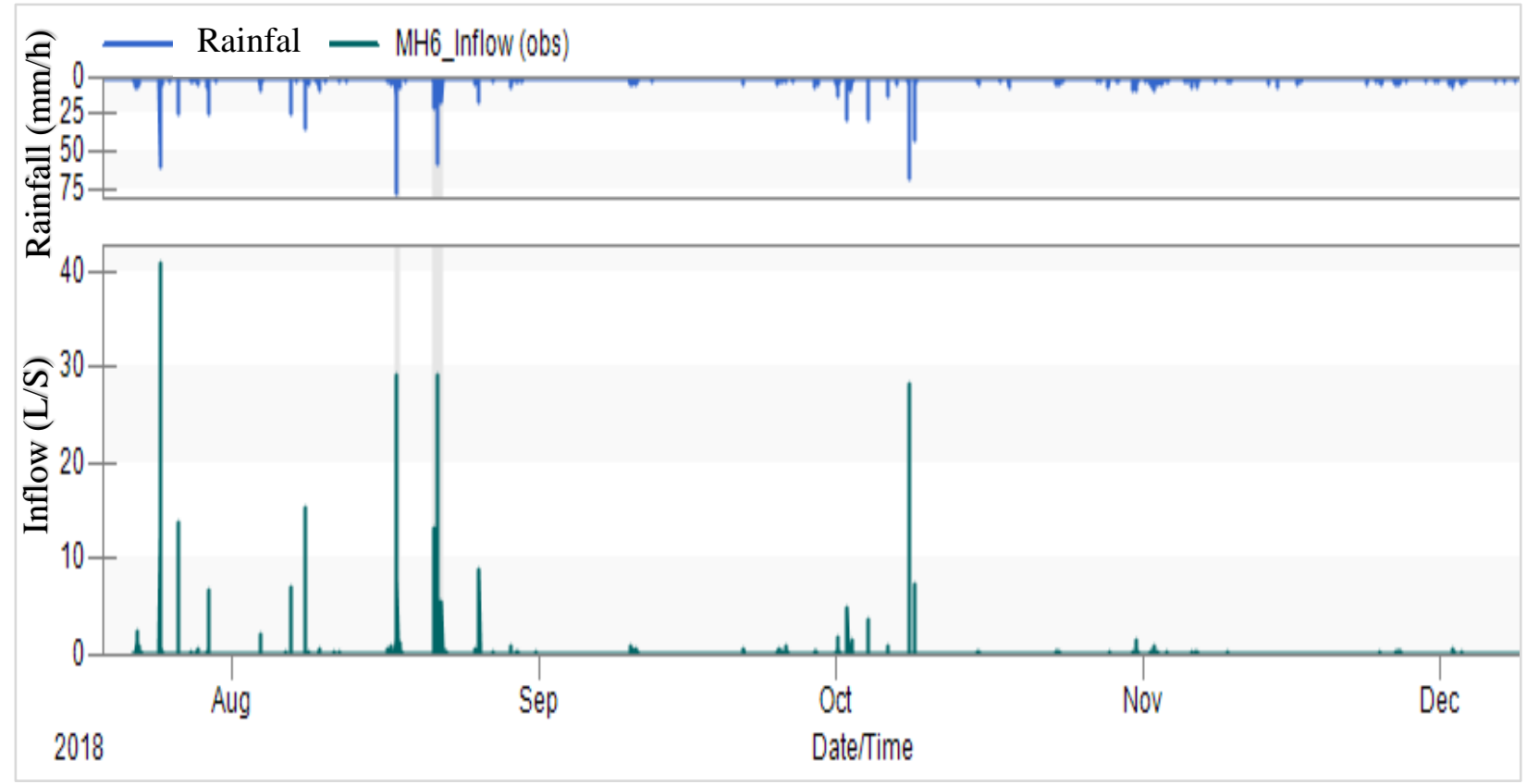

Figure 14: Performance Analysis of ES2 based on monitored data

\subsubsection{Overflow from ES}

Similarly, the area velocity flow probe was installed at the outlet pipe of MH6 to monitor the performance of ES2. Outflow was detected at the occurrence of three significant rainfall events exceeding $24 \mathrm{~mm}$ rainfall depth. A negligible amount of outflow was detected in the outlet pipe even if the water level in trench storage did not reach the overflow pipe invert level. The $52,400 \mathrm{~m}^{3}$ of total runoff volume was observed at the outlet pipe of control manhole as an ES overflow from $7^{\text {th }}$ July to $17^{\text {th }}$ Dec 2018 . The overflow rate in $\mathrm{L} / \mathrm{s}$ and rainfall intensity in $\mathrm{mm} / \mathrm{hr}$ is presented in Figure 15. 


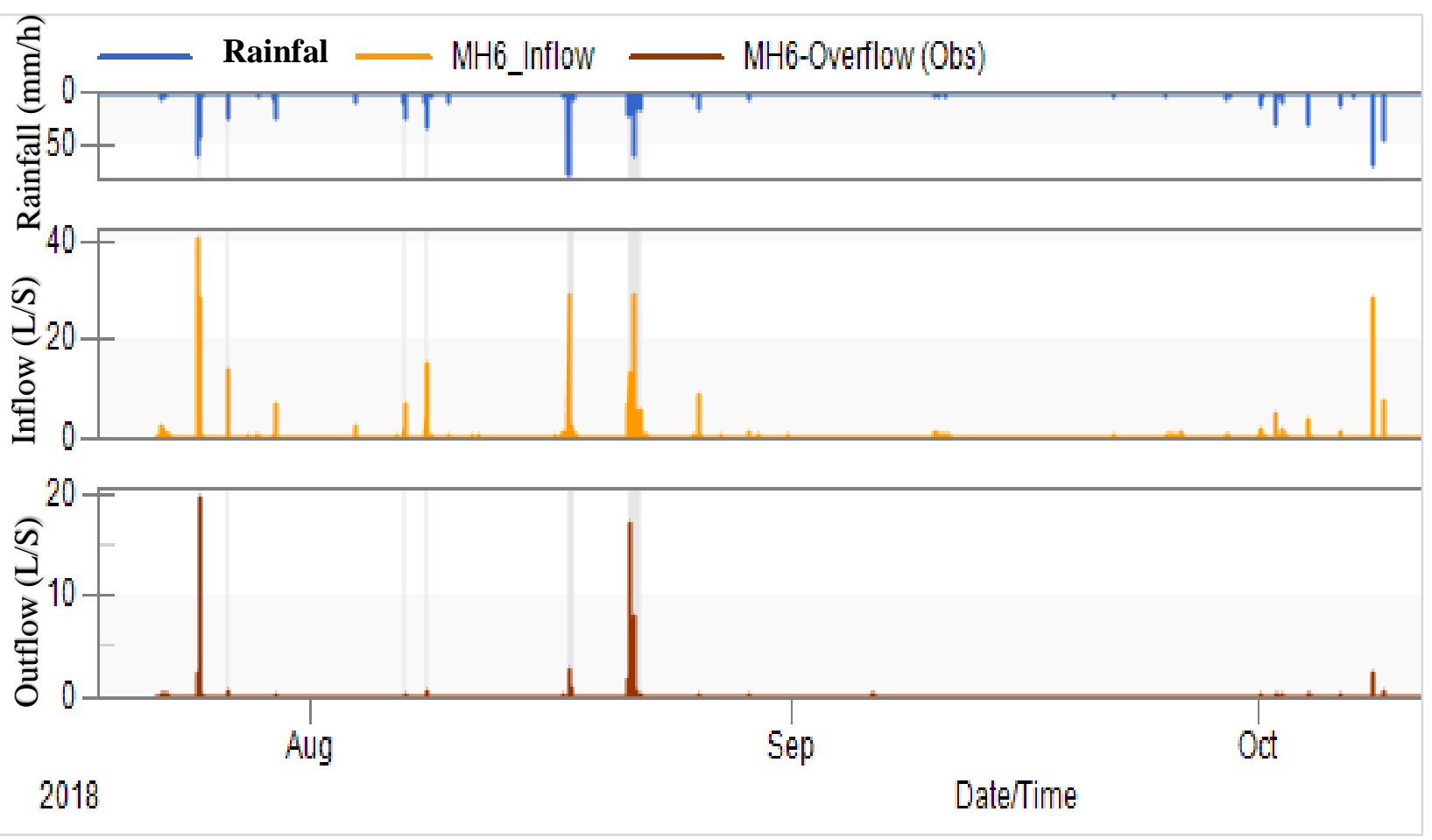

Figure 15: The monitored overflow events at outlet of MH6 (ES2 overflow)

The runoff volume exceeded the granular trench capacity in events 1, 6 and 7, as illustrated in Table 4.

Table 4: The overflow events at control manhole (MH6)

\begin{tabular}{|r|l|r|r|r|r|r|l|}
\hline Event & \multicolumn{1}{|c|}{ Date } & $\begin{array}{c}\text { Duration } \\
\text { (h) }\end{array}$ & $\begin{array}{c}\text { Total } \\
\text { Inflow } \\
\text { volume } \\
\text { (m3) }\end{array}$ & $\begin{array}{c}\text { Total flow } \\
\text { volume(m3) }\end{array}$ & $\begin{array}{c}\text { Total } \\
\text { Infiltrated } \\
\text { volume(m3) }\end{array}$ & $\begin{array}{c}\text { Total } \\
\text { Rainfall } \\
\text { (mm) }\end{array}$ & Remarks \\
\hline 1 & Jul 24,2018 & 3.58 & 556 & 15.4 & 540.6 & 24.4 & ES Capacity Full \\
\hline 2 & Jul 26,2018 & 2.83 & 64.47 & 0.1 & 64.3 & 4.2 & \\
\hline 3 & Jul 29,2018 & 1.17 & 28.32 & - & 28.3 & 2.6 & \\
\hline 4 & Aug 07,2008 & 1.17 & 46.76 & 0.0 & 46.7 & 4.2 & \\
\hline 5 & Aug 08,2018 & 2.17 & 185.9 & 0.4 & 185.5 & 12.8 & \\
\hline 6 & Aug 17,2018 & 11.42 & 449.5 & 6.7 & 442.8 & 33.6 & ES Capacity Full \\
\hline 7 & Aug 21,2018 & 22.33 & 649 & 27.9 & 621.1 & 51.2 & ES Capacity Full \\
\hline 8 & Oct 08,2018 & 2 & 100.2 & 0.8 & 99.4 & 9 & \\
\hline
\end{tabular}




\subsubsection{Water Level at Control Manhole}

The pressure transducer was installed to monitor the water level at the control manhole, MH6. The continuous water level at five minutes time interval from mid-July to December 2018 was obtained from the Schaeffer's Consulting Engineers report, as shown in Figure 16.

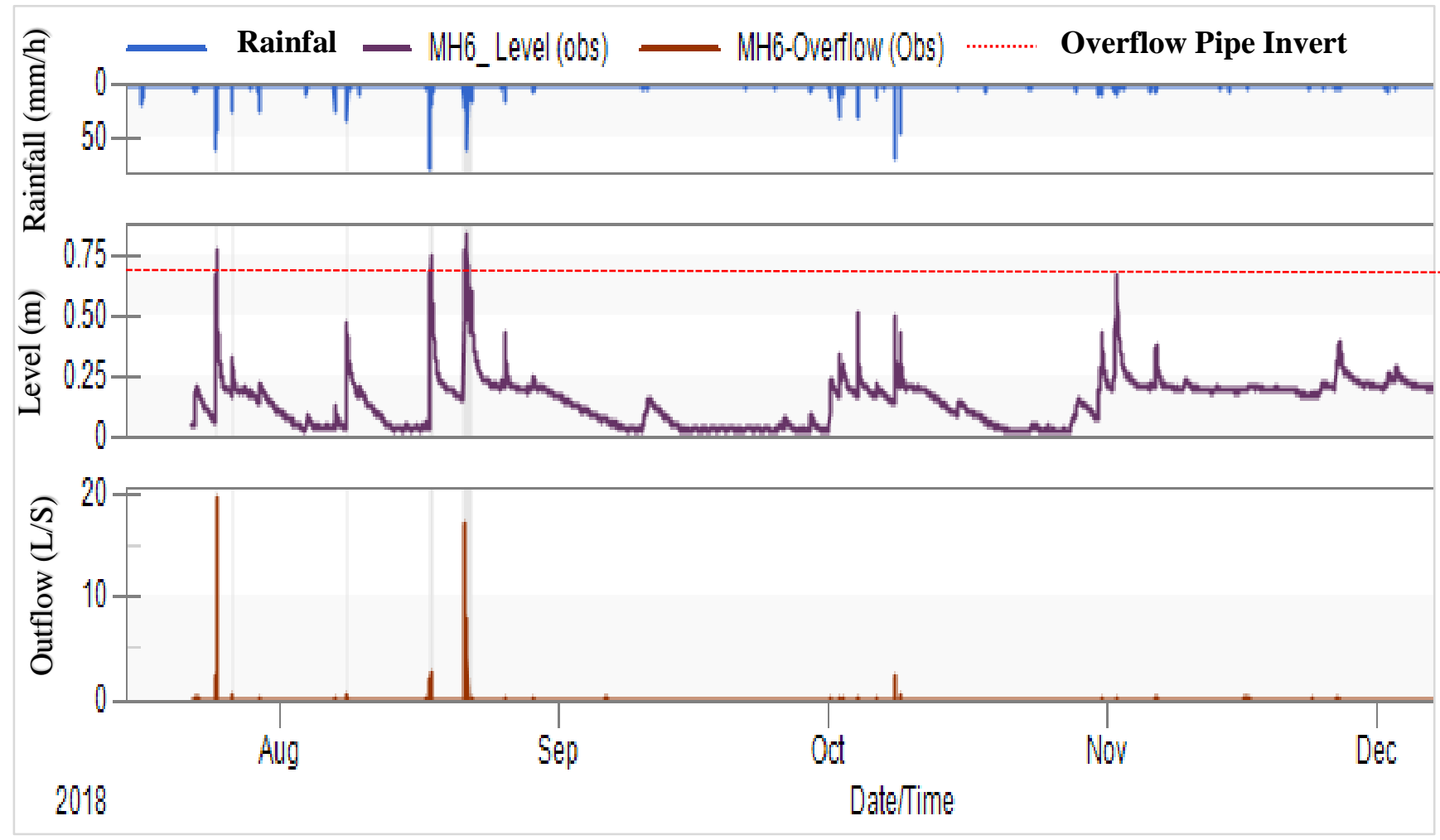

Figure 16: The monitored water level at $\mathrm{MH6}$

\subsubsection{Performance Analysis of Existing ES}

The performance of the exfiltration system (ES) was evaluated with regard to the volume of water infiltrated, post-construction infiltration rate of the underlying native soil and water storage capacity. Inflow and outflow monitoring data were used to estimate the total volume of stormwater infiltrated over the monitoring period to evaluate the degree to which the design objective of maintaining pre-development infiltration volume achieved. Infiltration rates were estimated for 
four observed drainage periods and compared to the native soil infiltration rate that was assumed as design criteria for sizing the facility.

It is assumed that the flow of water from the exfiltration system into the underlying native soil can be predicted by Darcy's law (Darcy, 1856), which states that, infiltration rate will be highest when the stone trench is full, as this will happen when the pressure difference (seepage head) is maximum. It can also be expected that the exfiltration rate (infiltration loss) will decrease as the water level (head) falls in the system, reaching a minimum when they are close to the bottom of the stone trench. For the Mosaik exfiltration system, estimates of exfiltration rates based on the volume of runoff infiltrated over the complete drainage from the beginning of a storm event to the time when the water level in the system had returned to the pre-event level.

In line with Darcy's Law, monitoring data portrays that actual infiltration rates are higher during periods when water levels in the stone trench are at their highest, and lowest when water levels are near the base. For drainage periods where antecedent dry periods following the end of individual storm events were not long enough for water levels in the stone trench to return to pre-event levels, cumulative precipitation over the period during which drainage to pre-event levels occurred was used to calculate the total inflow volume over the drainage period. Four monitoring periods were selected to evaluate the average infiltration rate, as shown in Figure 17. 


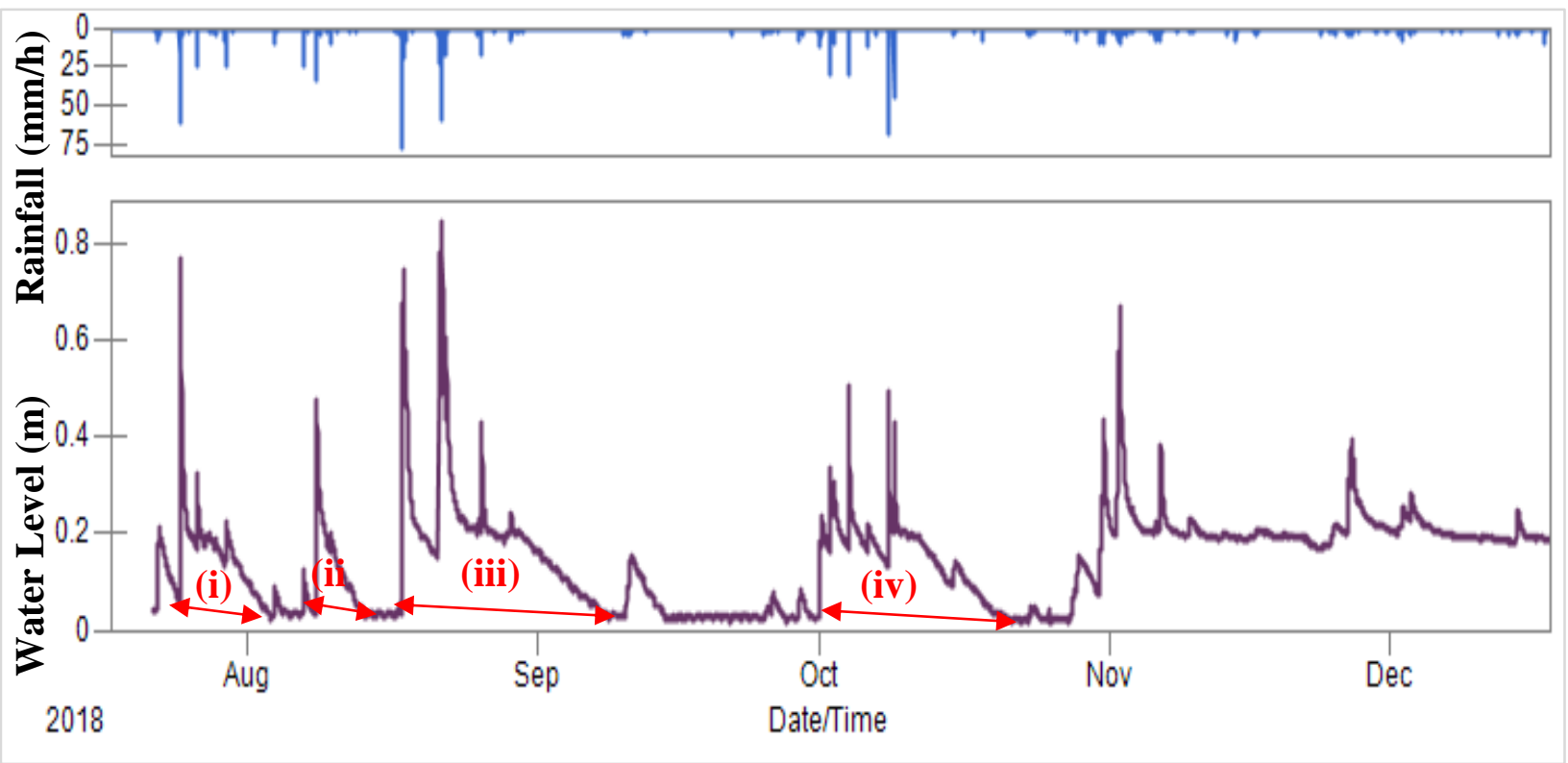

Figure 17: Four selected monitoring duration to evaluate ES performance

Absolute runoff reduction ratios calculated for those monitoring periods range from 0.77 to 0.98 . Therefore, the ES was successfully capturing and infiltrating the majority of runoff from the contributing drainage area. First event of monitoring drainage duration of 242 hours was selected (from $24^{\text {th }}$ July 2018 ,) when the storage trench started filling from the dry condition and got overflowed after filling up the trench and exfiltrated gradually until the water level dropped down to the empty bottom level.

Table 5 summarizes average exfiltration rates of the ES observed over four event-based drainage periods during which all necessary information was available. As anticipated, exfiltration rates varied according to the water level (head) in the storage trench. When the system was at full capacity and the greatest hydraulic pressure (maximum seepage head) on the underlying soil, exfiltration was observed to occur at rates as high as $4.6 \mathrm{~mm} / \mathrm{h}$, as shown in Figure 18. When the water level dropped down below half of its full capacity, then exfiltration rates decreased drastically, contributing average exfiltration rates of $1.05 \mathrm{~mm} / \mathrm{hr}$, as depicted in Figure 18 . 


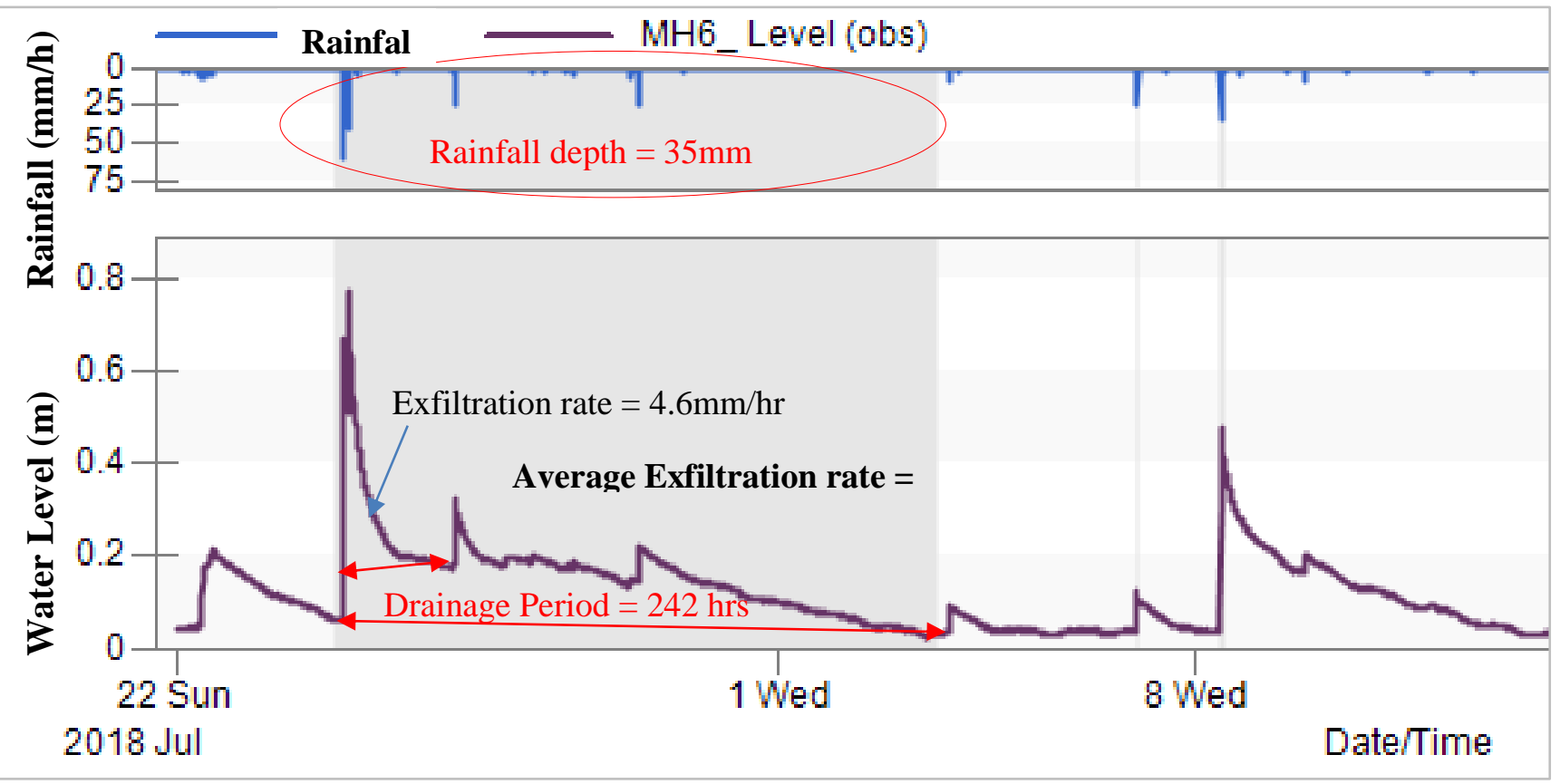

Figure 18: Average exfiltration rate (drainage period 242 hrs starting from $24^{\text {th }}$ July, 2018)

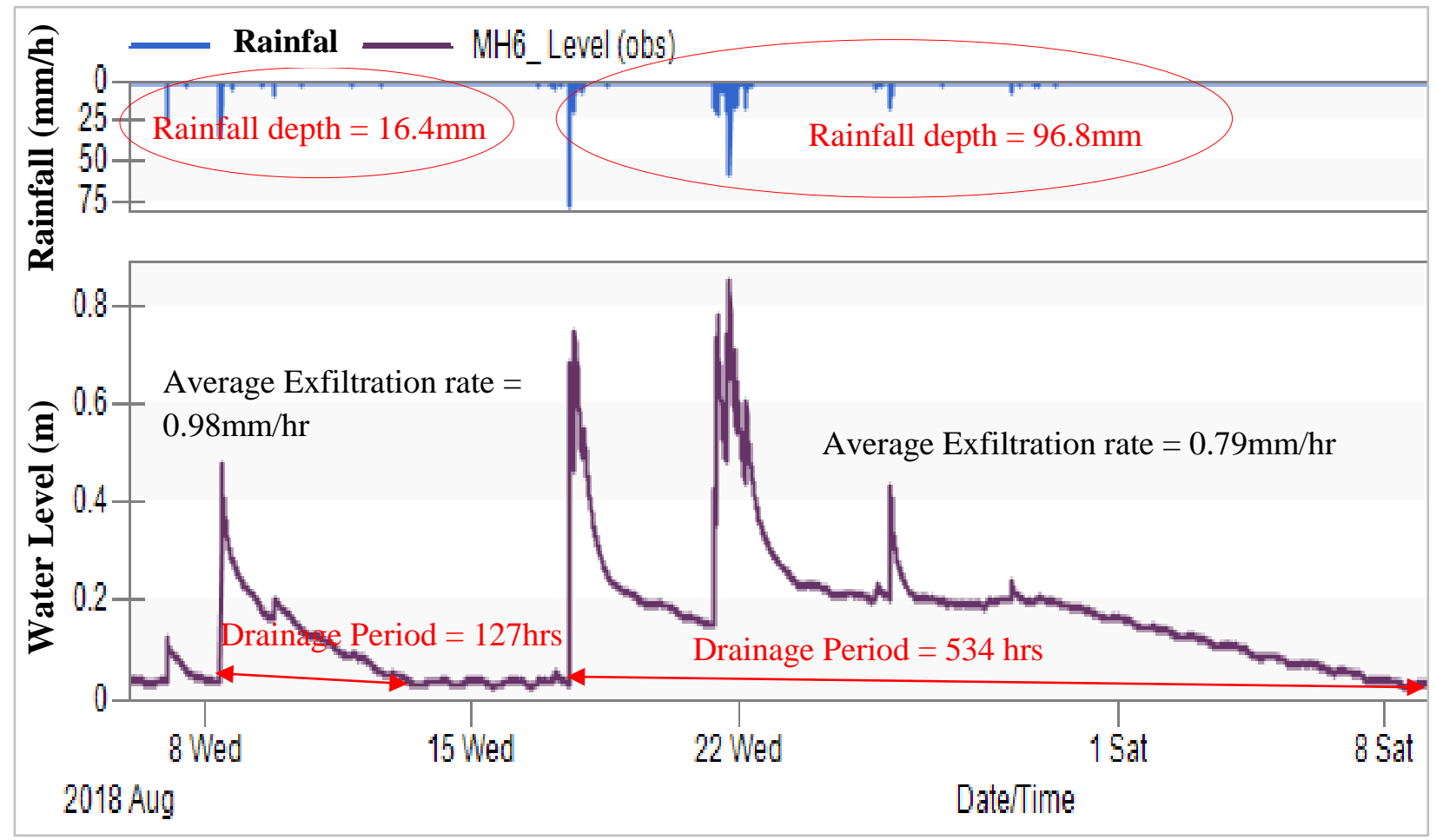

Figure 19: Average exfiltration rate (drainage period 127 hrs and 534 hrs starting from 8th Aug and 17th Aug 2018 respectively) 


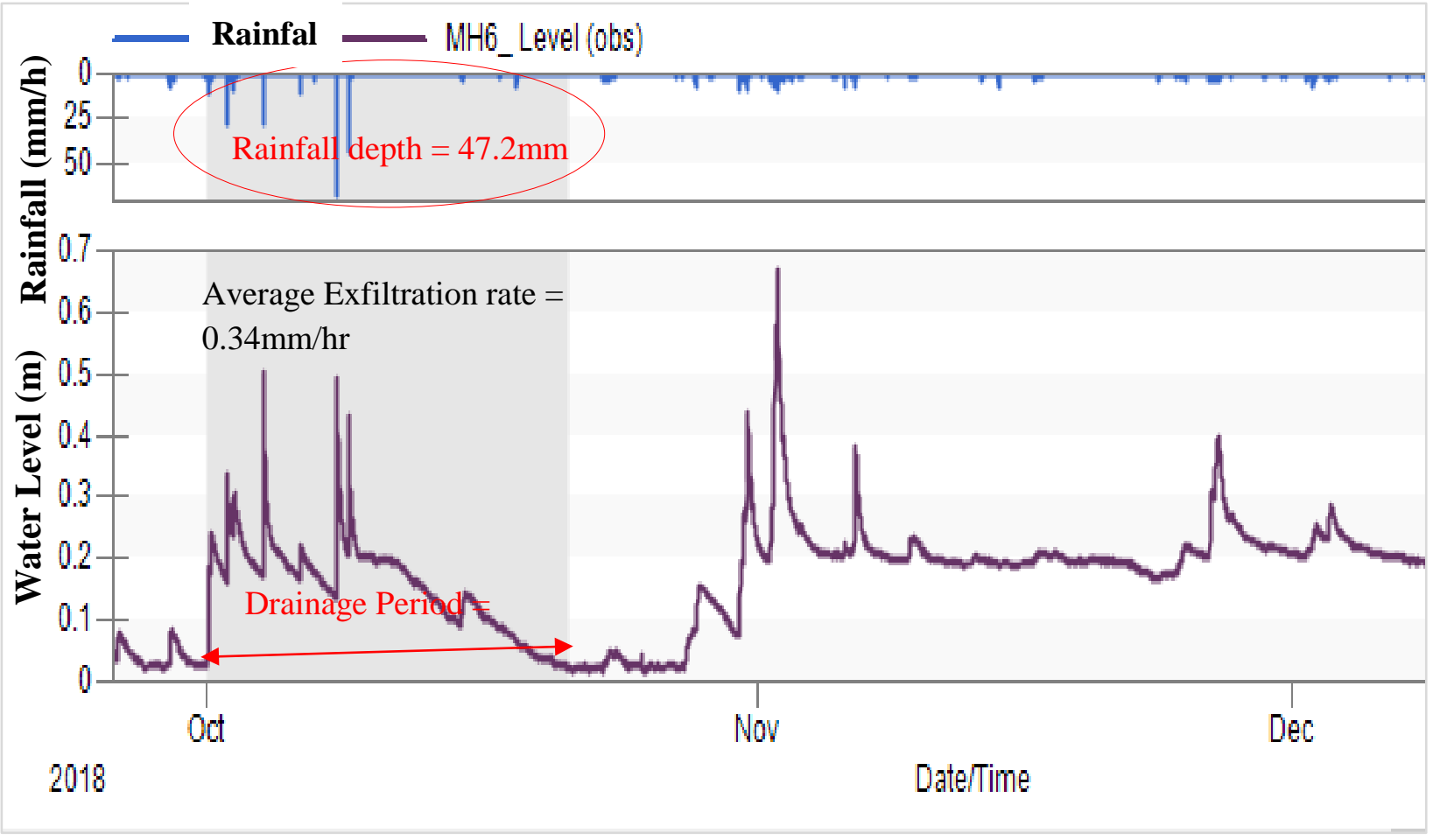

Figure 20: Average exfiltration rate (drainage period 127 hrs starting from $8^{\text {th }}$ Aug 2018)

Infiltration volumes were calculated by subtracting observed outflow volume values from estimated inflow volume values on an event-by-event basis. Table 5 provides a summary of inflow, outflow, and infiltrated volume results, as well as overall runoff reduction ratio estimates for various periods of evaluation. Results are summarized for four different monitoring periods, as shown in Figures 18, 19, and 20.

Table 5: Average exfiltration rate and runoff reduction for different monitoring periods

\begin{tabular}{|c|c|c|c|c|}
\hline \multirow{2}{*}{ Parameter } & \multicolumn{4}{|c|}{ Monitoring Start Date and Duration } \\
\cline { 2 - 5 } & Jul 24, 5:50 & Aug 08, 8:50 & Aug 17, 8:00 & Sep 30, 11:45 \\
\hline Duration (hr) & 242.50 & 127.42 & 534 & 333.92 \\
\hline Total Precipitation Depth (mm) & 35 & 16.4 & 96.8 & 47.2 \\
\hline Total Inflow Volume (m3) & 66.69 & 19.87 & 119.3 & 23.67 \\
\hline Total Outflow Volume (m3) & 15.56 & 0.418 & 34.68 & 1.18 \\
\hline Total Infiltrated Volume(m3) & 51.13 & 19.452 & 84.62 & 22.49 \\
\hline Average Infiltration rate (mm/hr) & 1.05 & 0.76 & 0.79 & 0.34 \\
\hline Runoff Reduction Ratio & 0.77 & 0.98 & 0.71 & 0.95 \\
\hline
\end{tabular}


To evaluate whether or not the exfiltration system drained at its assumed design rate $(7.7 \mathrm{~mm} / \mathrm{h})$, average infiltration rate over selected drainage periods were calculated using Equation 4 (infiltration was assumed to occur primarily by the vertical flow of water from the base of the system):

Equation 4, Average Infiltration Rate

$f=\left(V_{i}-V_{o}\right) / A_{f} * 1 / t * 1000$

Where,

$f=$ Average infiltration rate over the drainage period $(\mathrm{mm} / \mathrm{h})$

$V_{i}=$ Inflow Volume (m3) during the drainage period

$V_{o}=$ Outflow Volume (m3) during the drainage period

$A_{f}=$ Footprint surface area of exfiltration system $(\mathrm{m} 2)=200 \mathrm{~m}^{2}$

$t=$ Drainage period duration $(\mathrm{h})$

Based on the monitored full drainage cycle, and infiltration area of $200 \mathrm{~m}^{2}$ (i.e., the ES footprint area), the average exfiltration rates observed over the monitoring period ranged from 0.76 to 1.05 $\mathrm{mm} / \mathrm{h}$, indicating that the system drained at a much slower rate than the assumed design capacity of $7.7 \mathrm{~mm} / \mathrm{h}$. As a result, the system requires a much longer drawdown period than the estimated 78 hours.

\subsubsection{Peak flow Reduction}

As discussed in section 4.2.2, eight rainfall events were selected to evaluate the peak flow performance of ES. During events 1, 6 and 7, overflow was detected and peak flow reduction ranged from 41 to $92 \%$ as shown in Table 6 and Figure 21. 
Table 6: Peak flow Performance Analysis of ES2 based on monitored data

\begin{tabular}{|c|c|c|c|c|c|c|}
\hline \multirow[b]{2}{*}{ Event } & \multirow[b]{2}{*}{ Date } & \multirow{2}{*}{$\begin{array}{l}\text { Duration } \\
\text { (h) }\end{array}$} & \multirow[b]{2}{*}{$\begin{array}{c}\text { Total } \\
\text { Rainfall } \\
\text { (mm) }\end{array}$} & \multirow{2}{*}{$\begin{array}{l}\text { ES Inflow } \\
\text { Peak Flow } \\
\text { Rate (L/S) }\end{array}$} & \multirow{2}{*}{\begin{tabular}{l}
\multicolumn{1}{c}{ ES } \\
Overflow \\
Peak \\
Flow Rate \\
(L/S)
\end{tabular}} & \multirow{2}{*}{\begin{tabular}{c}
\multicolumn{1}{c}{ ES } \\
Performance \\
\\
Peak Flow \\
Reduction
\end{tabular}} \\
\hline & & & & & & \\
\hline 1 & Jul 24,2018 & 3.58 & 24.4 & 40.88 & 19.64 & $52 \%$ \\
\hline 2 & Jul 26,2018 & 2.83 & 4.2 & 13.72 & 0.428 & $97 \%$ \\
\hline 3 & Jul 29,2018 & 1.17 & 2.6 & 6.533 & 0 & $100 \%$ \\
\hline 4 & Aug 07,2008 & 1.17 & 4.2 & 6.941 & 0 & $99 \%$ \\
\hline 5 & Aug 08,2018 & 2.17 & 12.8 & 15.25 & 0.544 & $96 \%$ \\
\hline 6 & Aug 17,2018 & 11.42 & 33.6 & 29.21 & 2.475 & $92 \%$ \\
\hline 7 & Aug 21,2018 & 22.33 & 51.2 & 29.06 & 17.18 & $41 \%$ \\
\hline 8 & Oct 08,2018 & 2 & 9 & 28.31 & 2.235 & $92 \%$ \\
\hline
\end{tabular}

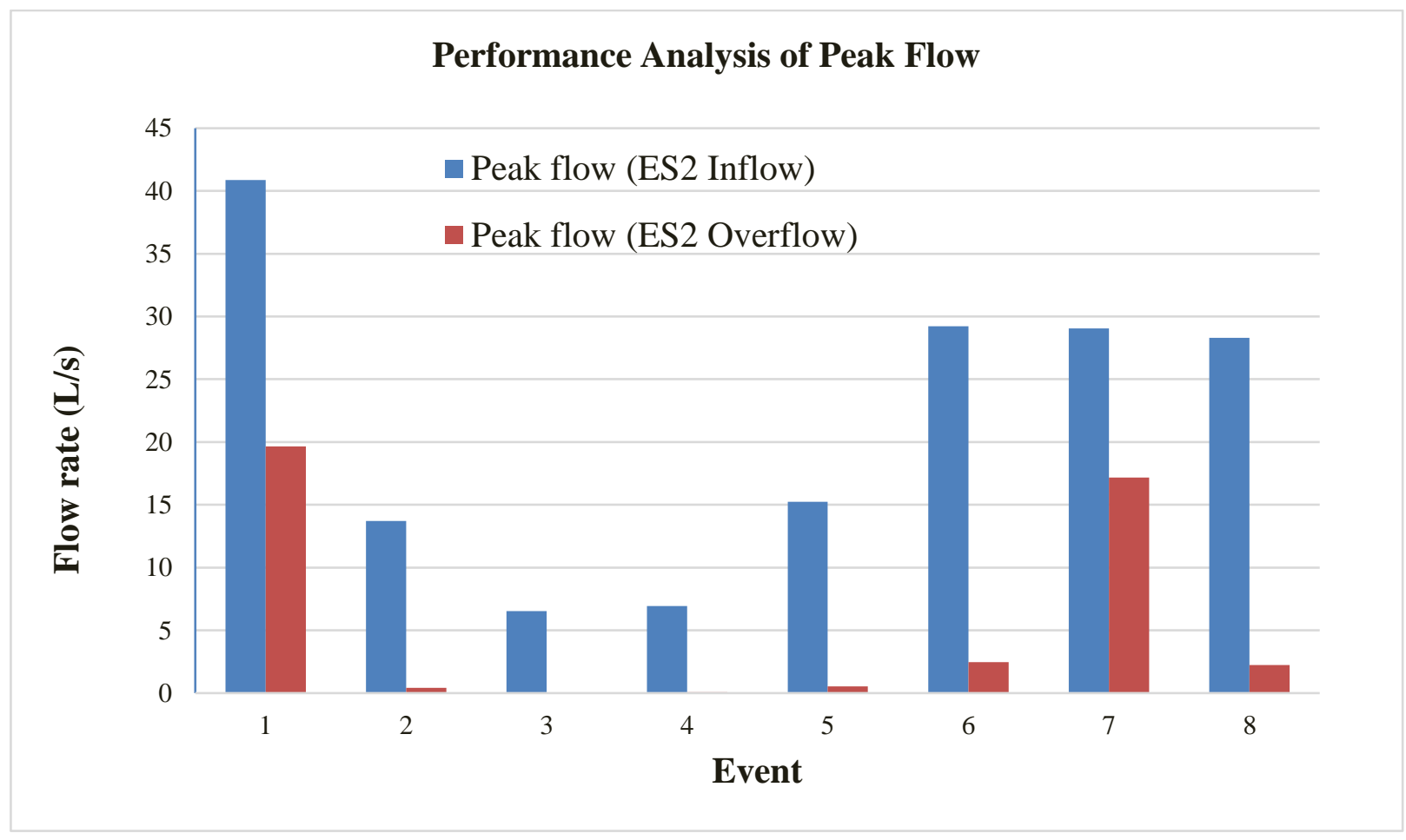

Figure 21: Peak flow reductions of ES for selected events

\subsubsection{Runoff volume reduction}

As mentioned in the previous sections, the inflow and outflow from the control manhole, MH6 was monitored from $12^{\text {th }}$ July to $17^{\text {th }}$ December 2018. During that time, the total inflow and 
outflow runoff volume were observed $317.7 \mathrm{~m}^{3}$ and $52.4 \mathrm{~m}^{3}$, respectively. The total exfiltrated volume by ES2 was $265.3 \mathrm{~m}^{3}$, representing $83.5 \%$ reduction of runoff volume, as shown in Figure 22.

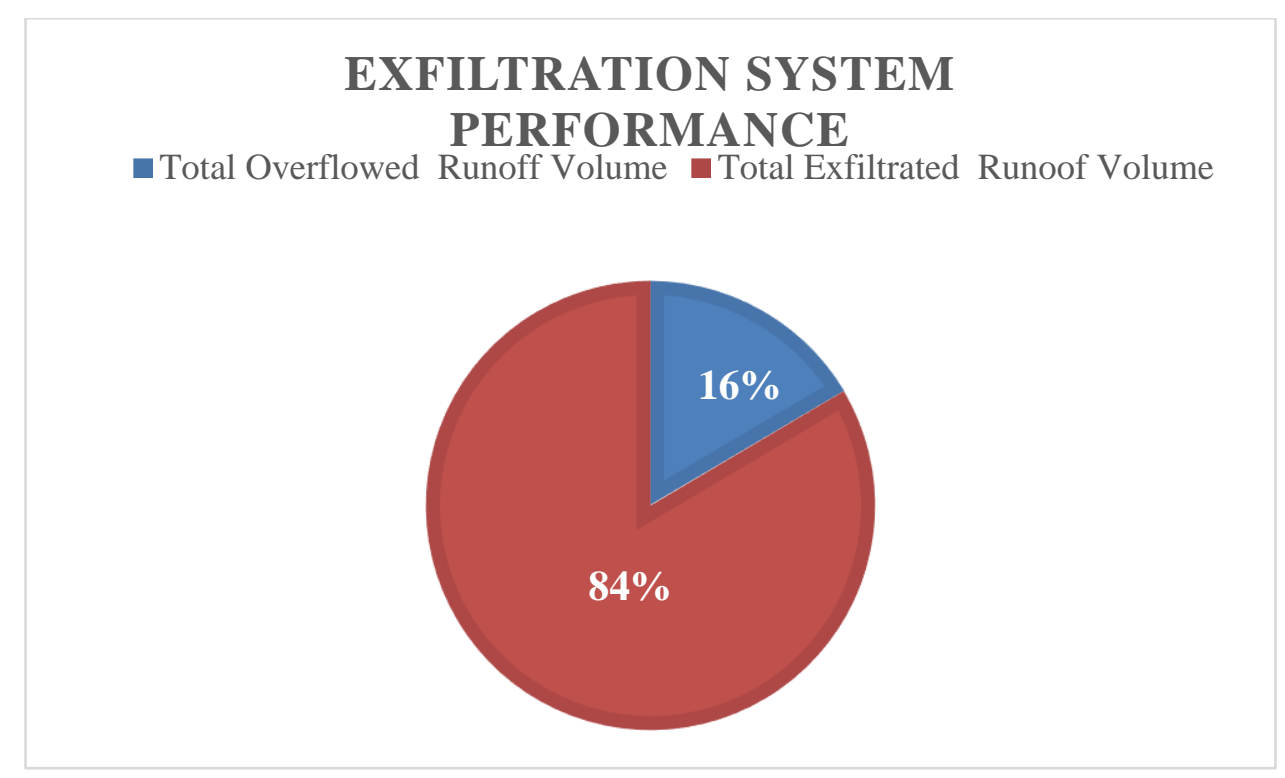

Figure 22: Overall ES performance in terms of runoff volume reductions

\subsection{Model Setup}

The ES model was set up in McGregor Farm Trail between MH4-MH5 (ES1) and MH6-MH7 (ES2) and modeled by considering stone trench storage as a storage unit and 300mm PVC perforated pipe as an orifice using PC SWMM 5.1.013. The exfiltration storage model includes a storage unit (SU) and an orifice which drains the water collected at control manhole to the ES and storage unit represents the stone trench storage, which is discussed further in the following sections.

\subsubsection{The ES Model with a Storage Unit}

The exfiltration via the storage unit model includes a storage unit $(\mathrm{SU})$ and an orifice which represent exfiltration loss, as shown in Figure 23. Based on the SWMM Manual (CHI, 2017), 
the storage unit loss (exfiltration) was calculated using the Green-Ampt method.

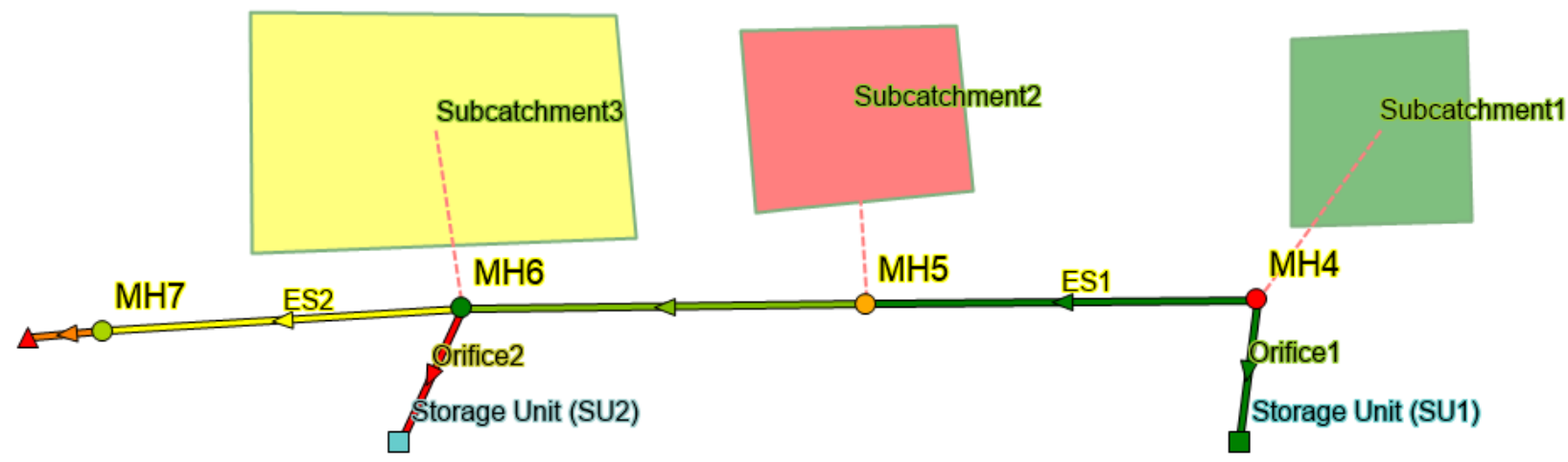

Figure 23: Schematic diagram of exfiltration via storage unit model

As discussed in Section 2.3, the hydraulic conductivity is a function of the suction head and the soil moisture content. The exfiltration rate into the surrounding soil of trench and the cumulated infiltration volume were calculated based on the Green-Ampt equation. Characteristics of the soil (e.g., initial moisture deficit, hydraulic conductivity, and suction head) are the primary inputs of the Green-Ampt equation and eventually input data of the final model. Based on the geotechnical investigation report, the soil type of the study area was silty clay to sandy clay loam (Schaeffer Consulting Engineer, 2016). The seepage properties of the clay loam were taken from Table 10.4 of the NVCA Stormwater Technical Guide prepared by Glenn Switzer in 2013 for Green and Ampt method, as presented in Table 7. Based on that Table, the value of seepage properties of clay loam are as follows:

- $\quad$ Hydraulic Conductivity: $2 \mathrm{~mm} / \mathrm{h}$

- $\quad$ Suction Head: $208.8 \mathrm{~mm}$

- Initial Deficit: 0.146 
Table 7: Green and Ampt Method Parameters (Adapted from NVCA Stormwater Technical Guide, 2013)

\begin{tabular}{|c|c|c|c|c|}
\hline \multirow{3}{*}{$\begin{array}{l}\text { USDA Soil } \\
\text { Texture } \\
\text { Classification }\end{array}$} & \multirow{3}{*}{$\begin{array}{l}\text { SUCT } \\
\text { Average } \\
\text { Capillary } \\
\text { Suction } \\
\\
(\mathrm{mm})\end{array}$} & \multirow{3}{*}{$\begin{array}{l}\text { HYDCON } \\
\text { Saturated } \\
\text { Hydraulic } \\
\text { Conductivity } \\
(\mathrm{mm} / \mathrm{hr})\end{array}$} & \multicolumn{2}{|c|}{ SMDMAX } \\
\hline & & & \multicolumn{2}{|c|}{$\begin{array}{c}\text { Initial Moisture Deficit for soil } \\
\text { (Vol. of Air/ Vol. of Voids, expressed as a } \\
\text { fraction) }\end{array}$} \\
\hline & & & $\begin{array}{l}\text { Moist Soil Climates } \\
\text { (Eastern US) }\end{array}$ & $\begin{array}{l}\text { Dry Soil Climates } \\
\text { (Western US) }\end{array}$ \\
\hline Sand & 49.5 & 235.6 & 0.346 & 0.404 \\
\hline Loamy Sand & 61.3 & 59.8 & 0.312 & 0.382 \\
\hline Sandy Loam & 110.1 & 21.8 & 0.246 & 0.358 \\
\hline Loam & 88.9 & 13.2 & 0.193 & 0.346 \\
\hline Silt Loam & 166.8 & 6.8 & 0.171 & 0.368 \\
\hline Sandy Clay Loam & 218.5 & 3 & 0.143 & 0.25 \\
\hline Clay Loam & 208.8 & 2 & 0.146 & 0.267 \\
\hline Silty Clay Loam & 273 & 2 & 0.105 & 0.263 \\
\hline Sandy Clay & 239 & 1.2 & 0.091 & 0.191 \\
\hline Silty Clay & 292.2 & 1 & 0.092 & 0.229 \\
\hline Clay & 316.3 & 0.6 & 0.079 & 0.203 \\
\hline
\end{tabular}

\subsubsection{The Storage Curve}

PCSWMM calculates the volume of the storage unit using the user-specified storage curve. The storage curve is the relationship between the depth of the storage unit and the surface area (Rossman, 2017). There are two types of storage curves in SWMM model:

- Functional Curve

- Tabular Curve

\subsubsection{Tabular Curve}

The tabular curve can be used to define the relationship between water depth and water surface area of a stone trench in the exfiltration storage model. This method is applicable as long as the upstream invert elevation of the storm sewer is lower than the stone trench depth. The relationship between the increasing surface area of the trench and the growing water level in the sloped trench 
is depicted in Figure 24. Figure 25 shows the relationship between the storage volume versus th e level of water in the storage trench.

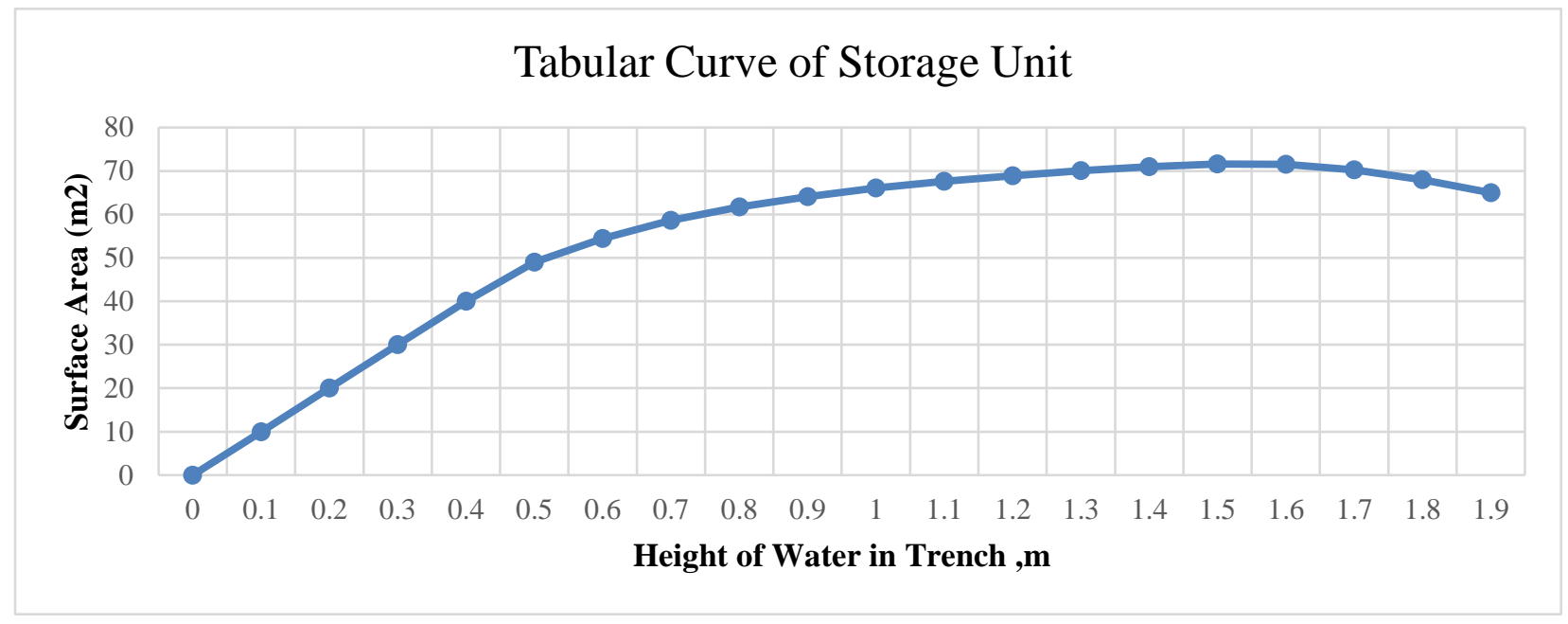

Figure 24. Storage Tabular Curve for ES2 (MH6- MH7)

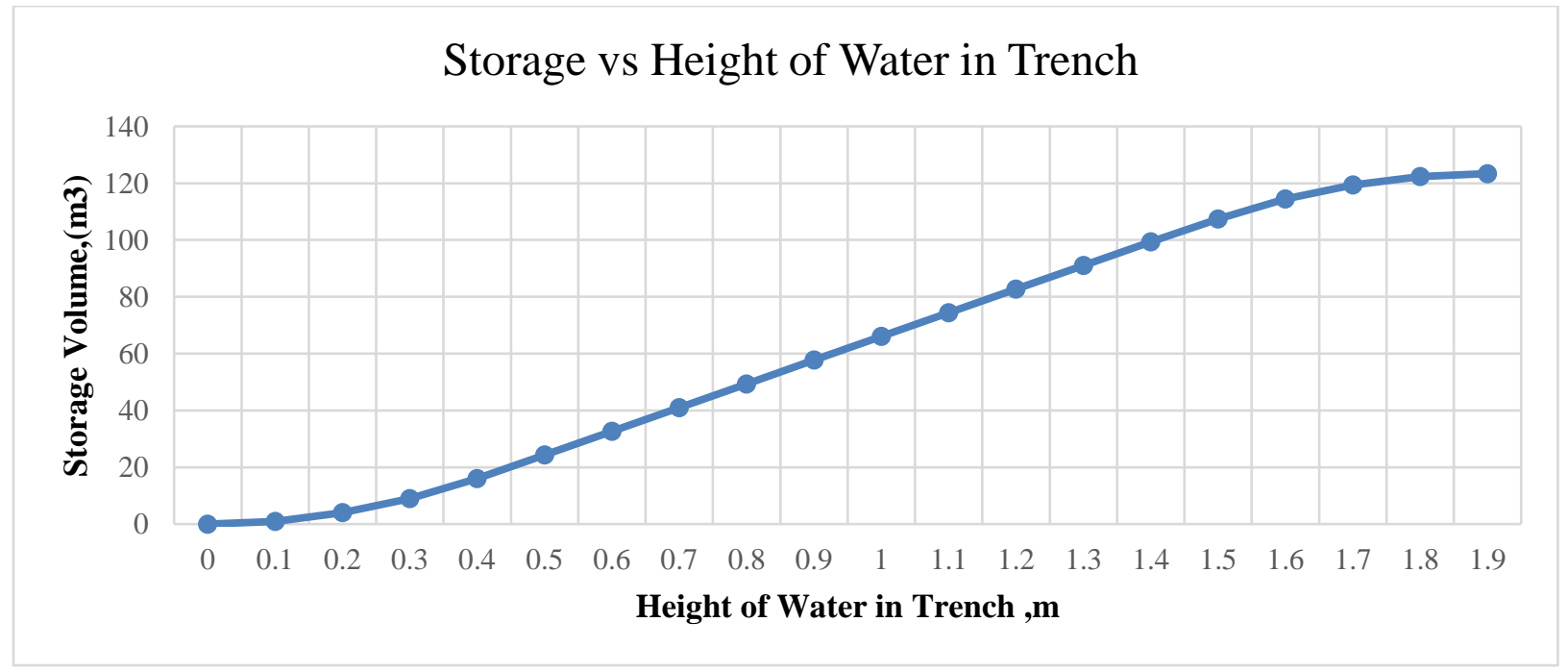

Figure 25. Storage volume Curve for ES2

In order to illustrate how the surface area of trench varies according to the water level in the trench, the entire ES section was partitioned into three parts, as shown in Figure 26. 


\section{Upstream Manhole, MH6}

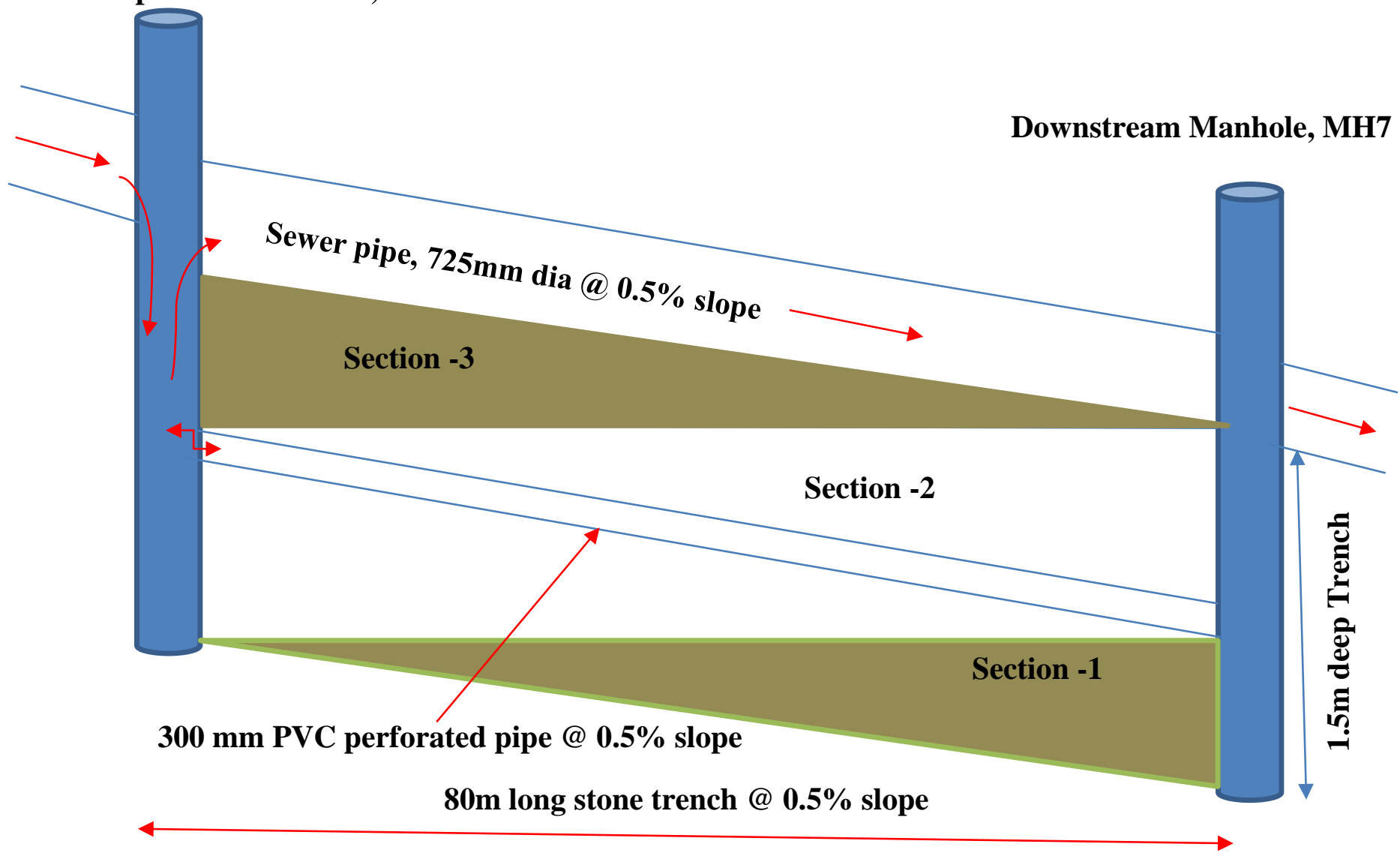

Figure 26: Different sections of ES representation to calculate trench surface area

For the sake of simplicity, the calculation of surface area and storage volume for three different three sections are discussed below.

\section{Equation for section -1}

This section includes the area from the bottom level of trench up to end the inclined height (slopeintercept) of the storage trench where the water level fills up inclined (triangular portion) and just reaches the top of slope-intercept level. The water level rises zero to the maximum slope-intercept height (top of lower triangular portion), and surface area of trench increase linearly from zero to theoretical maximum value. In this section, the length of trench varies and storage increases as 
trapezoidal volume.

Surface area of the trench $=\quad \underline{0.4 * \text { Width } * \text { height of water in trench }}$

Slope of Trench

Volume of storage trench $=$ Surface area of trench $*$ Height of Trench

\section{Equation for section - 2}

This section includes area from top of slope-intercept (top level of triangular portion in crosssectional area) to the obvert level of the downstream end of the stone trench. Length of the stone trench remains constant for this section, and the volume of storage increases as cylindrical volume. This elevation difference of trench is $0.4 \mathrm{~m}$ due to $0.5 \%$ longitudinal slope of the stone trench and remains constant for this section. Theoretically, surface area remains maximum and constant for this section; however, to accommodate perforated pipe volume, the surface area was adjusted.

Surface area of the trench $=\quad \underline{0.4 * \text { Width } * \text { Elevation difference of trench }}$ Slope of Trench

Volume of storage trench $=$ Surface area of trench $*$ Height of Trench

\section{Equation for section - 3}

This section includes the area between sill level of downstream end to the upstream end of the stone trench. For this section, the surface area varies slightly and remains constant once water fills up to trench top-level (full capacity).

Surface area of the trench $=\underline{0.4 * \text { Width* height of water in the trench above top of downstream end }}$ Slope of Trench

Volume of storage trench $=$ Surface area of trench $*$ Height of Trench

The detailed calculation of the surface area of the trench with different levels of water in the trench is presented in Table 8. 
Table 8: Tabular curve calculation at different sections

\begin{tabular}{|c|c|c|c|c|}
\hline $\begin{array}{l}\text { Height of Water } \\
\text { in Trench }(\mathbf{m})\end{array}$ & $\begin{array}{l}\text { Length of } \\
\text { Trench }\end{array}$ & $\begin{array}{l}\text { Surface Area of } \\
\text { Trench } \mathbf{( m 2 )}\end{array}$ & $\begin{array}{l}\text { Volume of } \\
\text { storage, } \mathbf{m} 3\end{array}$ & Remarks \\
\hline 0 & 0 & 0 & 0 & Section-1 \\
\hline 0.1 & 20 & 20 & 1 & Section-1 \\
\hline 0.2 & 40 & 30 & 9 & Section-1 \\
\hline 0.3 & 60 & 40.00 & 16.00 & Section-1 \\
\hline 0.4 & 80 & 49.02 & 24.34 & Section-2 \\
\hline 0.5 & 80 & 54.46 & 32.68 & Section-2 \\
\hline 0.6 & 80 & 58.60 & 41.02 & Section-2 \\
\hline 0.7 & 80 & 61.70 & 49.36 & Section-2 \\
\hline 0.8 & 80 & 64.11 & 57.70 & Section-2 \\
\hline 0.9 & 80 & 66.03 & 66.03 & Section-2 \\
\hline 1 & 80 & 67.61 & 74.37 & Section-2 \\
\hline 1.1 & 80 & 68.93 & 82.71 & Section-2 \\
\hline 1.2 & 80 & 70.04 & 91.05 & Section-2 \\
\hline 1.3 & 80 & 70.99 & 99.39 & Section-2 \\
\hline 1.4 & 80 & 71.59 & 107.39 & Section-3 \\
\hline 1.5 & 80 & 71.49 & 114.39 & Section-3 \\
\hline 1.6 & 80 & 70.23 & 119.39 & Section-3 \\
\hline 1.7 & 80 & 67.99 & 122.39 & Section-3 \\
\hline 1.8 & 80 & 64.94 & 123.39 & Section-3 \\
\hline 1.9 & 80 & & & \\
\hline
\end{tabular}

\subsubsection{Orifice flow to the Exfiltration storage}

As discussed in the previous sections, a 300mm perforated pipe was embedded inside the granular trench to convey storm water from the control manhole to ES. The exfiltration rate of the perforated pipe was simulated via a single side orifice with the inlet offset of $0.053 \mathrm{~m}$ from the bottom of the upstream manhole. The other property of the orifice such as discharge coefficient was assumed to be 0.65. However, the discharge coefficient of orifices, similar to the minor loss coefficient in the energy equation and is a function of entrance constriction, and exit expansion is discussed in the sensitivity analysis in the following sections. The discharge through an orifice is calculated using the following equations. 
Equation 4. The discharge through an orifice (David, C., 2013)

$Q_{0}=C_{d} \cdot A_{0} \cdot(\sqrt{ } 2 g h)$

Where,

$\mathrm{Q}_{0}=$ discharge capacity of an orifice

$C_{d}=$ discharge coefficient

$A_{0}=$ cross-sectional area of the orifice

$h=$ head difference between the headwater and tailwater elevations

\subsubsection{Drainage Area Discretization}

The most significant parameters of the model simulation are the study area's width and flow length of the sub-catchment, which depend on the discretization level. Different studies and research have shown that the result of the simulation can vary significantly with the resolution of the model and finely discretized models provide a better match to the observed data, but may need longer computational runtime. Moreover, an adequately discretized model can match the observed flow conditions without any calibration of the model.

Therefore, the total drainage area was finely discretized into several sub-watersheds. A single house plot was discretized into the several finer subwatershed representing roof area, parking lot, backyard, front yard without driveways, and driveways as a separate subwatershed, as presented in Figure 27 Each subwatershed was defined either pervious or impervious, there is no any subwatershed which combines both pervious and impervious surface. 


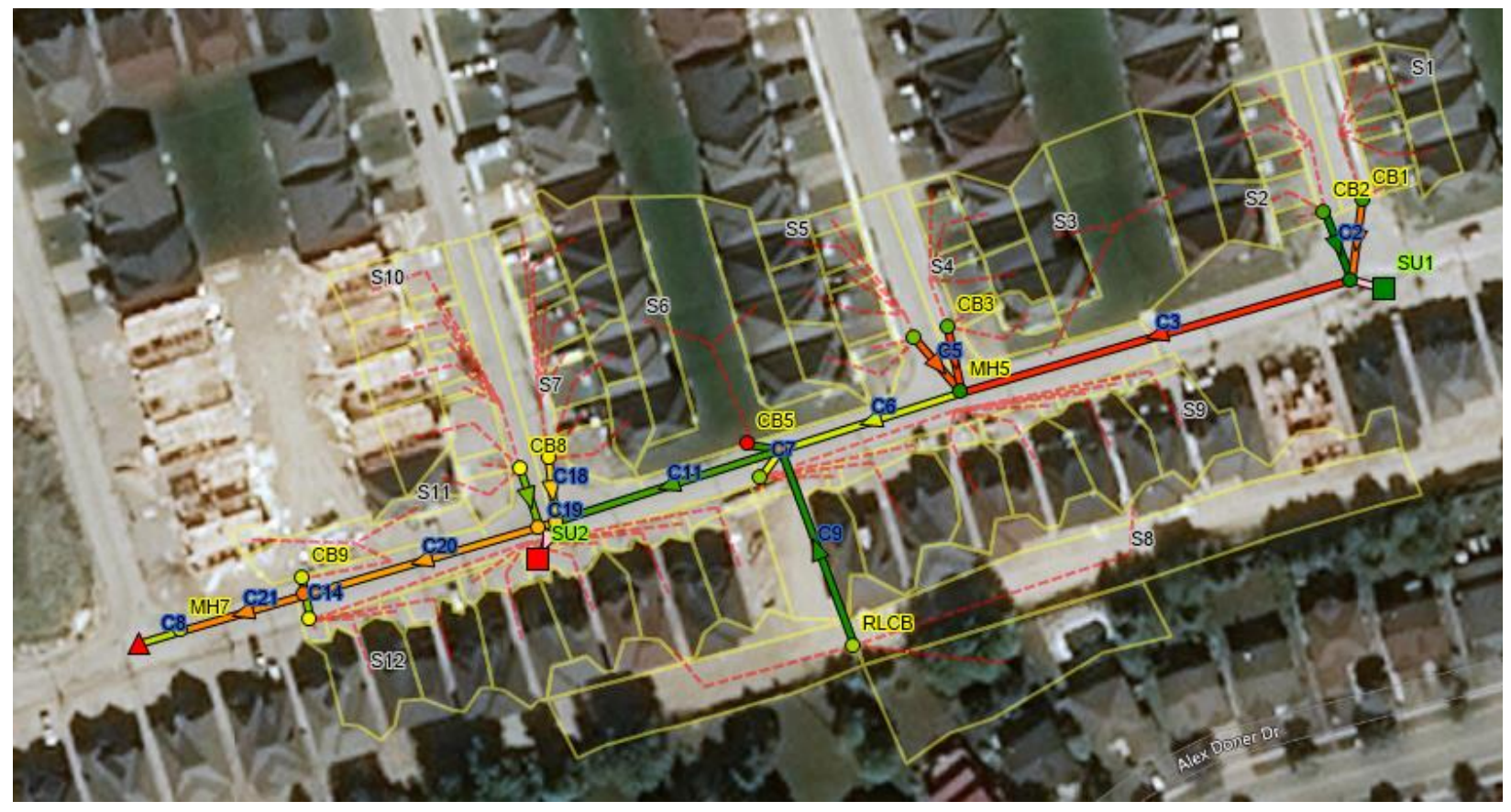

Figure 27: Subwatershed discretization

\subsubsection{Subwatershed parameters}

After discretizing the subwatersheds, the subwatershed model parameters were assigned as close as to the real-world characteristics of the study area. The percentage of imperviousness area for the roof area was considered as $85 \%$. The data of the percentage of the impervious area was derived based on the existing google map of study area. In this research, Depression storage of the permeable area was assumed based on the land use and the guideline given in the PCSWMM manual. The Manning's n was determined based on the existing google land cover map. For this particular study area, the impervious area is mainly of smooth asphalt road pavement and building roof area, so Manning's $n$ was assumed 0.011 as guided by the USEPA stormwater manual.

The soil type of the study area was silty clay to sandy clay loam (Schaeffer Consulting Engineer, 2014). As discussed in section 4.1.1 the seepage properties of the clay loam were taken from Table 
10.4 of the NVCA stormwater Technical Guide prepared by Glenn Switzer in 2013 for Green and Ampt Method parameters, as shown in Table 7. Based on that Table, the value of seepage properties of clay loam soil of subwatershed are as follows:

Hydraulic Conductivity: $2 \mathrm{~mm} / \mathrm{h}$

Suction Head: $208.8 \mathrm{~mm}$

Initial Deficit: 0.146

\subsubsection{Conveyance parameters}

The conduits and junctions were assigned based on the google map and Schaeffer's Consulting Engineers' report. The inlet elevation, diameter, slope, of storm sewer, and catchment basin leader were assigned based on the Schaeffer's Consulting Engineer's report. Also, junctions' depths for each manhole, catch basin and outfall after manhole 7 (MH7) were assigned based on the Schaeffer's Consulting Engineers report, as shown in Figure 28. According to the USEPA storm sewer manual, the roughness coefficient for the concrete storm sewer was assigned 0.013 .

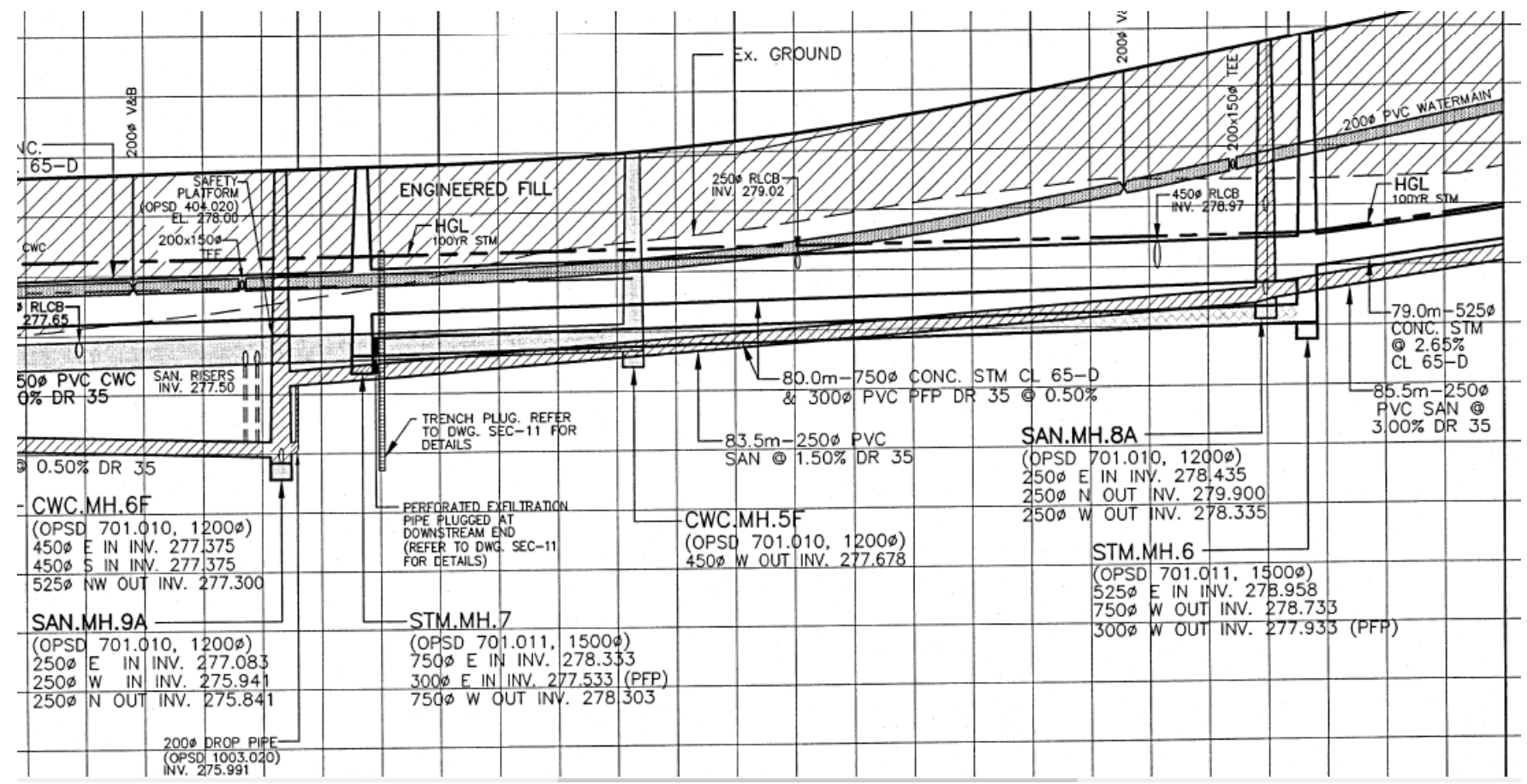

Figure 28: L-profile of Storm sewer along with exfiltration system from MH6 to MH7 


\subsection{Model Run}

The PCSWMM model was set up on McGregor Farm Trail storm sewer (MH4 to MH7) by entering all the required input parameters. The Green and Ampt method was chosen as the infiltration method in the model. Rainfall and flow routing were selected as the process of modeling for this study. The dynamic wave approach was chosen as the routing method, and ponding was allowed. For the hydrologic routing, the time step was chosen 5 minutes for both dry and wet periods. The routing time step for the dynamic wave method was fixed at 1 second to avoid instability problems and ensure minimum continuity errors. Finally, the model was run for simulation periods between $12^{\text {th }}$ July to $17^{\text {th }}$ December 2018 in the first stage.

\section{Sensitivity Analysis}

The sensitivity analysis was carried out in order to determine the sensitiveness of the model result with respect to the input parameters. In other words, degree of influence of uncertain input parameters over the model output was tested through sensitivity analysis. For this process, the PCSWMM built-in Sensitivity-based Radio Tuning Calibration (SRTC) tool of the PCSWMM software was used. Parameters such as percentage impervious, depression storage, hydraulic conductivity, subwatershed slope and width, initial deficit, storage conductivity, orifices discharge coefficients were taken into consideration for sensitivity analysis, which was carried out separately for inflow and outflow of MH6, which are the inlet and outlet of exfiltration system 2 (ES2) installed between MH6 to MH7.

\subsubsection{Sensitivity analysis at MH6 inflow (ES2-inflow)}

The sensitivity analysis result indicated that most sensitive parameters for peak inflow, as well as total runoff volume at node MH6, are subwatershed imperviousness followed by hydraulic 
conductivity, initial deficit, a width of subwatershed depression storage, etc. Figure 29 shows the graph of the ranking of the tested input parameters by their sensitivities.

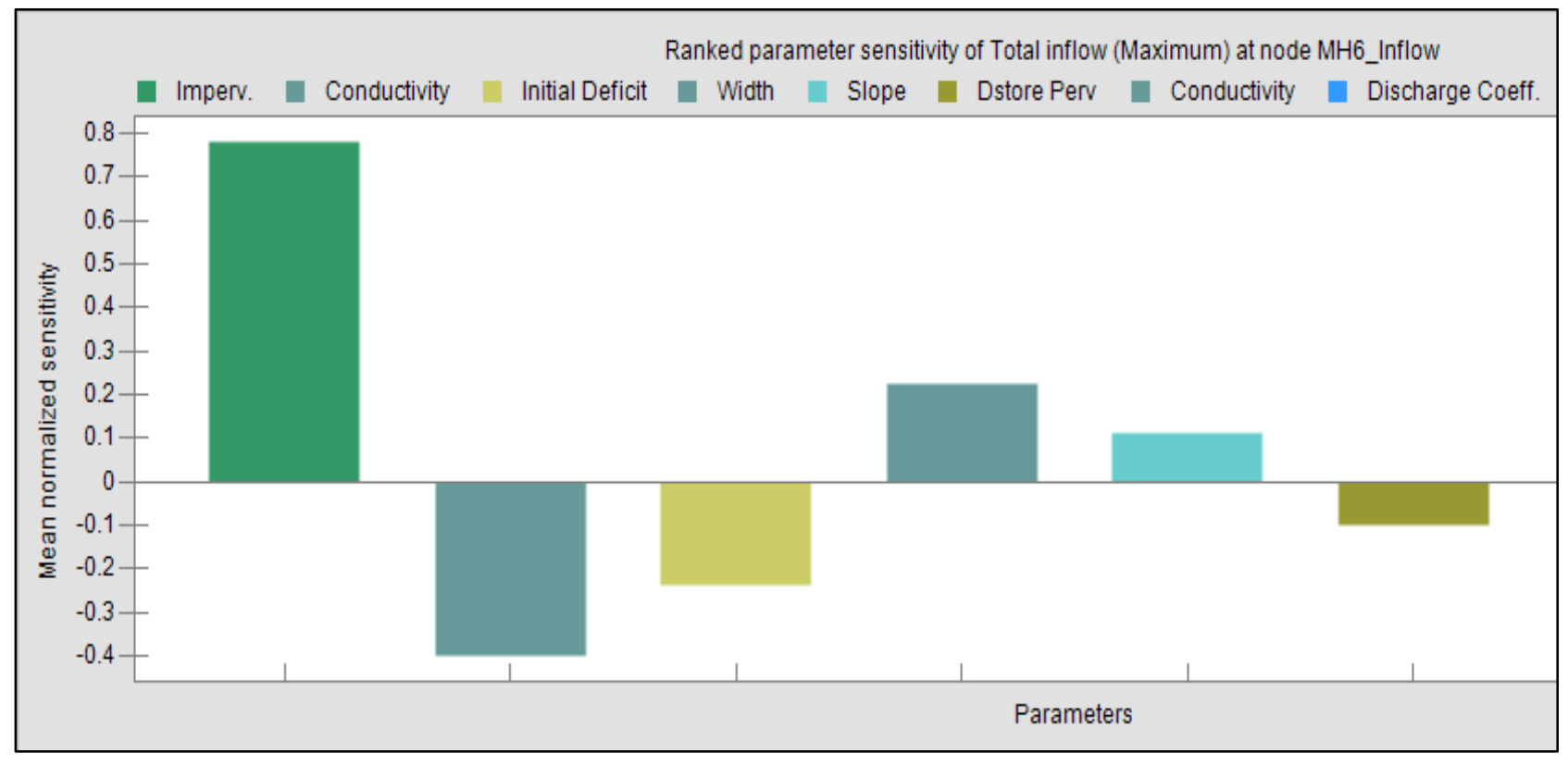

Figure 29: Ranking of the sensitive parameter for maximum total inflow at MH6 inflow

Similarly, Figure 30 shows a non-linear sensitivity analysis for inflow, a graph of change in the objective function (maximum total inflow) over the range of specified uncertainty. 


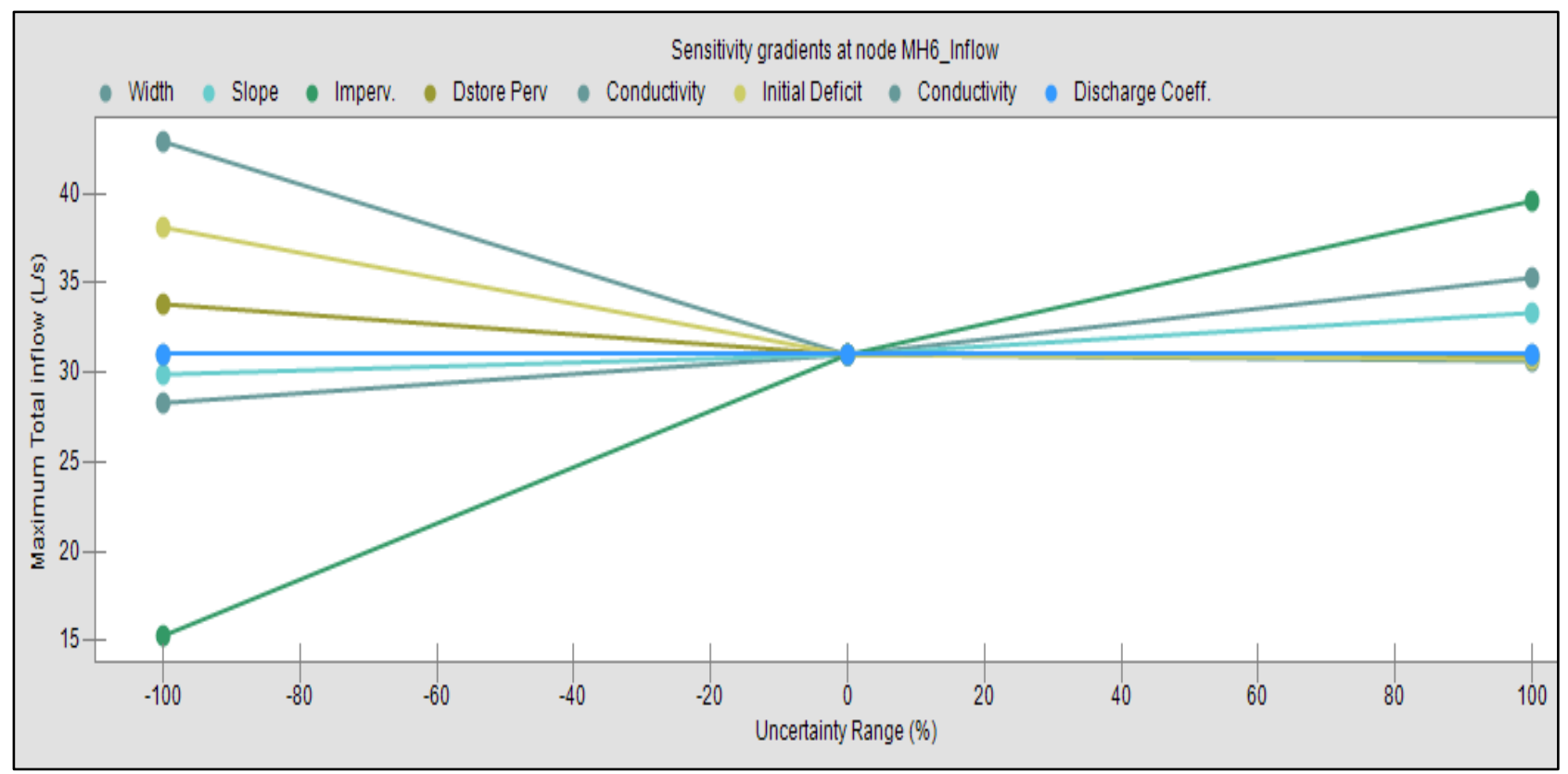

Figure 30: change in the objective function due to each parameter over the uncertainty range

The sensitivity test depicts that the model was significantly sensitive to the percentage imperviousness and hydraulic conductivity of subwatershed; all the other parameters seemed negligibly sensitive in comparison to the former two parameters.

\subsubsection{Sensitivity analysis at MH6 outflow (ES2-overflow)}

Similarly, sensitive parameters were identified for the ES-2 overflow from storage trench by carrying out sensitivity analysis at the outflow sewer pipe connecting MH6 and MH7. The most sensitive parameters for MH6 overflow in a rank are the imperviousness, hydraulic conductivity of storage unit, orifice discharge coefficient, etc., as shown in Figure 31. 


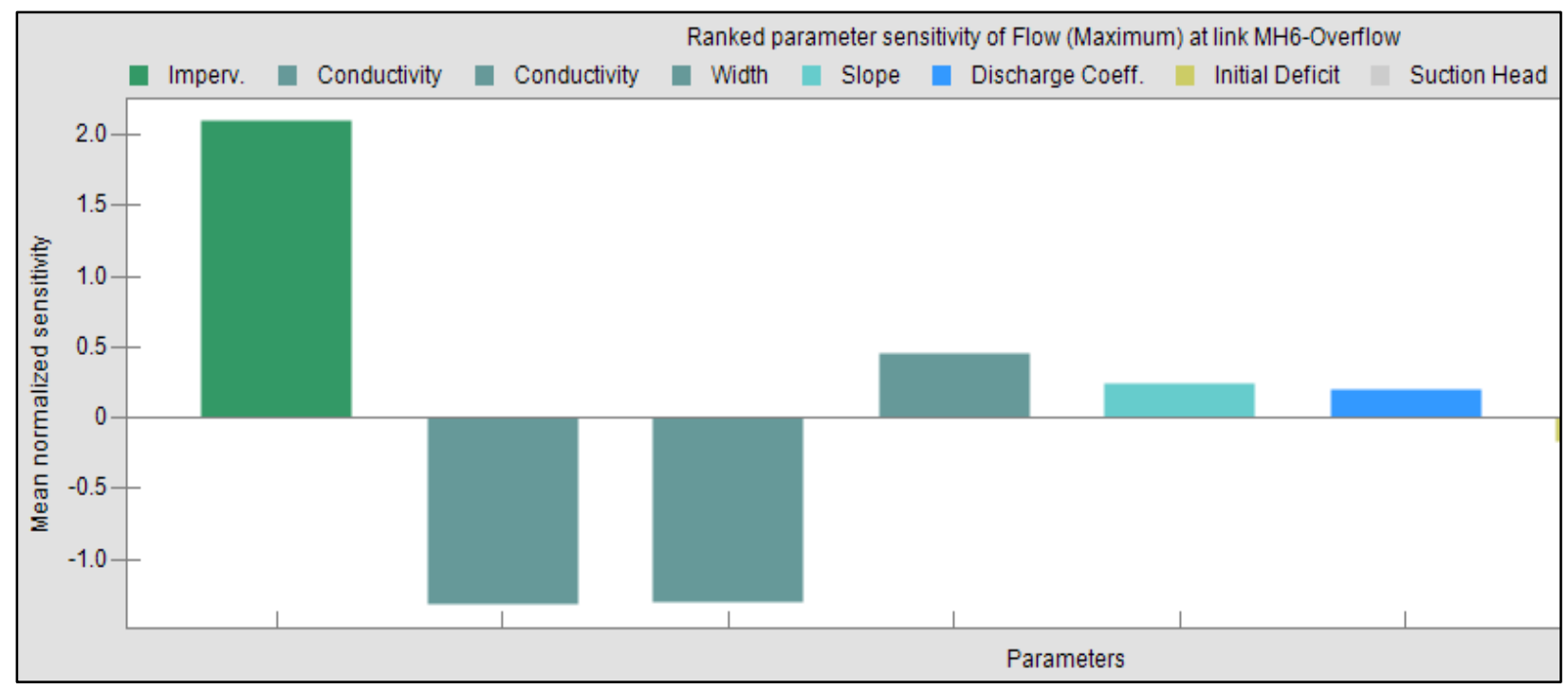

Figure 31: Ranking of the sensitive parameter for total flow at ES-2 overflow

\section{Calibration and Validation of Model}

The simulated model at the existing development state was calibrated and validated using eight selected rainfall events, as discussed in section 4.2.2. Out of 8 events, 5 events were used for calibration, and the rest of the events were used for validation. The calibration of the model was accomplished on a trial and error basis using different parameters indicated by sensitivity analysis. The percentage change of the individual parameter or set of parameters was tuned to fit the model inflow with the observed inflow as best as possible. Moreover, the calibrated model was tested by verifying the output of the calibrated model with the observed streamflow, and finally, a validated model at the existing development condition was developed for further analysis.

Percent imperviousness and hydraulic conductivity were identified as the two most sensitive watershed parameters for this model, as indicated by the built-in SRTC tool. The calibration performance was measured using the Nash Sutcliffe Efficiency (NSE) calculated by the built-in SRTC tool. The equation used to calculate the NSE is presented below. 


$$
N S E=1-\frac{\sum\left(y_{o b s}^{i}-y_{\text {model }}^{i}\right)^{2}}{\sum\left(y_{o b s}^{i}-\overline{y_{o b s}}\right)^{2}}
$$

Where,

$\overline{\mathrm{y}_{\mathrm{obs}}}=$ mean of the observed values.

NSE can be any value ranging between $-\infty$ to 1 . The value of 1 represents the perfect match of the modeled result to the observed data (Nash and Sutcliffe, 1970). The calibration process for each case is presented in the following sections.

\subsubsection{Calibration of the model at MH6 inflow (ES2-inflow)}

Since the percentage impervious is not uncertain parameters for this study area, only the most uncertain input parameter that has significant sensitivity effect, is the hydraulic conductivity. Therefore, the model was calibrated for hydraulic conductivity and imperviousness; a 100\% increase of hydraulic conductivity and a $15 \%$ decrease of imperviousness showed the best match of the model with the observed data. Thus, the model with a $100 \%$ increase in hydraulic conductivity and a 15\% decrease in imperviousness was finalized as a calibrated model as shown in Figure 32.

The reason behind the increase of hydraulic conductivity and decrease of perviousness may be due to presence of six small offline rain gardens within the drainage area. 


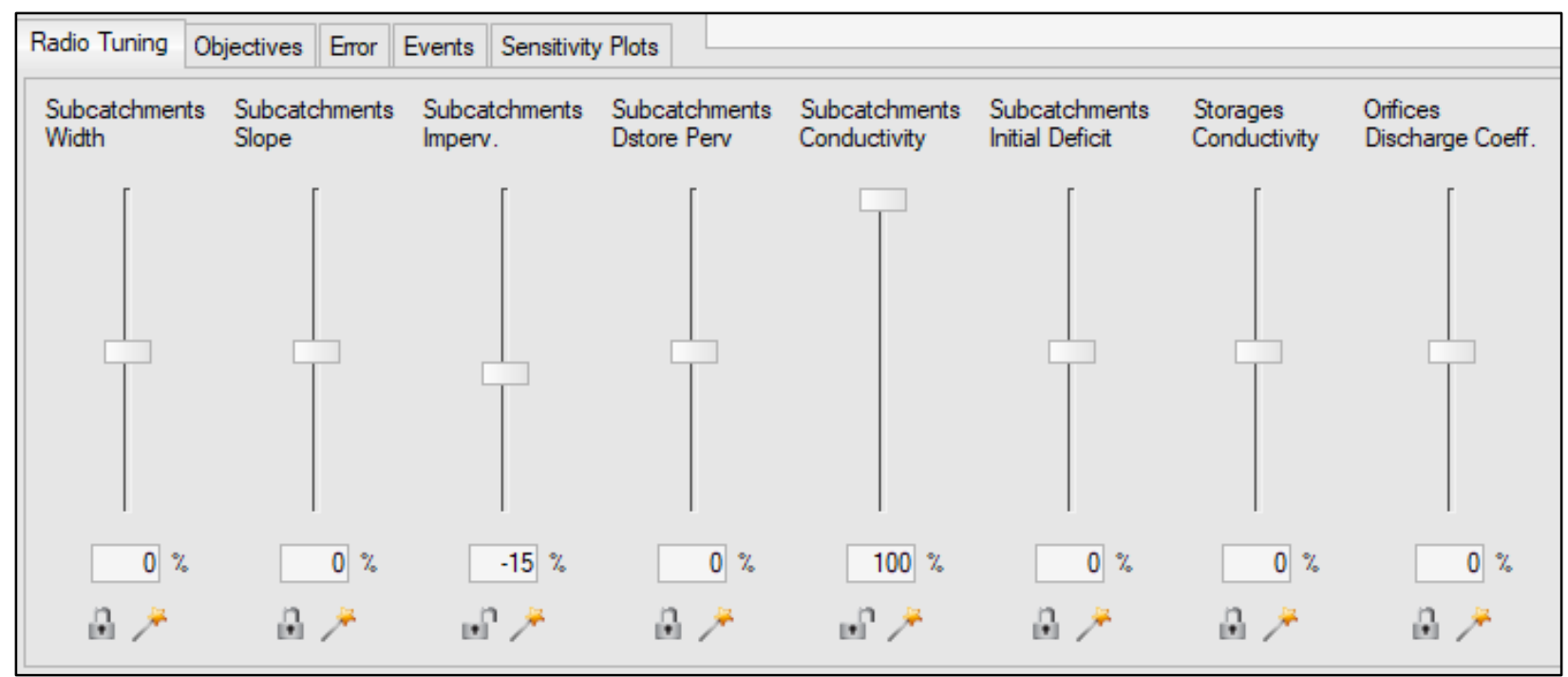

Figure 32: Calibration of model at MH6 inflow

\subsubsection{Calibration for Total Inflow Volume}

Thus, the efficiency of an event-based model for MH6 inflow (inflow to the ES2) was analyzed.

The model calibration efficiency based on total inflow for event 1 to event 5 and validation for event 6 to 8 are presented in Figure 33. The average Nash Sutcliffe efficiency (NSE) of the calibrated model for selected eight events was found 84.3\%, as depicted in Figure 25.

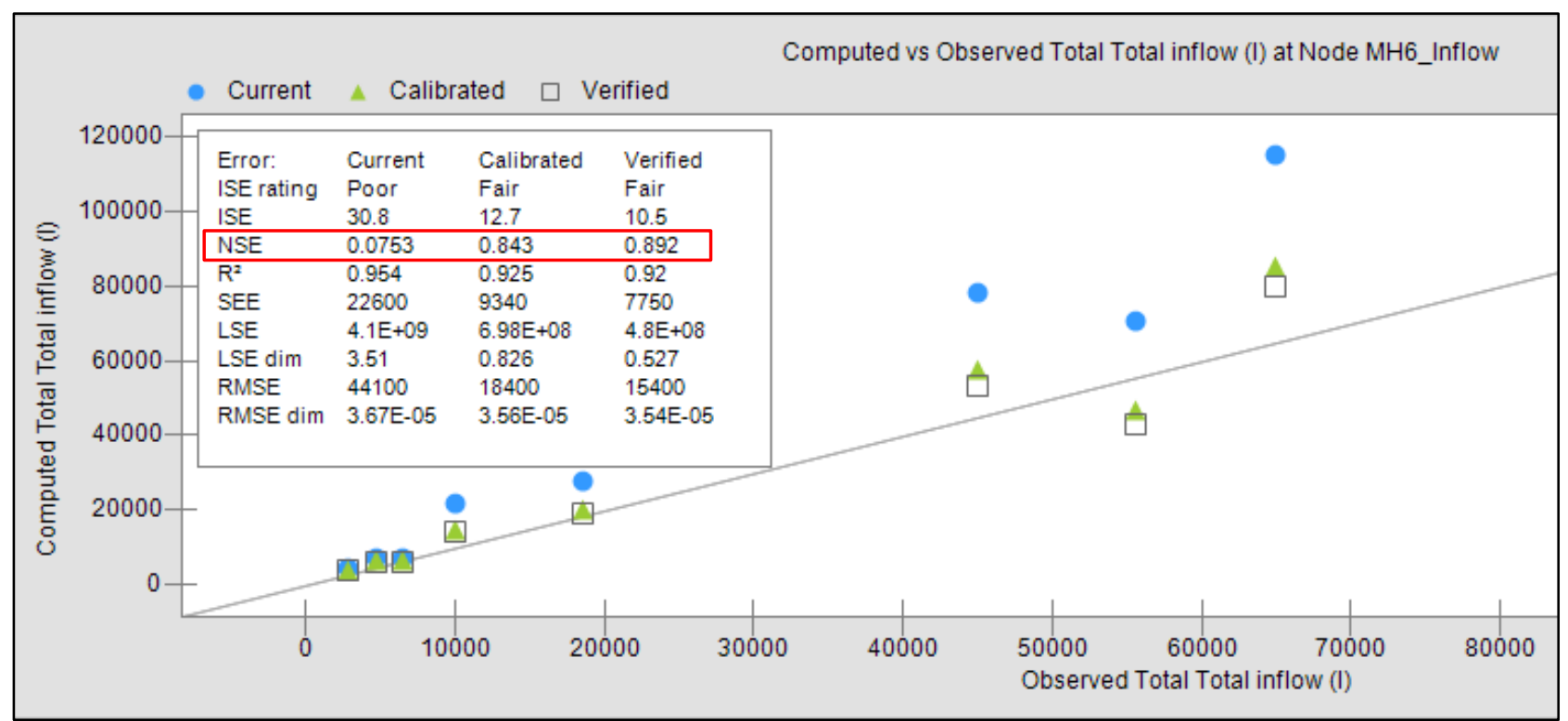

Figure 33: Calibration and validation of all events at ES2 inflow 
Similarly, each event was calibrated with respect total inflow volume to achieve maximum NSE as far as possible. The NSE of total inflow volume calibration of event 1 was obtained $81.1 \%$, and interestingly some trade-off between peak flow and flow volume seemed as depicted in Figure 34. Therefore, calibration was accomplished by considering possible higher NSE for both peak flow and total inflow volume.

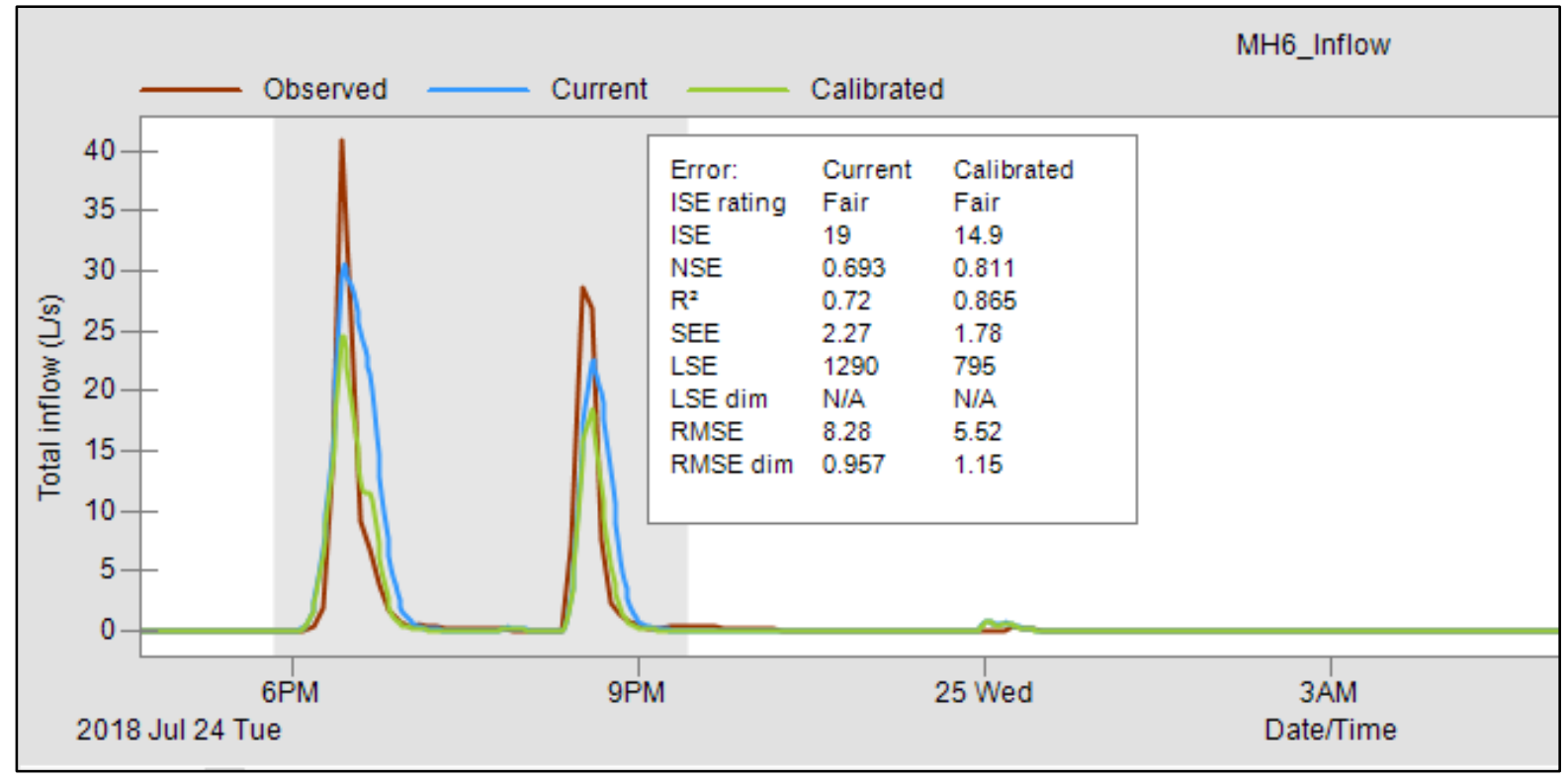

Figure 34: Calibration of event 1 at ES2 inflow

All eight events were calibrated, and the last three events were validated as expressed in Table 9. The graphical representative Figure of calibration and validation of each events are presented in annex. 
Table 9: Calibration and Validation of events for total inflow volume

\begin{tabular}{|c|c|c|c|c|c|c|}
\hline \multirow[b]{2}{*}{ Event } & \multirow[b]{2}{*}{ Date } & \multirow[b]{2}{*}{$\begin{array}{l}\text { Duration } \\
\text { (h) }\end{array}$} & Observed & Computed & Calibration & Validation \\
\hline & & & $\begin{array}{l}\text { Total flow } \\
\text { volume (L }\end{array}$ & $\begin{array}{l}\text { Total flow } \\
\text { volume (L) }\end{array}$ & NSE & NSE \\
\hline 1 & Jul 24,2018 & 3.58 & 55,600 & 51,690 & $81 \%$ & \\
\hline 2 & Jul 26,2018 & 2.83 & 6,447 & 6,335 & $81 \%$ & \\
\hline 3 & Jul 29,2018 & 1.17 & 2,832 & 3,826 & $79 \%$ & \\
\hline 4 & Aug 07,2008 & 1.17 & 4,676 & 6,363 & $71 \%$ & \\
\hline 5 & Aug 08,2018 & 2.17 & 18,590 & 19,410 & $93 \%$ & \\
\hline 6 & Aug 17,2018 & 11.42 & 44,950 & 59,390 & $90 \%$ & $91.1 \%$ \\
\hline 7 & Aug 21,2018 & 22.33 & 64,900 & 86,150 & $73 \%$ & $75.5 \%$ \\
\hline 8 & Oct 08,2018 & 2 & 10,020 & 14,200 & $69 \%$ & $70.5 \%$ \\
\hline
\end{tabular}

\subsubsection{Callibration for Peak Inflow Rate}

Similar to total inflow volume, the peak inflow rate of each event was also calibrated and the average NSE value of all events was found 83.7\%, as depicted in Figure 35.

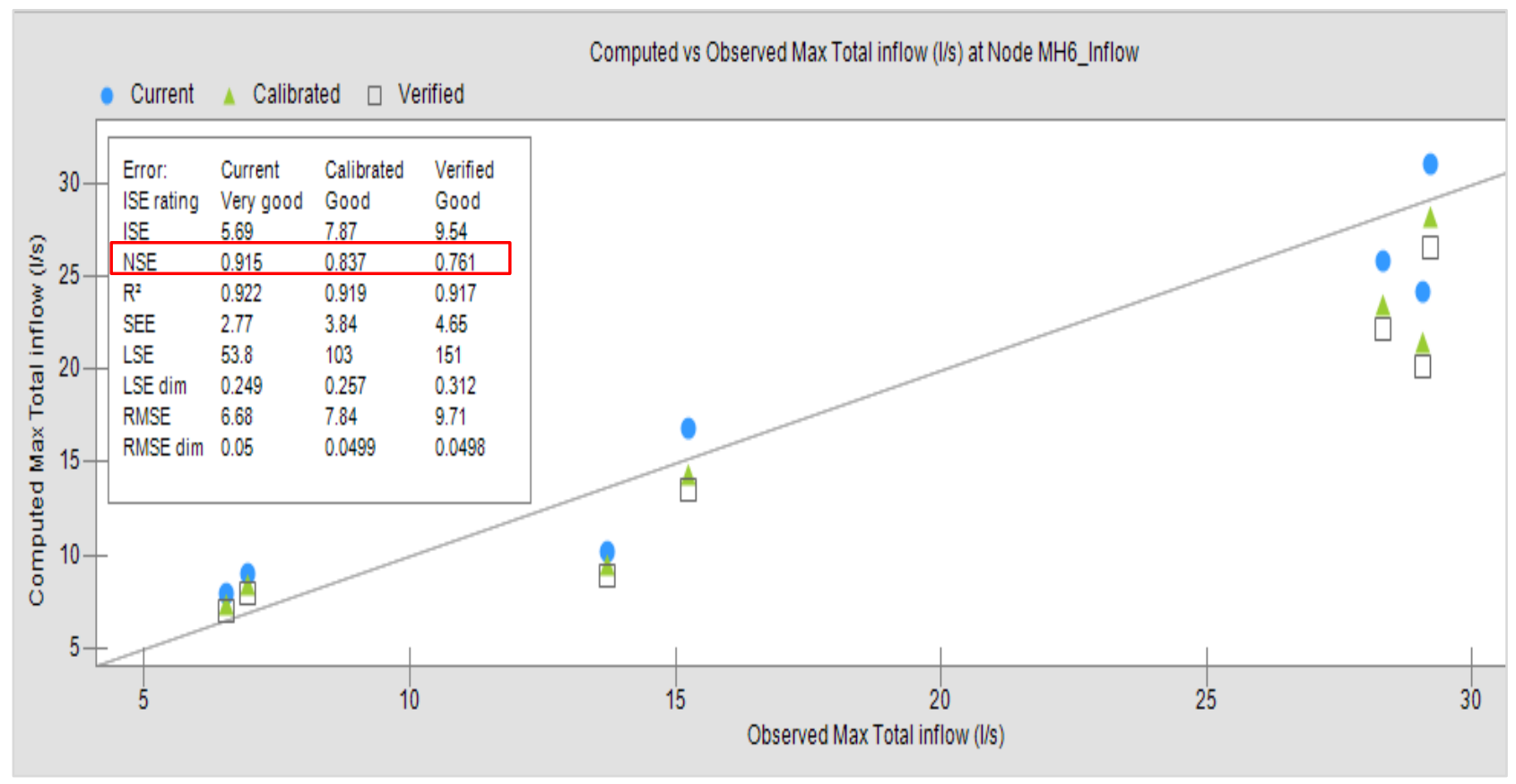

Figure 35: Calibration and validation of all events for peak inflow at ES2 inflow 
The graphical plot of observed and computed inflow rate is presented in Figure 36.

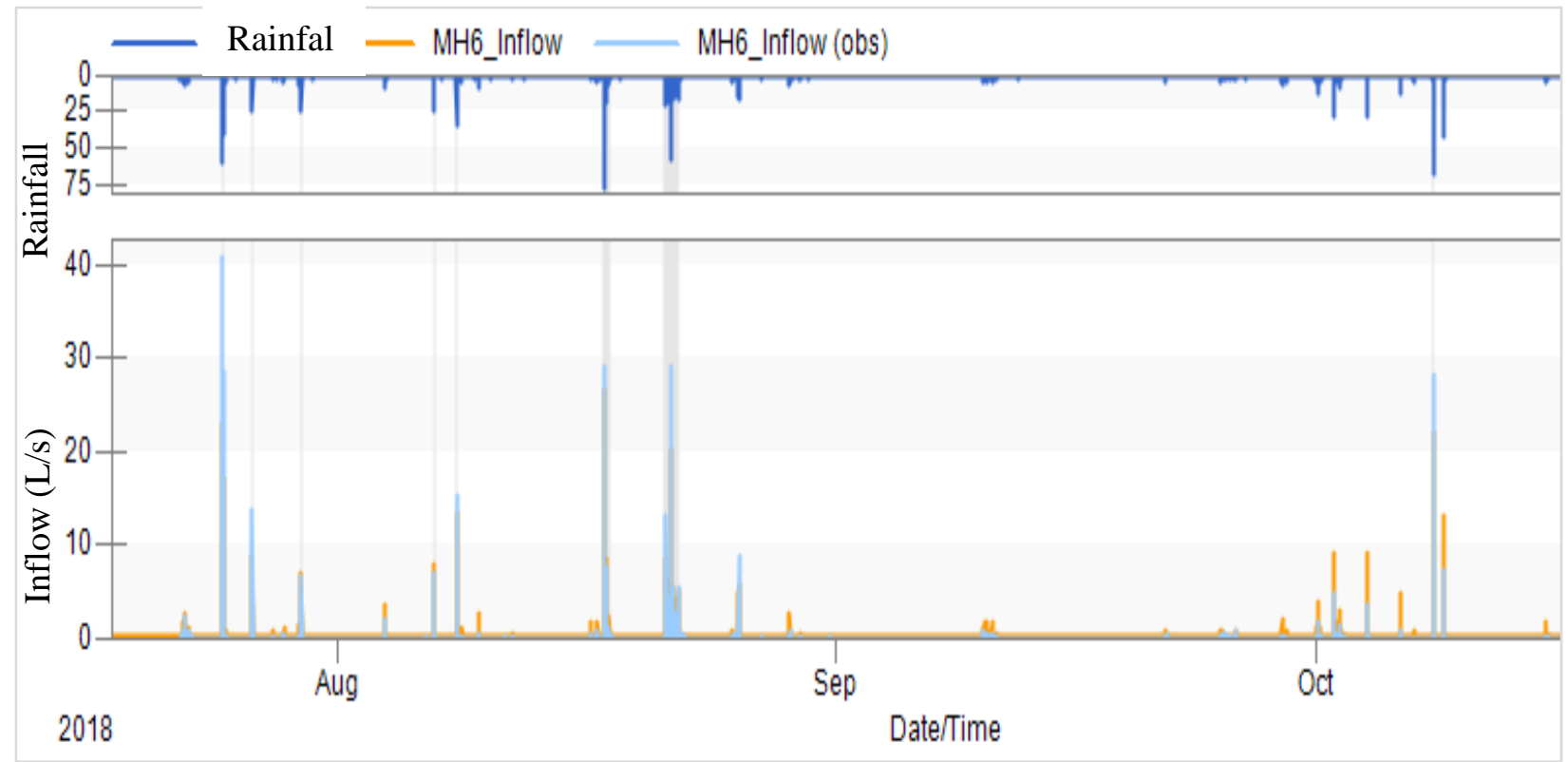

Figure 36: Comparison of simulated and observed flow at MH6 inflow

\subsubsection{Calibration of Model at MH6 outflow (ES2-Overflow)}

Some monitored exfiltration system overflow events were used to calibrate the exfiltration system storage unit. At MH6-inflow the model was already calibrated, so only parameters that could be calibrated for MH6-outflow is the hydraulic conductivity of storage unit and discharge coefficient of the orifice. The discharge coefficient of the orifice is less sensitive in comparison to the conductivity of the storage unit. So, the model was calibrated by decreasing conductivity of the storage unit by $60 \%$ to fit the model with the observed outflow of ES2 as shown in Figure 37. 


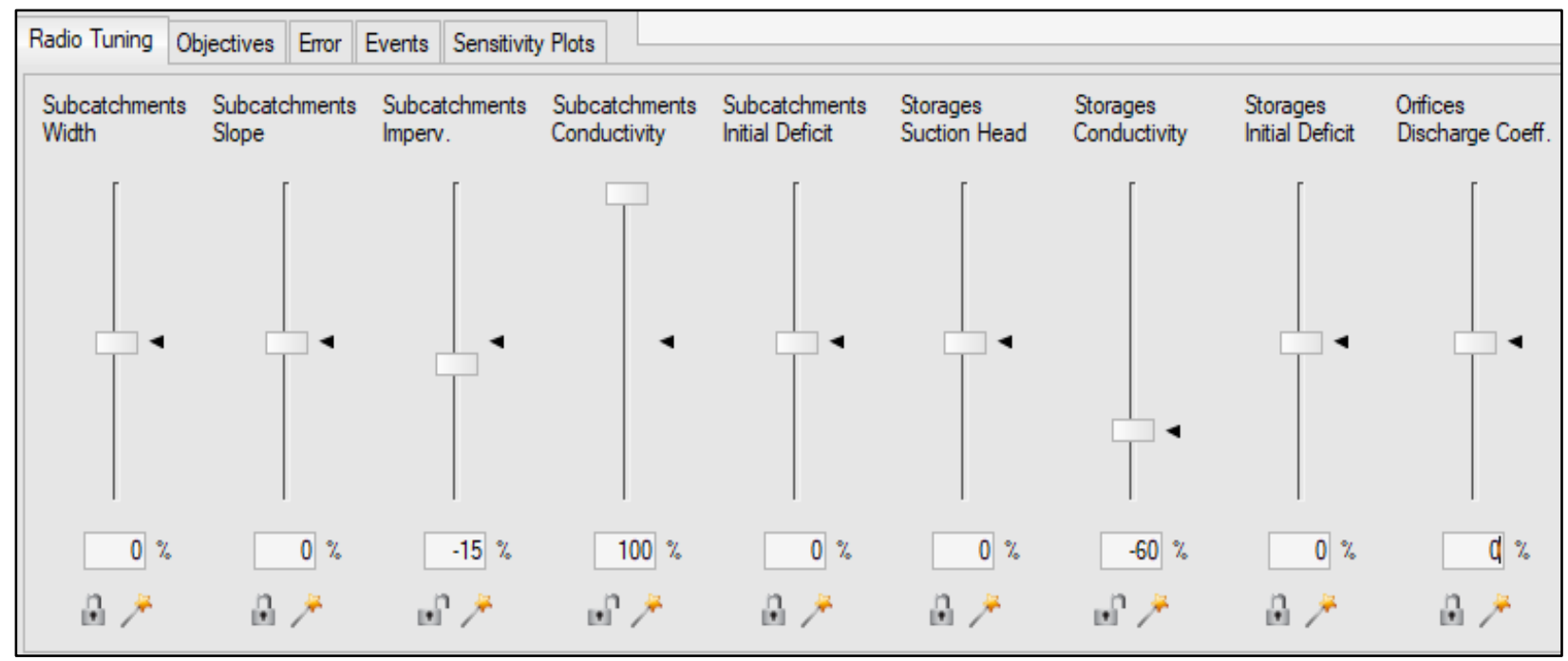

Figure 37: Calibration of the model for total outflow at MH6 outlet

Out of the three-overflowing event, one of the overflow events shows the NSE value of $79.8 \%$ for calibration of observed versus simulated overflow rate, as shown in Figure 38.

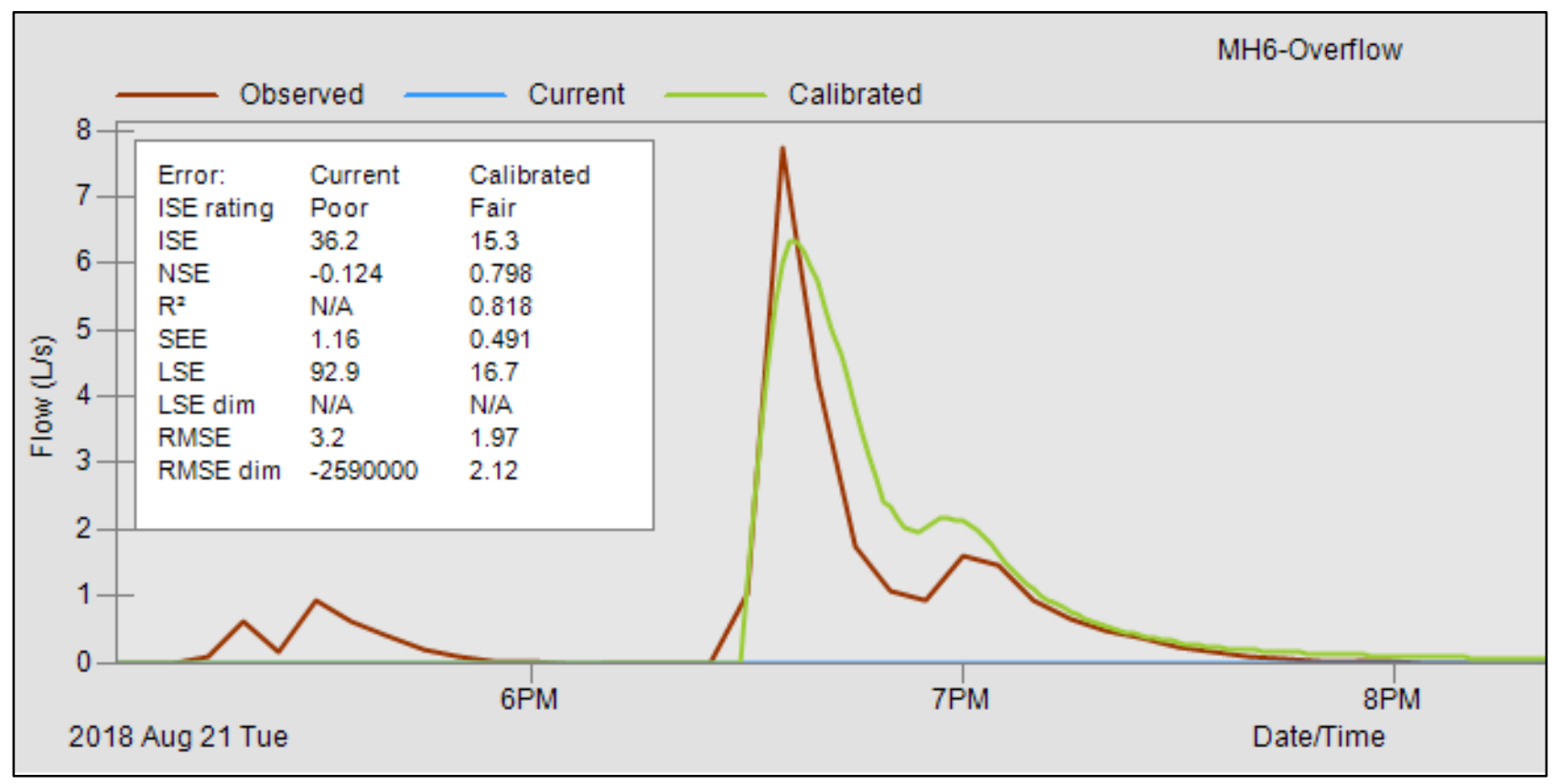

Figure 38: Calibration of the model for an overflowing event at MH6 outlet 


\section{Model Result and Discussion}

The calibrated and validated model was again run for the simulations period $1^{\text {st }}$ Jan to $31^{\text {st }}$ Dec 2018 (365days) to analyze the annual water balance of ES. As mentioned in section 4.2.4, based on the six months monitored time-series data, the hydrologic performance of ES indicated the $84 \%$ reduction of runoff volume and significant reduction in peak flow by exfiltrating stormwater into the underlying native soil. Similar to observed ES performance, the model result also depicts a similar ES performance, which is discussed a little bit more in the preceding sections.

\subsection{Water Balance}

After the successful run of the calibrated model for a full annual hydrologic cycle, a water balance analysis was carried out. Water balance results are shown in Figure 39, where the left chart indicates how the overall rainfall amount $(814.4 \mathrm{~mm})$ is partitioned into surface runoff, water lost through surface infiltration and water lost by evapotranspiration (ET). Using the conventional drainage system, all of surface runoff $(1546 \mathrm{~m} 3)$ remained after hydrologic losses flows through the stormwater sewer and ultimately discharges to the receiver. On the other hand, the right chart indicates the addition of ES in a conventional drainage system, resulting $81 \%$ reduction in runoff volume by allowing stormwater to exfiltrate into the underlying native soil, thus mimicking the pre-development infiltration level even after the post-development condition. 


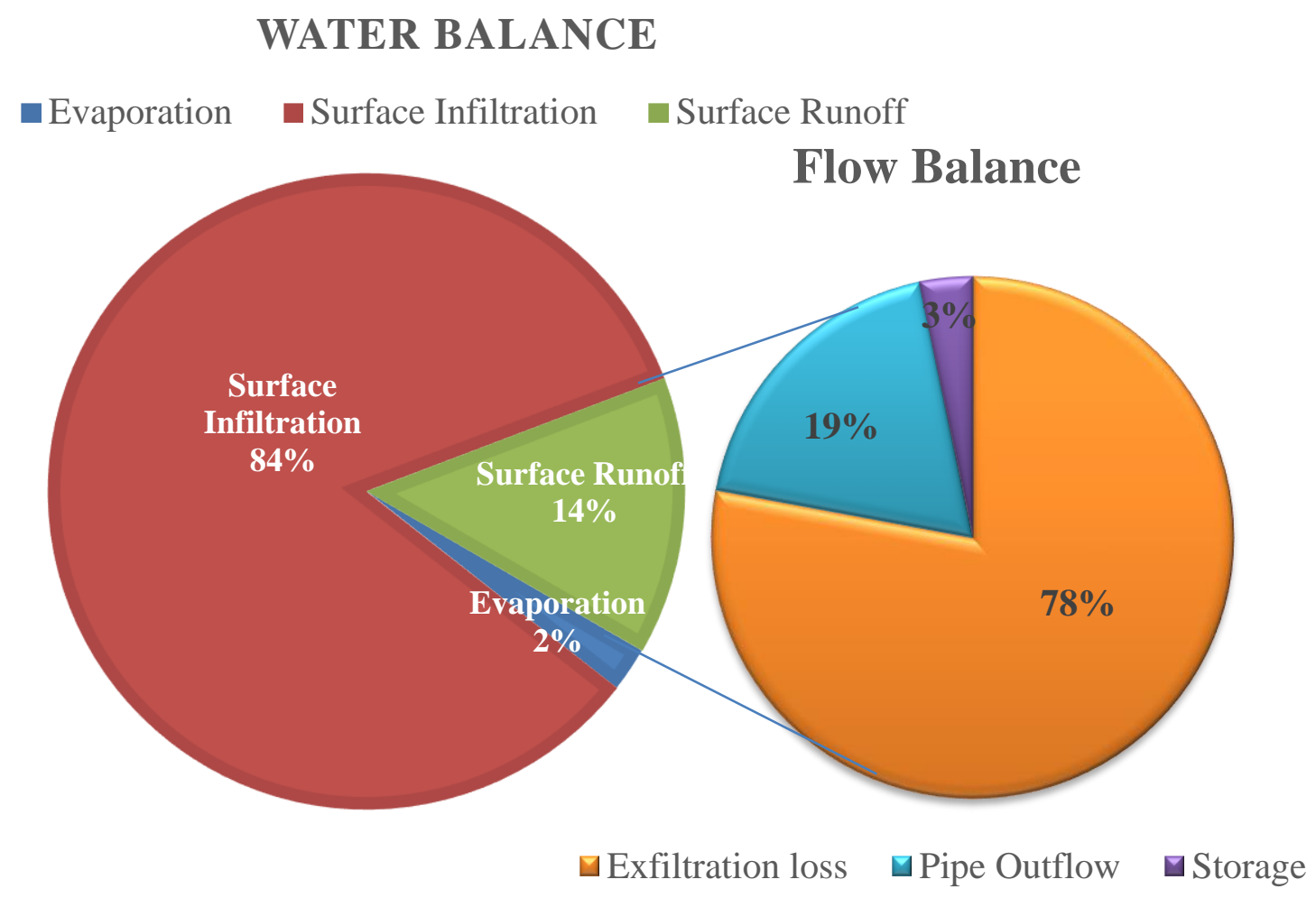

Figure 39: Water balance analysis of ES for the annual hydrologic cycle

\section{Future Retrofit to avoid ES2 overflow}

As a model result and monitored flow data already showed that overflow occurs at a large storm event higher than $24 \mathrm{~mm}$ rainfall amount. In order to avoid the overflow and ensure long term smooth performance of ES2, some extent of peak runoff should be reduced as a future retrofit.

\subsubsection{Diversion of Some amount of flow to the MH4}

Outflow from the MH4 (ES1-outlet) demonstrates that the ES1 is underutilized and surface topography is also favorable to divert some portion of MH6 contributing drainage area, (subcatchment -2, the drainage area of MH5, as shown in Figure 40) could easily divert towards MH4 to reduce the inflow load to MH6. 


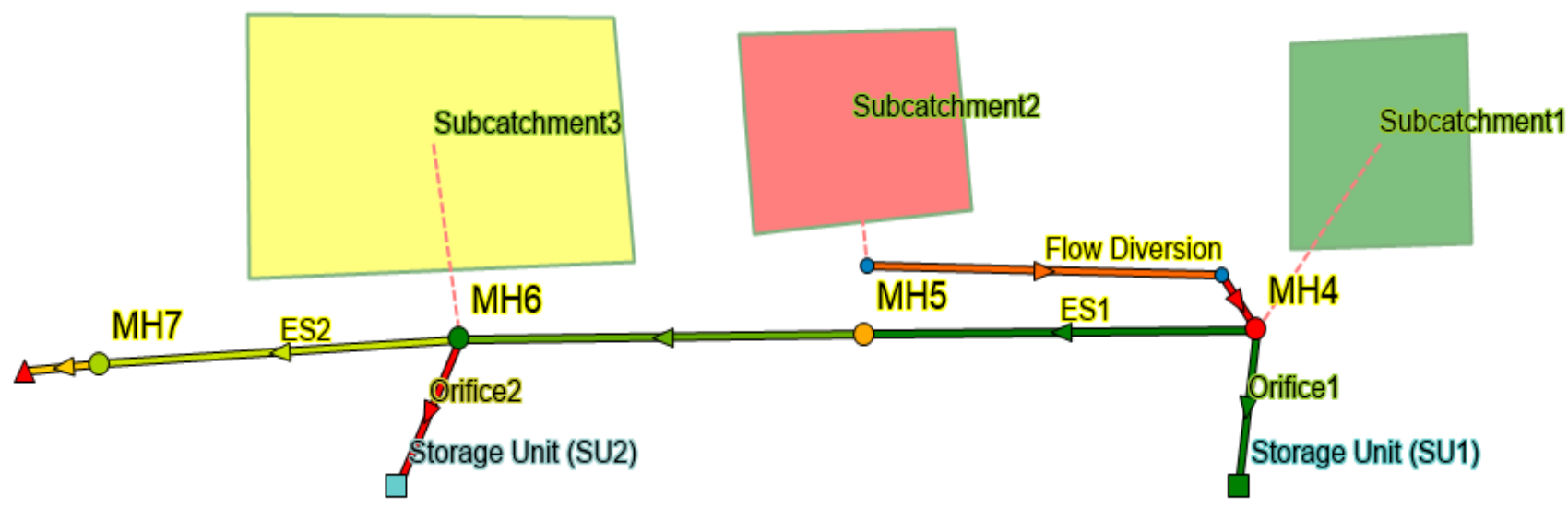

Figure 40: Some portion of MH6 drainage area diverting towards $\mathrm{MH4}$

Even after diversion of the MH5 contributing drainage area inflow to MH4, no overflow seemed from ES1, and most importantly, no overflow was seen from ES2. Thus, the exfiltration storage never filled up even at the large events which are illustrated by Figures 41 and 42.

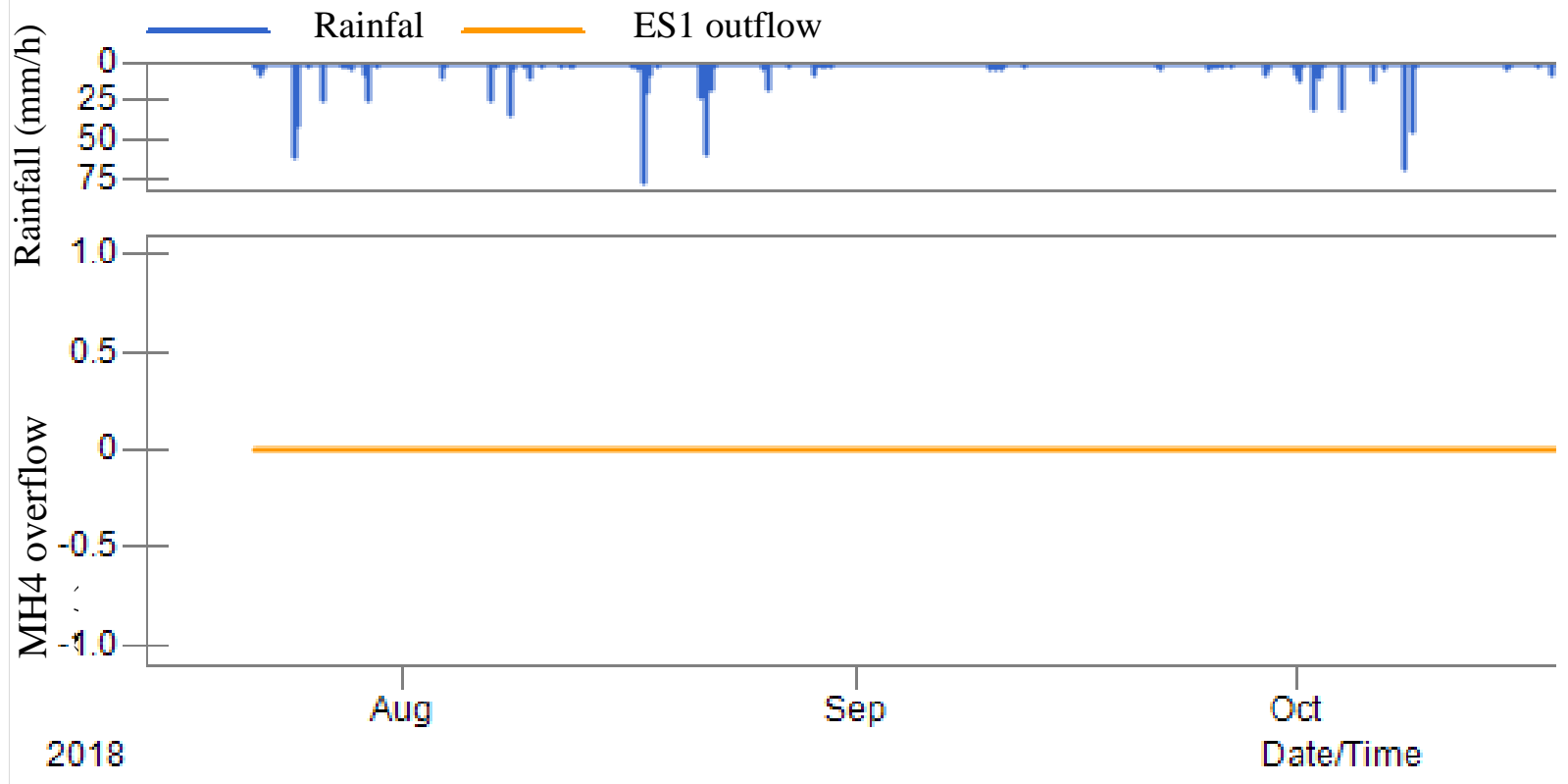

Figure 41: Overflow from MH4 outlet sewer pipe after flow diversion 
After diversion of MH5 drainage area flow to MH4 instead of MH6, no overflow was seen at MH6 outlet (ES2 outflow), which is depicted in Figure 42.

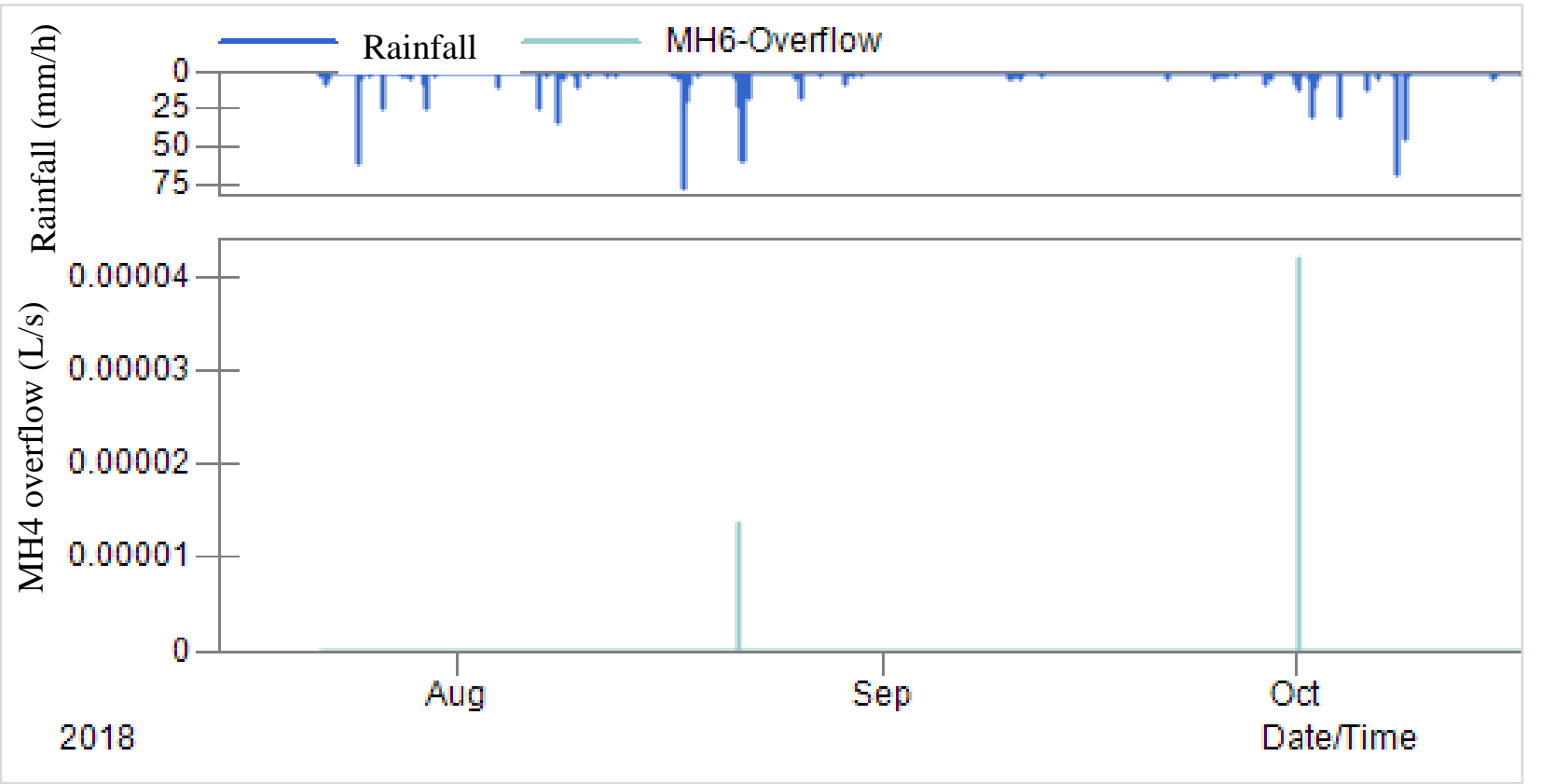

Figure 42: Overflow from MH6 outlet sewer pipe after flow diversion

Similarly, the model result after diversion of MH5 contributing drainage area to MH4 is illustrated in Table 10.

Table 10: Inflow and overflow to MH4 after flow diversion

\begin{tabular}{|c|c|c|c|c|c|c|}
\hline \multirow{2}{*}{ Event } & \multirow{2}{*}{ Date } & \multirow{2}{*}{$\begin{array}{c}\text { Duration } \\
\text { (hr) }\end{array}$} & \multicolumn{2}{|c|}{ MH4 ES1 Inflow } & \multicolumn{2}{c|}{ MH4 ES1 Overflow } \\
\cline { 4 - 7 } & & & $\begin{array}{c}\text { Peak Flow } \\
\text { Rate (L/S) }\end{array}$ & $\begin{array}{c}\text { Total flow } \\
\text { volume(L) }\end{array}$ & $\begin{array}{c}\text { Peak Flow } \\
\text { Rate (L/S) }\end{array}$ & $\begin{array}{c}\text { Total flow } \\
\text { volume(I) }\end{array}$ \\
\hline 1 & Jul 24,2018 & 3.58 & 13.71 & 25,240 & 0 & 0 \\
\hline 2 & Jul 26,2018 & 2.83 & 4.628 & 4,170 & 0 & 0 \\
\hline 3 & Jul 29,2018 & 1.17 & 2.711 & 2,548 & 0 & 0 \\
\hline 4 & $\begin{array}{c}\text { Aug } \\
\text { 07,2018 }\end{array}$ & 1.17 & 3.921 & 4,197 & 0 & 0 \\
\hline & $\begin{array}{c}\text { Aug } \\
08,2018\end{array}$ & 2.17 & 8.465 & 12,750 & 0 & 0 \\
\hline 5 & $\begin{array}{c}\text { Aug } \\
17,2018\end{array}$ & 11.42 & 14.7 & 33,910 & 0 & 0 \\
\hline 6 & $\begin{array}{c}\text { Aug } \\
21,2018\end{array}$ & 22.33 & 10.67 & 52,320 & 0 & 0 \\
\hline 7 & Oct 08,2018 & 2 & 11.59 & 9,304 & 0 & 0 \\
\hline
\end{tabular}




\subsubsection{Upgradation of existing rain gardens}

There are already six offline rain gardens like structures within the study area as shown in Figures 43, if some roof drainage is allowed to enter into the rain gardens and under-drained or surface overflowed to the nearby catch basins, the runoff would be significantly reduced, thereby no any diversion arrangement would be necessary to eliminate ES2 overflow.

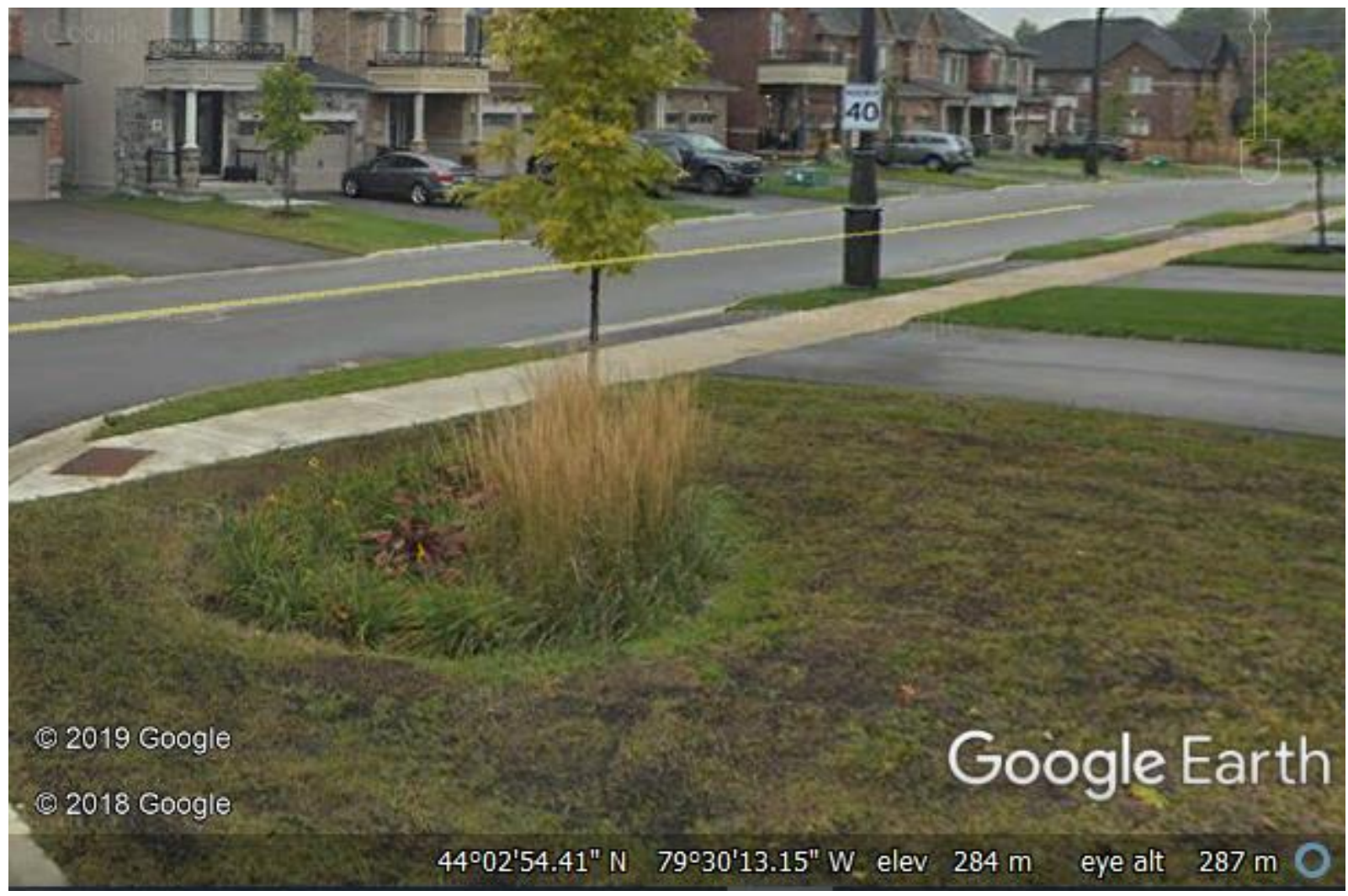

Figure 43: Offline Rain gardens like structures in Mosaik Homes Glenway subdivisions 


\section{Conclusion and Recommendation}

The Exfiltration System, one of the innovative LID techniques, is a relatively simple and practical addition to the conventional storm sewer design and construction that could address contemporary stormwater management goals in urbanized area (post-development infiltration volume to predevelopment levels). Both continuous and event-based modeling results and monitoring data analysis indicate that the significant impact on the water balance, reducing the surface runoff by $84 \%$ over the long term. In addition to runoff volume control, the substantial reduction in peak flow was also observed and consequently helps to reduce nutrient and suspended sediment load to the downstream receiving water bodies.

The range of average infiltration rate values observed over the monitoring four different drainage cycle $(0.76$ to $1.05 \mathrm{~mm} / \mathrm{h})$ indicates that the system drained at a much slower rate than what was assumed to be the capacity of the underlying soil when designing the system $(7.7 \mathrm{~mm} / \mathrm{h})$. As a result, it caused the system to require much more extended periods to achieve complete drainage (drawdown) than the estimated 78 hours.

Rainfall Events larger than $24 \mathrm{~mm}$ caused the storage capacity of the trench storage to be exceeded and overflow occurred from the exfiltration system (ES2). Model results depict that, ES2 overflow could be easily avoided by diverting flow accumulated at manhole 5 (MH5) to manhole 4 (MH4). Alternatively, overflow via ES2 could also be eliminated by retrofitting existing offline rain gardens like structures without flow diversion to MH5. Only eight events were used for modeling ES, and if more monitored events and longer continuous measured time series data were found, the model could be more reliable for future use. 


\section{Appendices}

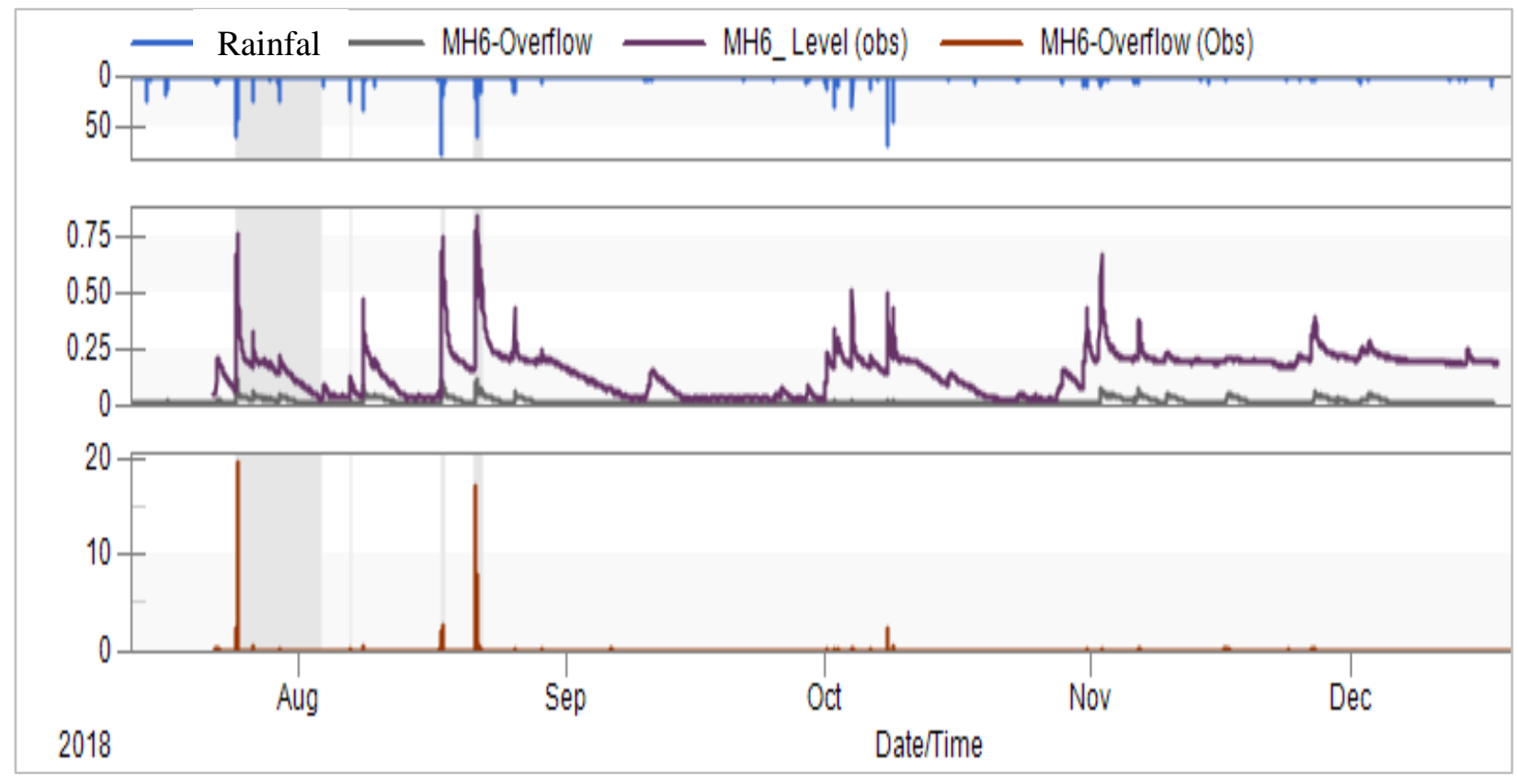

Figure A1: Comparison of observed and modeled overflow at MH6 with level and rainfall

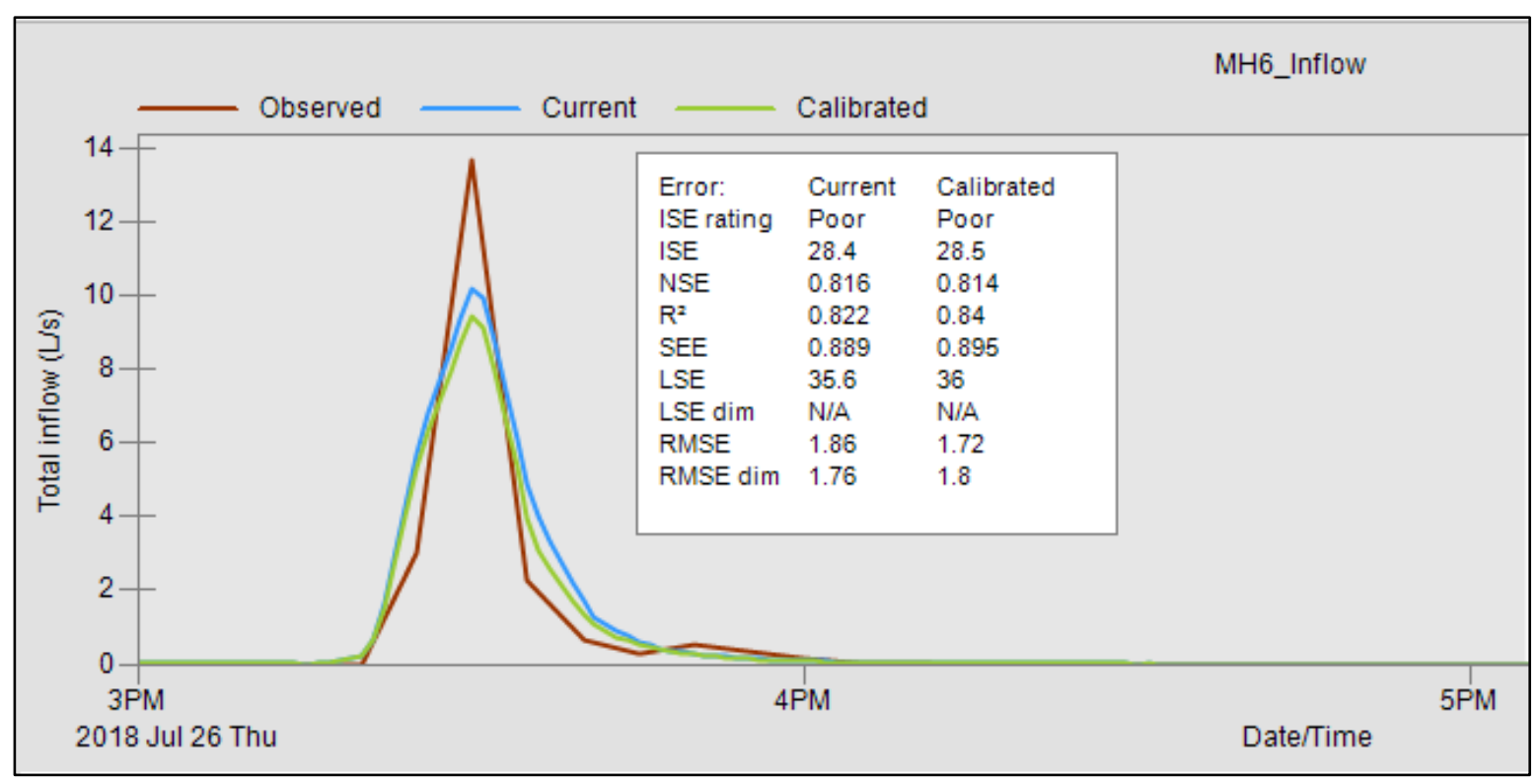

Figure A2: Calibration of event 2 at ES2 inflow 


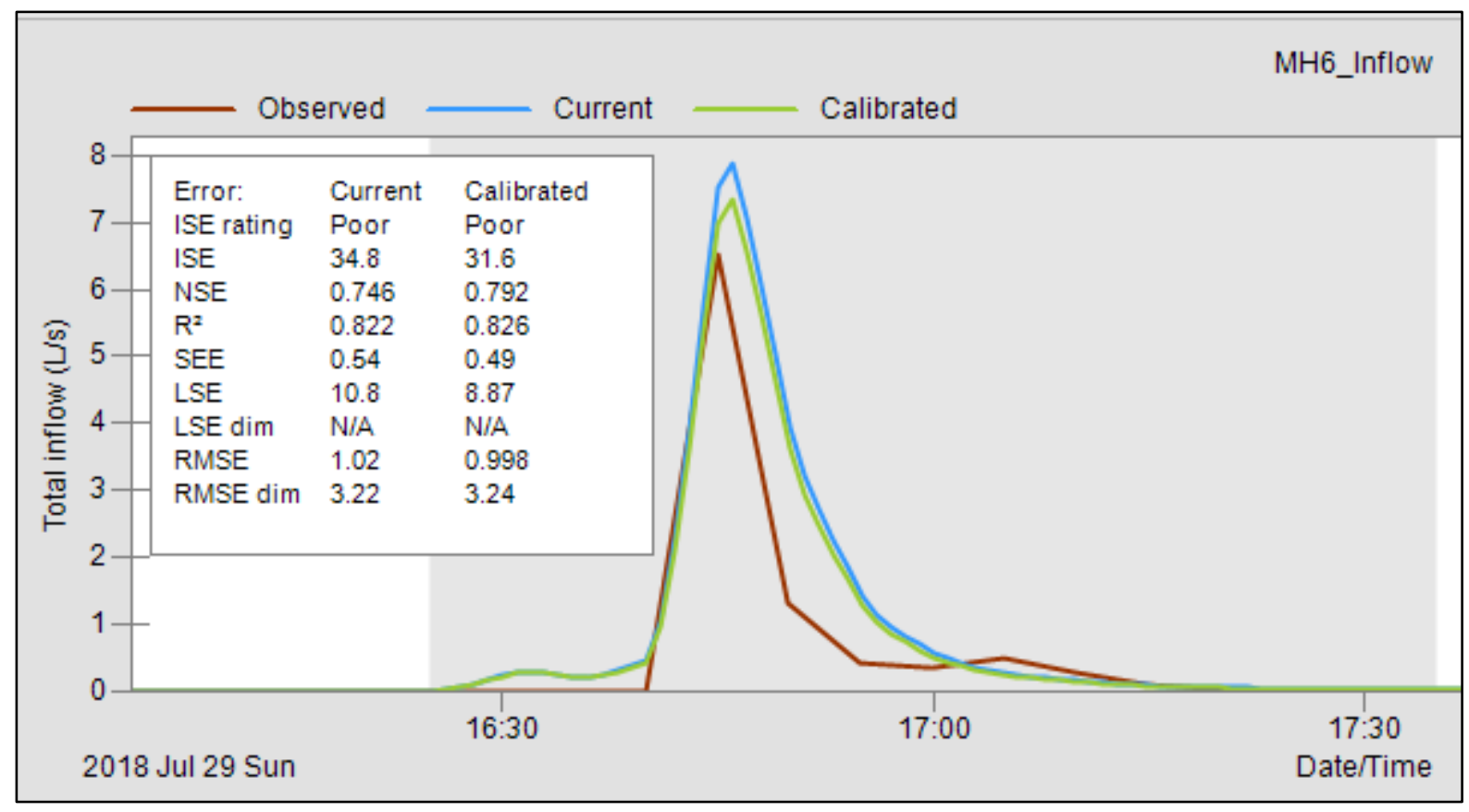

Figure A3: Calibration of event 3 at ES2 inflow

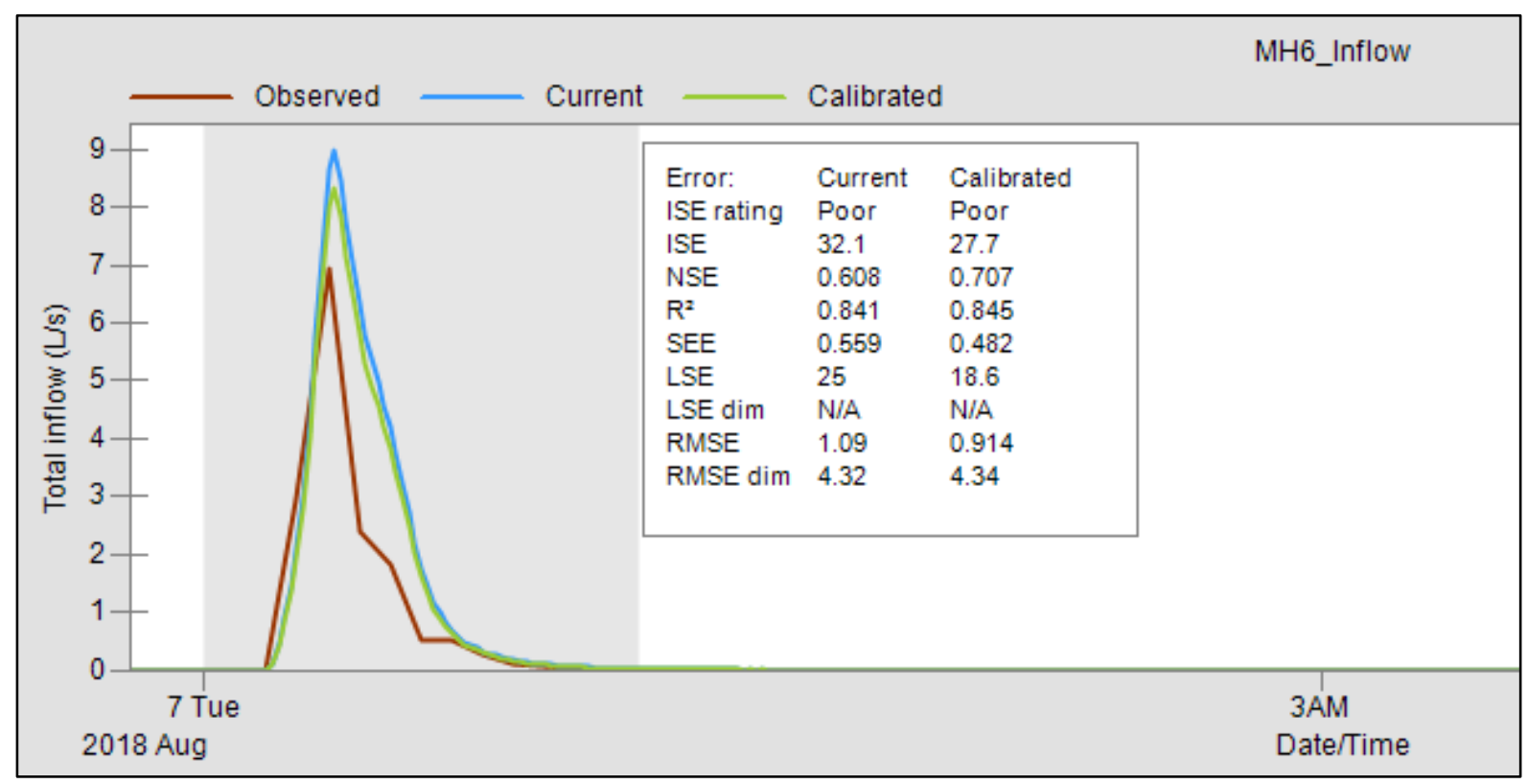

Figure A4: Calibration of event 4 at ES2 inflow 


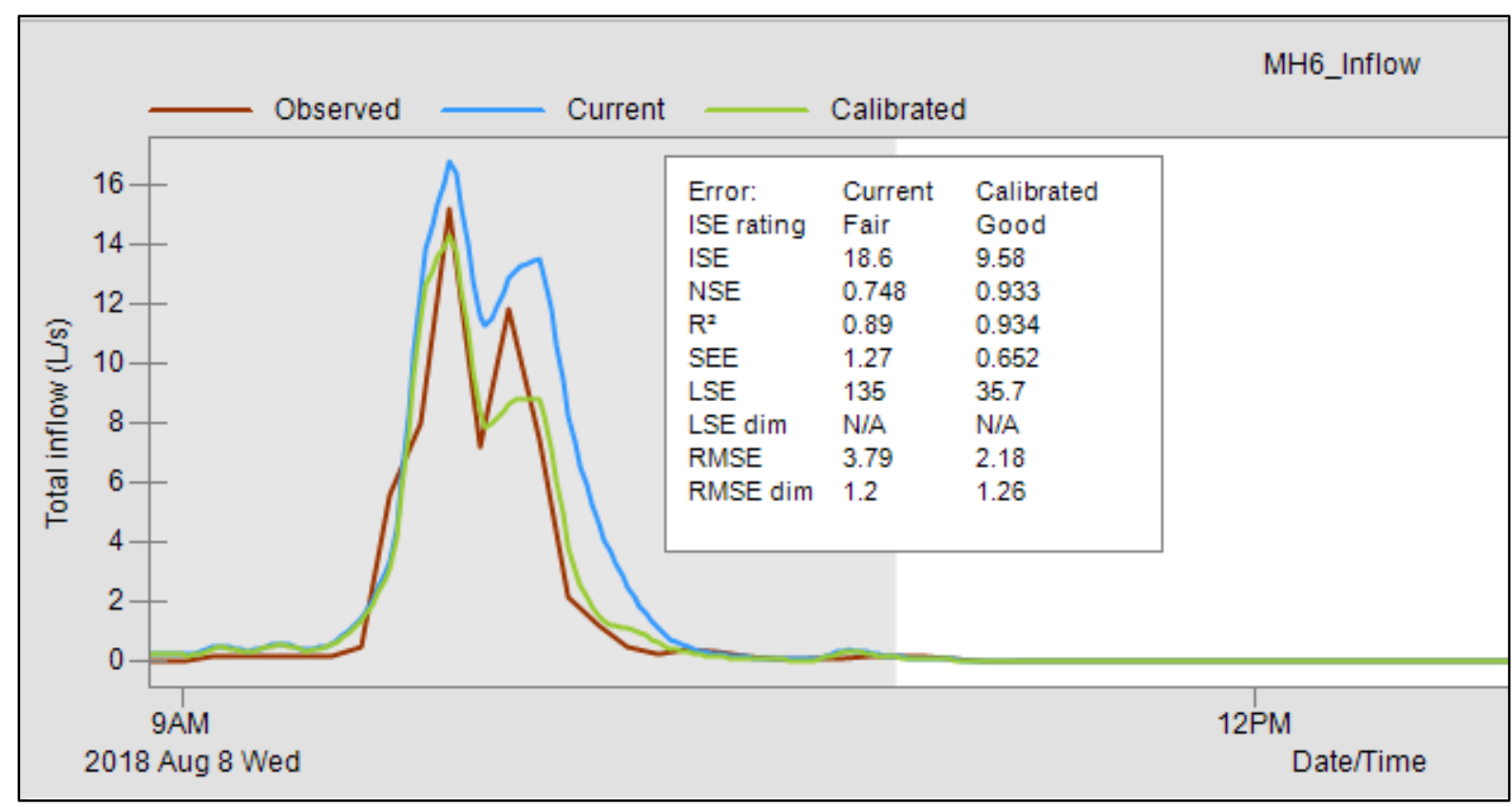

Figure A5: Calibration of event 5 at ES2 inflow

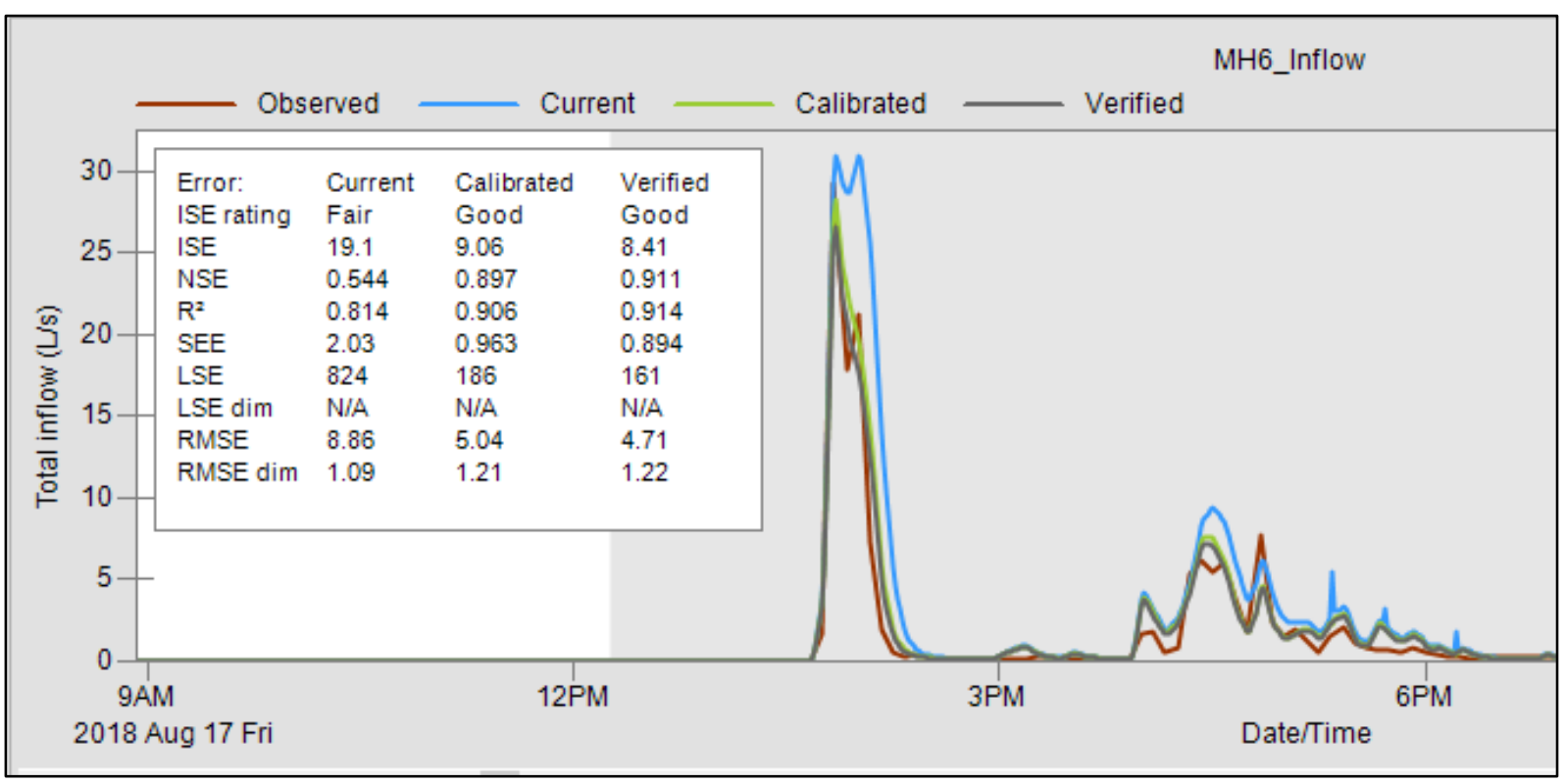

Figure A6: Calibration and validation of event 6 at ES2 inflow 


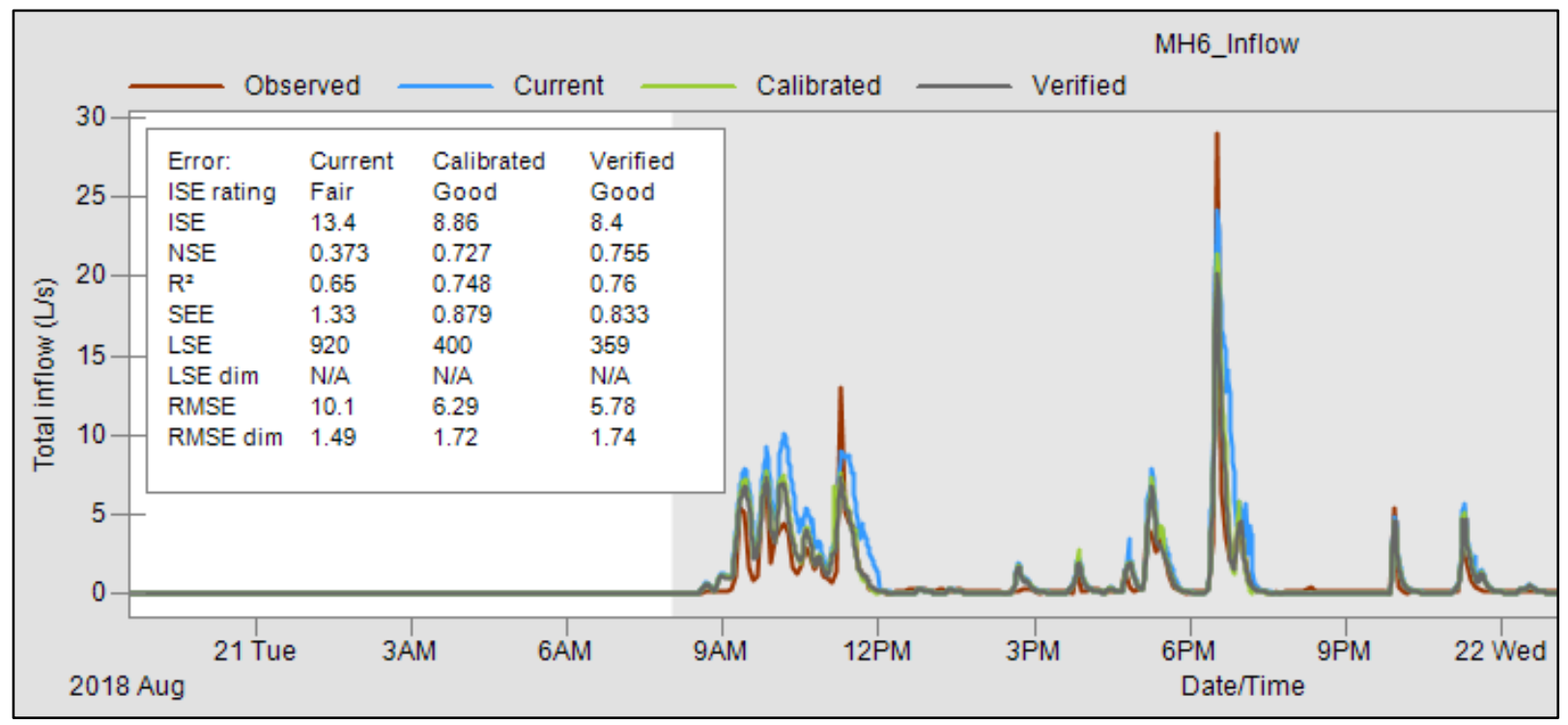

Figure A7: Calibration and Validation of event 7 at ES2 inflow

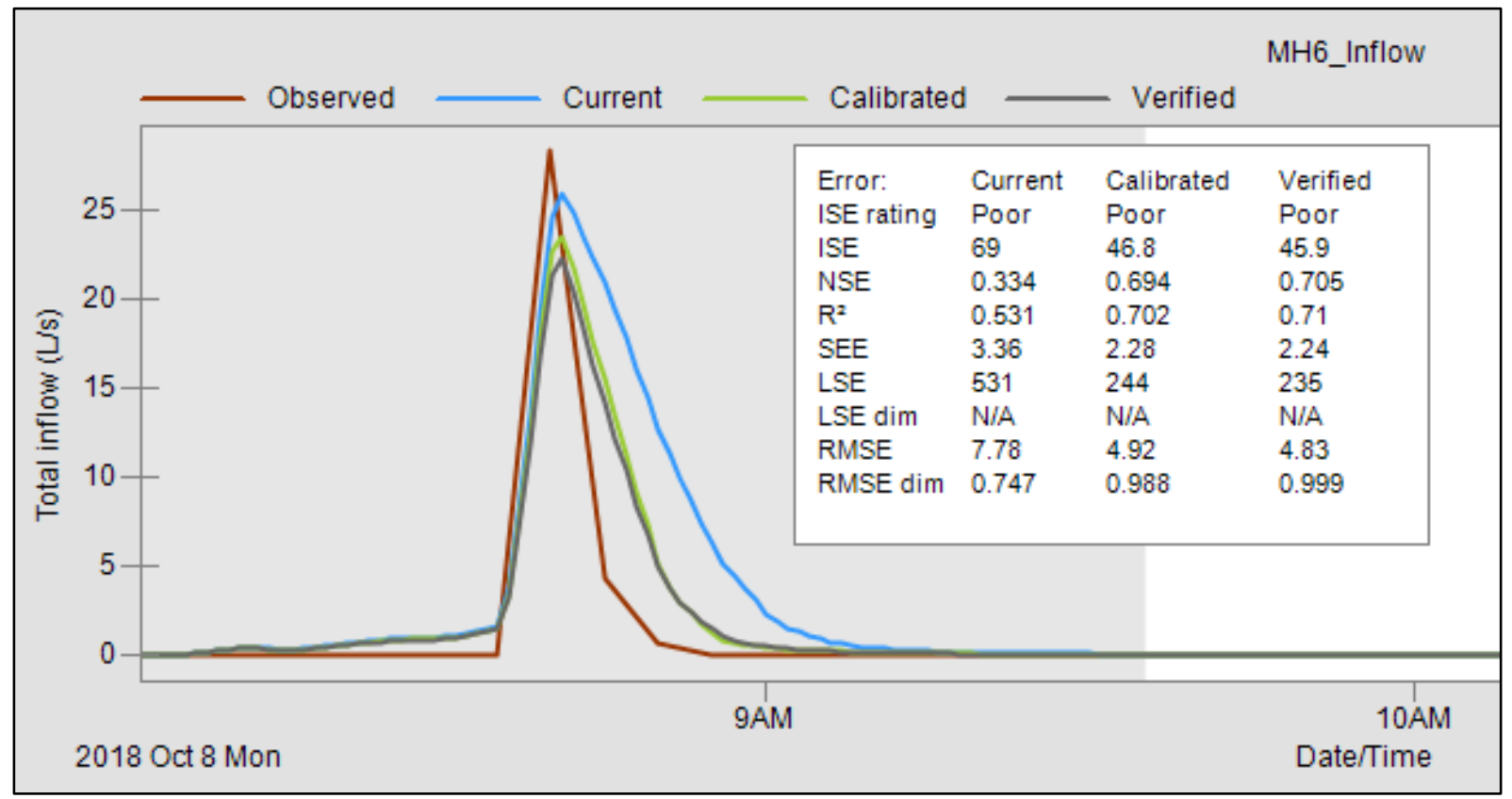

Figure A8: Calibration and validation of event 8 at ES2 inflow 


\section{References}

A.M. Candaras Associates Inc. (1997). "Post-Construction Evaluation of Stormwater Exfiltration \&Filtration System', Etobicoke, Ontario: Queen's Printer for Ontario.

Aquafor Beech. (2006). "Stormwater management and watercourse impacts: The need for a water balance approach". Prepared for the Toronto and Region Conservation Authority. Toronto, Ontario

Chin, D. A., (2013). “Water Resources Engineering. Third edition”. New Jersey: PEARSON.

City of Toronto, (2009). "Design Criteria of Sewers and Water Mains Manual”. Toronto. Ontario

Credit Valley Conservation (CVC) and Toronto and Region Conservation (TRCA). (2010). “Low Impact Development Stormwater Management Planning and Design Guide’, Version 1.0

Darcy, H. (1856). "The Public Fountains of the Town of Dijon", Dalmont, Paris

Joksimovic, D. and Li, J. (2018), "Performance Modelling of Etobicoke Exfiltration System (EES)". Conference of $1^{\text {st }}$ International WDSA and CCWI. Kington, Ontario.

Joksimovic, D., and Alam, Z. (2014). "Cost efficiency of Low Impact Development (LID) stormwater management practices.” Procedia Engineering, Elsevier B.V., 89(Lid), 734-741

Glenn, S. and Kate N., (2013). "NVCA stormwater Technical Guide”. Nottawasaga Valley Conservation Authority, Utopia, Ontario

International Computational Hydraulics (CHI). (2017). Open SWMM,5.1.012. Guelph. 
James, R. and Rossman, L. (2012, March 28). "Modelling LIDs using PCSWMM and EPA SWMM5".

Li, J., Joksimovic, D. and Tran, J., (2015). "A Right-of-Way Stormwater Low Impact Development Practice." Journal of Water Management Modeling C390. doi: 10.14796/JWMM.C390

Ontario Ministry of Environment (MOE). (2003, March). “Stormwater management planning and design manual”.

Schaeffer's Consulting Engineer (SCE). (2014). "Stormwater Management Report”.

Prepared for Mosaik Homes Glenway Inc, Residential Subdivision, Bathurst and Davis drive, Newmarket, Ontario

Sustainable Technologies and Evaluation Program (STEP), (2013, February). "Evaluation of Underground Stormwater Infiltration Systems". Toronto.

Rossman, L. (2016, January). “Storm Water Management Model Reference Manual”. Volume I Hydrology (Revised)., Canada, Government of. 2018.

United States Environment Protection Agency. (2017). "Storm Water Management Model Reference Manual". Volume II - Hydraulic, EPA/600/R-17/11.

United States Environment Protection Agency. (2016). Storm Water Management Model Reference Manual, Volume I-Hydrology (Revises), EPA/600/R-15/162A, January 2016.

United States Environment Protection Agency. (2009). Storm Water Management Model Application Manual, EPA/600/R-09/000, July 2009.

United States Environmental Protection Agency (USEPA). (2012, March). "Urban Runoff: Low Impact Development". Retrieved from URL: https://www.epa.gov/nps/urban-runofflowimpact-development. 
